Bulletin of the Seismological Society of America

October 2018, Volume 108, Issue 5A, Pages 2650-2674

http://dx.doi.org/10.1785/0120170258

Archimer

http://archimer.ifremer.fr/doc/00453/56416/

(C) 2018 Seismological Society of America

\title{
An Alternative View of the Microseismicity along the Western Main Marmara Fault
}

\author{
Batsi Evangelia ${ }^{1,{ }^{*}}$, Lomax Anthony ${ }^{2}$, Tary Jean-Baptiste ${ }^{3}$, Klingelhoefer Frauke ${ }^{1}$, Riboulot Vincent ${ }^{1}$, \\ Murphy Shane ${ }^{1}$, Monna Stephen ${ }^{4}$, Meral Ozel Nurcan ${ }^{5}$, Kalafat Dogan ${ }^{5}$, Saritas Hakan ${ }^{6}$, \\ Cifci Gunay ${ }^{6}$, Cagatay Namik ${ }^{7}$, Gasperini Luca ${ }^{8}$, Geli Louis ${ }^{1}$
}

${ }^{1}$ Institut français de recherche pour l'exploitation de la mer (Ifremer), Laboratoire Aléas géologiques et Dynamique sédimentaire - LAD Marine Geosciences Research Unit, CS 7020280 Plouzané, France

${ }_{2}^{2}$ ALomax Scientific ,320 Chemin des Indes 06370 Mouans Sartoux ,France

${ }^{3}$ Departamento de Geociencias Universidad de los Andes Carrera 1ํㅡㄴ No $18-A-10$-Edificio M1 Tercer

Piso Bogotá, Colombia

${ }^{4}$ Istituto Nazionale di Geofisica e Vulcanologia (INGV) Via di Vigna Murata, 605 Unit RU Integrated

Systems for Marine Environmental Infrastructures 00143 Rome, Italy

${ }^{5}$ Boðaziçi University Kandilli Observatory and Earthquake Research Institute (KOERI) 34684

Cengelkoy Istanbul, Turkey

${ }^{6}$ Dokuz Eylül University (DEU) Cumhuriyet Bulvarý No. 14435210 Alsancak Ýzmir, Turkey

${ }^{7}$ Faculty of Mines Department of Geology Istanbul Technical University (ITU) 34469 Maslak Istanbul,

Turkey

${ }^{8}$ Institute of Marine Science National Research Council (ISMAR-CNR) Via Gobetti 10140129 Bologna, Italy

* Corresponding author : Evangelia Batsi, email address : Evangelia.Batsi@ifremer.fr

\begin{abstract}
:
A detailed study, based on ocean-bottom seismometers (OBSs) recordings from two recording periods (3.5 months in 2011 and 2 months in 2014) and on a high-resolution, 3D velocity model, is presented here, which provides an alternative view of the microseismicity along the submerged section of the North Anatolian fault (NAF) within the western Sea of Marmara (SoM). The nonlinear probabilistic software packages of NonLinLoc and NLDiffLoc were used for locating earthquakes. Only earthquakes that comply with the following location criteria (e.g., representing $20 \%$ of the total amount of events) were considered for analysis: (1) number of stations $\geq 5$; (2) number of phases $\geq 6$, including both $P$ and $S$; (3) root mean square (rms) location error $\leq 0.5 \mathrm{~s}$; and (4) azimuthal gap $\leq 180^{\circ}$. $\mathrm{P}$ and $\mathrm{S}$ travel times suggest that there are strong velocity anomalies along the Western High, with low Vp, low Vs, and ultrahigh $\mathrm{Vp} / \mathrm{Vs}$ in areas where mud volcanoes and gas-prone sediment layers are known to be present. The location results indicate that not all earthquakes occurred as strike-slip events at crustal depths (>8 km) along the axis of the Main Marmara fault (MMF). In contrast, the following features were observed: (1) a significant number of earthquakes occurred off-axis (e.g., 24\%), with predominantly normal focal mechanisms, at depths between 2 and $6 \mathrm{~km}$, along tectonically active, structural trends oriented eastwest or southwest-northeast, and (2) a great number of earthquakes was also found to occur within the upper sediment layers (at depths $<2 \mathrm{~km}$ ), particularly in the areas where free gas is suspected to exist, based on high-resolution 3D seismics (e.g., 28\%). Part of this ultra-shallow seismicity appears to occur
\end{abstract}


in response to deep earthquakes of intermediate (ML 4-5) magnitude. Resolving the depth of the shallow seismicity requires adequate experimental design ensuring source-receiver distances of the same order as hypocentral depths. To reach this objective, deep-seafloor observatories with a sufficient number of geophone sensors near the fault trace are needed. 


\section{Introduction}

54 The study and understanding of seismicity for large and devastating earthquakes as well as

55 for background micro-seismicity is of fundamental importance for earthquake hazard

56 assessment. Hence, considerable effort is spent world-wide for characterizing active faults

57 through enhanced seismic monitoring. In submarine environments, however, the presence of

58 the water column makes monitoring particularly complicated and difficult. Because deep-sea

59 environments are remote, hostile and corrosive, there are to date only a few permanent

60 deep sea-floor observatory networks funded at the national or international level, e.g.,

61 offshore Japan (DONET for Dense Oceanfloor Network system for Earthquakes and

62 Tsunamis), Canada (NEPTUNE), USA (MARS) and at some sites of Europe (EMSO, for

63 European Multidisciplinary Seafloor and water-column Observatory). Due to their elevated

64 maintenance costs, offshore facilities require more detailed and more specific justification

65 than onshore facilities. The case of the submerged section of the North Anatolian Fault

66 (NAF), within the Sea of Marmara (SoM), is a strong motivator in that respect. In a recent

67 review paper, (Aktar, 2017) underlines that the uncertainty for earthquake locations along the

68 western part of the SOM, is higher in the vertical direction but this could be improved

69 considerably by the application of double difference method using land-based seismological

70 data, including data from seismometers installed in near-shore boreholes or from arrays

71 installed on islets. The question of the value added by offshore data from seismometers

72 installed on the sea bottom near the fault trace is addressed here.

73 The highly active, right lateral strike-slip NAF has produced devastating historical

74 earthquakes along its $1600 \mathrm{~km}$ long trace (e.g., Ambraseys and Finkel, 1995). In 1912, the

75 fault was ruptured by the Ganos earthquake, which ended at the Western extremity of SoM

76 (e.g., Ambraseys and Finkel, 1987). To the east of SoM, the spatial progression of 
77 earthquakes along this fault system has a more or less westward progression since 1940,

78 with a sixty year sequence of rupturing towards Istanbul (e.g., Stein et al., 1997). The last

79 destructive earthquake occurred at the eastern end of the SoM (1999 Izmit and Duzce

80 earthquakes) and therefore the next large $(\mathrm{Mw}>7)$ earthquake is now expected to nucleate

81 beneath the SoM, putting at risk the 15 million inhabitants of the Istanbul megacity (e.g.,

82 Pondard et al., 2007; Parsons et al., 2004).

83 As a result, the SoM (see Figure 1a) was extensively surveyed since 1999, allowing a

84 wealth of geological, geophysical and geochemical data to be collected. The Main Marmara

85 Fault (MMF) system was identified as a major target for the implementation of seafloor

86 observatories, and important preparatory work was done to address this long term challenge.

87 In 2009 and 2010, five cabled sea-bottom seismometers were deployed on the Marmara

88 seafloor by Kandilli Observatory and Earthquake Research Institute (KOERI), which collected

89 broadband data until 2013. Site surveys and autonomous instrument deployments were

90 conducted within European Union funded projects, respectively the ESONET/MARMARA-

91 DM Project (2008-2011, e.g., (Géli, et al., 2011) and the MARSITE Project (2012-2016).

92 Here, we present a high-resolution seismological study of the Western SoM, based on all

93 the geological knowledge acquired since 1999 and on the Ocean Bottom Seismometer

94 (OBS) data collected within the latter two projects, in 2011 and 2014 respectively (see

95 Figure 1b).

96 This work complements a previous study by (Géli et al., 2018), of only a part of the 2011

97 dataset, that showed the existence of shallow, gas-related seismicity, based on the

98 combination of seismological and geochemical arguments. Because there was no station at

99 the center of the OBS network during the last month of the 2011 experiment, a new

100 deployment was carried out in 2014, with a denser network closer to the fault (see Figure

101 1b). The results obtained with a high resolution 3D velocity model provide new insights on 
102 the nature of the micro-seismicity and on the behavior of the western segments of the

$103 \mathrm{MMF}$

104

105 Geological background: specificities to take into account for

106 precise earthquake location

107

108 According to (Şengör et al., 2005), the NAF was formed by a progressive strain

109 localization, mostly along an interface juxtaposing subduction-accretion material to its south

110 and older and stiffer continental basement rocks to its north. The shear-related, post-

111 Miocene deformation produced four separate basins within the Marmara shear zone, filled

112 with Plio-Quaternary sediment sequences, respectively from west to east: the Tekirdag

113 Basin, the Central Basin, the Kumburgaz Basin and the Cinarçik Basin (see Figure 1a).

114 After the numerous bathymetric and seismic surveys that were conducted since 1999 (e.g.,

115 Le Pichon et al., 2001; Imren et al., 2001; Armijo et al., 2002; Rangin et al., 2004;

116 Carton et al., 2007; Shillington et al., 2012), the currently active fault traces are now well

117 known. So are the main trends of the basins and crustal structure, based on deep seismic

118 soundings (e.g., Laigle et al., 2008; Bécel et al., 2006; Bayrakci et al., 2013). From these

119 surveys, it is clear that: i) the geological structure along the MMF is essentially 3D from

120 the surface to the deep crust, both along and across the strike of the fault, and ii) the

121 central part of the Marmara Trough is filled with "soft" Plio-Quaternary sediment

122 sequences, more than $5 \mathrm{~km}$ thick. These features are key elements to take into account

123 when deriving appropriate velocity models for high-resolution earthquake location near the

124 fault zone.

125 Another aspect that should be considered is the existence of widespread gas emissions from 
126 the Marmara seafloor (e.g., Kuscu et al., 2005; Géli et al., 2008; Dupré et al., 2015) and

127 the realization that the NAF beneath the SoM cuts across hydrocarbon gas prone sediment

128 layers (e.g., Bourry et al., 2009). As stated in (Dupré et al., 2015), the distribution of gas

129 emissions in the SoM appears to be controlled by a number of factors, e.g.: the fault and

130 fracture networks; the nature and thickness of sediments; the connectivity between the

131 seafloor and the gas sources; and the microseismicity. Hence, the role of gas must be

132 identified and discriminated from the tectonics. To reach this goal, it is necessary to

133 improve the depth determination of shallow seismicity using nearby monitoring stations and

134 detailed velocity models, that take into account the upper sedimentary layers.

\section{3D velocity-structure of the Western Sea of Marmara}

137 Given the considerations above, specific 3D velocity models are required to account for: i)

138 the sharp seafloor topography; ii) the slow P-wave velocity of Plio-Quaternary sediments;

139 and iii) the differences in the deep crustal structure between the northern and southern parts

140 of the NAF. Published 3D-models do exist with grid spacing of $9 \times 9 \mathrm{~km}$ and $10 \times 10$

$141 \mathrm{~km}$ for the Marmara Region (e.g., Gürbüz et al., 2013 and Yamamoto et al., 2017),

142 respectively and grid spacing of $6 \times 6 \mathrm{~km}$ for the Marmara offshore domain (e.g., Bayrakci

143 et al., 2013). The horizontal grid-spacing (9, 10 and $6 \mathrm{~km}$, respectively) of these models is

144 too large, however, to account for both the velocity contrast at the seafloor interface and

145 the sharp geometry of the basins, as well as the expected heterogeneties of the velocity

146 structure across the strike of the MMF. Hence, here we rather use the high-resolution, 3D-

147 velocity model (with a grid node spacing of $750 \mathrm{~m} \times 750 \mathrm{~m} \times 200 \mathrm{~m}$ ) that was

148 specifically tailored by the French Research Institute for Exploitation of the Sea (Ifremer, Institut

149 français de recherche pour l' exploitation de la mer) for the $20 \mathrm{~km} \times 60 \mathrm{~km}$ area covered 
150 by the submarine networks deployed in 2011 and 2014 in the Western SoM (see Figure

151 2a) and details reported in (Cros and Géli, 2013) and in (Gürbüz et al., 2013). This model 152 is based on all available geological and geophysical data from the SoM, including: i) the

153 high-resolution (38 m) bathymetric grid from (Le Pichon et al., 2001); ii) the 3D, P-wave

154 velocity grid derived from seismic tomography by (Bayrakci et al., 2013), with the S-wave

155 velocity model being the $\mathrm{P}$-wave model divided by the $\mathrm{V}_{\mathrm{p}} / \mathrm{V}_{\mathrm{s}}$ ratio; iii) the deep crustal

156 velocities inferred from wide-angle, 2D seismics by (Bécel, et al., 2009) and iv) the fault 157 mapping and basin geometry line-drawing, based on the interpretation of all existing seismic 158 profiles (e.g., Şengör et al., 2005; Şengör et al., 2014).

\section{Data}

162 The two following seismological datasets were analyzed (see details in Tables 1 and 2 and 163 Figure 1b):

- Dataset-1 was recorded from $15^{\text {th }}$ of April to $31^{\text {st }}$ of July, 2011, by 10 autonomous, 3 component (1 vertical and 2 non-oriented horizontal) short-period $(4.5 \mathrm{~Hz})$ OBSs from Ifremer and by 2 permanent, cabled broad-band, 3 components OBSs operated by KOERI. Unfortunately, the central station of the network, OBS2, stopped recording on July $1^{\text {st }}, 2011$.

- Dataset-2 was recorded from $19^{\text {th }}$ of September to $14^{\text {th }}$ of November, 2014, by 9 autonomous, 3 component (1 vertical, 2 non-oriented horizontal) short-period $(4.5 \mathrm{~Hz})$ OBSs from Ifremer and by 1 autonomous, broad-band OBS operated by the Istituto Nazionale Geofisica e Vulcanologia (INGV) (e.g. OBS13). Note that two autonomous, short-period OBS were also deployed by Ifremer, from the $1^{\text {st }}$ until the $15^{\text {th }}$ of November near gas emissions sites (e.g. close to the central station OBS4). The 
recording period of 2014 of Ifremer's and INGV's OBSs overlaps with the recording period of the Japan Agency for Marine Earth Science and Technology (Jamstec) OBSs that were independently deployed by (Yamamoto et al., 2017) for a duration of 10 months, from September 2014 to June 2015, in the Western part of the SoM, from the Tekirdag Basin to the Central Basin.

- Additional geological and geophysical data sets were used to guide our analysis: high-resolution 3D- and 2D-seismic data collected in 2009 with R/V Le Suroit and with R/V Piri Reis, respectively. The full description of the 3Dacquistion system and dataset is detailed in (Thomas et al., 2012).

multi-channel, deep seismic lines collected in 2001 during the Seismara Cruise of R/V Le Nadir (e.g., Laigle et al., 2008; Bécel et al., 2009; Bécel et al., 2010).

an unpublished bathymetric grid of the Central Basin and Western High, having a node spacing of 10 meters, based on multibeam echosounder system data collected in 2014 with $R / V$ Pourquoi Pas? (see Data and Resources section). This $10 \mathrm{~m}$ grid (courtesy of Charline Guérin of Ifremer) is available on request to the authors. 
202 For both OBS datasets of 2011 and 2014 recording periods, the same methodological 203 approach was used, based on the non-linear methods developed by (Lomax, 2014). The 204 3D-location process (fully described in (Lomax, 2014)) includes the 5 following steps (e.g., 205 see Data and Resources section):

1) Picking: The picking was performed using respectively the FilterPicker routine (e.g., Lomax et al., 2012) for the OBS dataset of 2014, and the Sytmis software package for the OBS dataset of 2011 (see Data and Resources Section). The 3 components of the geophone were used for this analysis. Specifically the vertical component was used for the detection of P-wave arrivals while the two non-oriented horizontal components were used for the S-wave onsets (e.g. strong velocity contrasts in areas with shallow sediments could generate converted phases, hence their identification on vertical channels could be misleading). All picks were visually checked. Uncertain picks were systematically removed. Manual corrections -when needed- were applied to the remaining picks.

2) Phase association: the Early-est routine of the Lomax Package was run to perform phase association and to determine the initial earthquake locations for step 3, using the 1D $\left(V_{p}\right.$ and $\left.V_{s}\right)$ model described in (Cros and Géli, 2013) (see also (Lomax, 2014) and Data and Resources section). In this initial phase, a non-constant $\mathrm{V}_{\mathrm{p}} / \mathrm{V}_{\mathrm{s}}$ 
3) Initial 3D absolute locations: NonLinLoc software was applied without station corrections using our high resolution, 3D P-velocity model (with a constant $\mathrm{V}_{\mathrm{p}} / \mathrm{V}_{\mathrm{s}}$ ratio equal to 1.78), to compute a preliminary set of absolute locations and station corrections.

4) Station corrections and final 3D absolute locations: The accuracy of travel-time picks was successfully improved by applying station corrections for both $\mathrm{P}$ and $\mathrm{S}$ travel time grids by using their average phase residuals obtained from a run of NonLinLoc (see Tables of station corrections in Supplementary Information). The objective was to account for: (i) the near-surface deviations of seismic velocities from the applied model (e.g., Hausmann et al., 2010), since all models (including 3D) do not take into account the real velocity variations (e.g. shallow, near-station, smaller scale and potentially low velocity structure cannot or are not modeled), (ii) algorithm instabilities, (iii) picking phases errors, etc. NonLinLoc was applied using the 3D, Pvelocity model (with $\mathrm{V}_{\mathrm{p}} / \mathrm{V}_{\mathrm{s}}=1.78$ ), along with the station corrections and the absolute locations of all the detected earthquakes resulting from step 3, to compute the final

5) Relative locations: NLDiffLoc was eventually run to compute the relative locations based on the final absolute locations. NLDiffLoc performs a differential earthquake absolute locations after 3 iterations. As described in (Lomax et al., 2008), this procedure is expected to produce a tighter cluster of events relative to the large scatter of events of the initial absolute locations (e.g. see step 3). location based on the double difference equation from (Waldhauser and Ellsworth, 
2000). The double difference code is using as input the files of: (i) initial absolute

248 locations (e.g. derived from NLLoc; see step 4) and (ii) differential travel times (e.g.

249 derived from Loc2ddct tool) which are calculated for a specified maximum distance

250 between event couples. The relative coordinates (e.g. x, y, z and t) are optimized for

251 a set of hypocenters given a set of differential phase arrival time measures at each

252 station for multiple hypocenters. This is achieved by using a non-linearized global

253 search (e.g. a Metropolis random walk, (Lomax et al., 2009)), which maximizes the

254 probabilistic solution likelihood as the hypocenter coordinates are perturbed. A double-

255 difference equation from (Waldhauser and Ellsworth, 2000) is then evaluated for

256 determining the misfit and the solution likelihood by using an L1 norm which is

257 more robust with outlier data (e.g. in contrast to L2 norm which is equivalent to 258 what HypoDD is using).

260 For both final absolute and relative locations (e.g. steps 4 and 5) the following criteria

261 were used for "well constrained events": (i) Number of stations $\geq 5$, (ii) RMS $\leq 0.5$ s,

262 (iii) azimuthal gap $\leq 180^{\circ}$, and (iv) number of phases $\geq 6$ including both $\mathrm{P}$ and $\mathrm{S}$ phases.

263 Consequently, only a small percentage $(20 \%)$ of the recorded seismicity was considered

264 (e.g. 191 and 78 relocated earthquakes for the 2011 and 2014 recording periods, 265 respectively). 


\section{Multiplet analysis}

272

273 The GISMO collection of Matlab tool boxes for seismic waveform analysis, (see Data and

274 Resources section) was used for multiplet analysis. The determination of cross-correlations

275 and lag times was performed for all pairs of events (e.g. no "master" events) and the cross

276 correlation was calculated for different time windows. More specifically, different tests were

277 performed for the cross-correlations on all three components of the geophone. For each

278 component (i) only P-waves were considered, (ii) only S -wave and (iii) a larger window

279 was taken into account to consider the whole wave train of the earthquake (e.g. $1 \mathrm{~s}$ before

280 P-wave arrival and $2 \mathrm{~s}$ after $\mathrm{S}$-wave arrival). In practice we found that both $\mathrm{P}$ and $\mathrm{S}$

281 phases were easier to identify on the vertical components compared to the horizontals. The

282 best correlation results were obtained in case (iii). Location tests were then performed on

283 the selected multiplet events.

\section{Computation of Focal mechanisms}

287 HASH software (e.g., Hardebeck and Shearer, 2008) was used for computing focal 288 mechanisms of single events of $\mathrm{M}>3$. Due to the fact that the majority of the events were 289 micro-earthquakes (e.g. $\mathrm{M}<2$ ), composite focal mechanisms were also computed with HASH 290 for the highly correlated events obtained from the multiplet analysis (see paragraph: 291 Discussion on location results based on case studies). For both cases (e.g. single and 292 composite), at least 8 P-wave first motion polarities (measured on the vertical component)

293 were considered. In total 8 focal mechanisms have been computed (e.g. 4 single and 4 294 composite focal mechanisms of the events of magnitude $M>3$ and $M<2$ respectively (see 


\section{Computation of synthetic tests}

300 The programs of NonLinLoc package were used for calculating the synthetic tests. Given:

301 (i) a hypocenter location and (b) a set of travel time grids (e.g. computed with Grid2Time), 302 Time2Eq was used for calculating the predicted travel times which were then used as input 303 for locating the specific event with NonLinLoc.

\section{Comparing 1D-models, based on synthetics}

307 Different tests were made to evaluate the effect of the different 1D-models on earthquake

308 locations, with the following procedure: i) One arbitrary event was positioned below the

309 Western High, at $40.80^{\circ} \mathrm{N}, 28^{\circ} \mathrm{E}$ and at 2 different depths, $2 \mathrm{~km}$ (Trial 1) and $12 \mathrm{~km}$

310 (Trial 2) respectively; ii) Synthetic travel times were computed using the 3D velocity 311 model, for the stations of the 2011 network (data-set 1); iii) these synthetic travel times

312 were used for relocating the corresponding synthetic epicenters with NonLinLoc, using the

313 "1D-this study" and the 1D-model of (Karabulut et al., 2011), respectively (see Figure 2b).

314 The same test was repeated by using the 3D velocity model of this study (see Figure $2 a$ ).

315 As expected, over-simplified 1D models (e.g. models that represent the velocity structure of 316 the on-shore domain), produce very important effects on earthquake depth determination, 317 particularly for shallow events below the deep, submerged basins in contrast with the 3D 
318 velocity model which succeeds in well locating the shallow earthquake of Trial 1 (see

319 Table 3). In common practice, 1D-location results are significantly improved by using

320 station corrections, and 1D-models are refined at each iteration. To be effective, however,

321 station corrections require that rays propagate vertically below the station, a valid

322 assumption only for deep-seated earthquakes and smoothly varying media. For shallow

323 earthquakes generating oblique rays in slow, P-wave velocity sediments, 1D-locations with

324 station corrections are less efficient than 3D-locations with station corrections. Therefore,

325 when only OBS are included, it is strongly recommended to use "appropriate 1D-models"

326 that take into account the velocity structure of the upper sediment layers in order to

327 properly locate shallow, micro-seismicity.

\section{Discussion on location results, based on case studies}

331 To illustrate the importance of 3D effects, three representative case studies are discussed

332 here below, with the purpose of comparing the relative location results obtained by

333 NLDiffLoc using “appropriate 1D" models vs the 3D velocity-model. The "appropriate 1D

334 model" used in this study is based on (Cros and Géli, 2013) and shown in Figure 2b. For

335 each case study the $10 \mathrm{~m}$ bathymetric grid (see for instance Figure 3 ) and a selection of a

336 highly correlated events (with a cross correlation coefficient $\geq 0.8$, see for example Figure

337 4) that occurred as clusters or as triplets were considered for the analysis. 
342 The first case study includes a triplet of earthquakes of local average magnitude $\mathrm{M}_{1}$ 1.65,

343 that occurred on the $25^{\text {th }}$ of October, 2014, in the Western High area (see Figures 5, 6a,

$3446 b, 7,8$ and Table 4). The seismograms plotted for earthquake 2 (Figure 7) indicate that

345 the P-wave arrived first at OBS4, whilst $t_{s^{-}} t_{p}$ values are very large at OBS4. In addition, $t_{s^{-}}$

$346 \mathrm{t}_{\mathrm{p}}$ are respectively greater at OBS7 and OBS3 (located on the northern side of the MMF)

347 compared to those at OBS8 and OBS1 (located on the northern side). These observations

348 underline the 3-dimensional structure of the medium. The travel-time data $\left(t_{s}, t_{p}, t_{s}-t_{p}\right)$

349 clearly tell us that: i) the central part of the Western High (e.g. in the vicinity of OBS4)

350 is characterized by extremely low $V_{P}$ and $V_{s}$ velocities (likely due to the known presence

351 of mud volcanoes and by gas-prone, low velocity sediment layers); ii) seismic velocities are

352 lower along than across the strike of the MMF.

353 Location results show that when using the 1D velocity model, hypocenters are located

354 within less than $1 \mathrm{~km}$ to the south of the fault zone and at a depth of $10.3 \mathrm{~km} \pm 0.3 \mathrm{~km}$

355 below seafloor. In contrast, with the 3D, high-resolution velocity model, the triplet is found

356 to be located $3 \mathrm{~km}$ to the north of the fault zone, at a depth of $6.2 \mathrm{~km}$ below seafloor,

357 e.g. at the base of the sedimentary basin. The computed composite focal mechanism (see

358 Supplementary Information) obtained with the 3D locations indicates a predominantly normal

359 fault motion, with a small strike-slip component. In contrast the composite focal mechanism

360 obtained for the 1D locations indicates strike-slip motion while the composite focal

361 mechanism for this triplet is not available in (Yamamoto et al., 2017). Our location results

362 differ from those obtained by (Yamamoto et al., 2017), who found that the cluster was

363 located underneath OBS4, at a hypocentral depth of $15 \mathrm{~km}$ (below sealevel), using a 3D-

364 model $(10 \mathrm{~km} \times 10 \mathrm{~km} \times 2 \mathrm{~km})$ and OBSs only. The differences between our 3D results 
365 and Yamamoto's are puzzling. Hence, they are further discussed in a subsequent section

366 below (see paragraph: Comparison with (Yamamoto's et al., 2017)).

367

368

369 - Case study 2: shallow seismicity within the upper sediment layers $(<2$

370 km):

371

372 The second case study regards a triplet of events (with correlation $>0.8$ ) that occurred on

$37319^{\text {th }}$ of May 2011 and $23^{\text {rd }}$ of June 2011 (see Figures 9a and 9b and Table 5) of local

374 average magnitude $\mathrm{M}_{1}$ 0.9. With the $1 \mathrm{D}$ velocity model, the computed epicenters are spread

375 out over an area of more than $\sim 20 \mathrm{~km}^{2}$ within the eastern part of the Central Basin and

376 the depth distribution of the individual hypocenters is dispersed, at $3 \mathrm{~km}, 15 \mathrm{~km}$, and 20

$377 \mathrm{~km}$, respectively. In contrast, with the 3D velocity model, the computed epicenters are

378 clustered over an area of $\sim 2 \mathrm{~km}^{2}$ at the base of the escarpment bordering the south-

379 eastern part of the Central Basin, while the hypocenters are located within the first two

380 kilometers of sediments, in an area where numerous gas emission sites have been found

381 and where reverse faulting is present (e.g., Armijo et al., 2002; Bécel et al., 2010). In both

382 cases, the computed composite focal mechanism indicates reverse faulting (see

383 Supplementary Information). It is interesting to note that the 1D locations are unstable, with

3843 very different depths (3, 15 and $20 \mathrm{~km}$ ) found for 3 highly correlated events (see

385 seismograms of the triplet in Supplementary Information), while the 3D-locations yield

386 comparable depths for the 3 events and smaller confidence ellipsoids. The cluster being

387 more or less near the center of the OBS network, small variations in the velocity model

388 are expected to generate large variations in depth determination, resulting in important

389 location instabilities. The seismograms for earthquake 3 (see Figure 10) indicate equivalent 
390 P-wave arrival times at OBS8 and at OBS10, but differences in $t_{\mathrm{s}}-\mathrm{t}_{\mathrm{p}}$ greater than $0.4 \mathrm{~s}$.

391 Also, the P-wave arrives $0.2 \mathrm{~s}$ earlier, but $\mathrm{t}_{\mathrm{s}}-\mathrm{t}_{\mathrm{p}}$ is slightly greater $(4.0 \mathrm{~s})$ at OBS7 compared

392 to OBS9. These observations suggest large 3D-heterogeneities in the seismic velocity

393 structure, notably with faster velocities across than along strike. In addition, the computed

394 reverse composite focal mechanism is consistent with the presence of a positive (e.g.

395 compressive) flower structure, based on the multi-channel seismic profile SM47 collected

396 during the Seismarmara cruise in 2001 across the NE corner of the Central Basin (Figure

397 11, after (Bécel et al., 2010)). Gas emissions have been detected near the epicentral area,

398 confirming that the faults rooted in the upper sediment layers are tectonically active,

399 allowing gas to migrate up to the seafloor. The results obtained from the synthetic records

400 for the earthquakes of case study 2 (see Figure 12), indicate that: (i) the $\mathrm{P}$ and $\mathrm{S}$ arrival

401 times and (ii) the synthetic locations were found to be relatively close to the real data for

402 the 3D model and not for the 1D, which clearly supports our preference for use of a 3D

403 model (see Tables 6 and 7).

404

405 - Case study 3: deep, crustal seismicity:

406

407 Finally the third case study concerns a cluster of 10 earthquakes of local average 408 magnitude $M_{1}$ 1.6, that occurred in 2011, below the western part of the Central Basin (see 409 Figure 13 and Table 8). Regardless the model used (1D vs 3D), the computed epicenters 410 are relatively well clustered over areas of less than $10 \mathrm{~km}^{2}$, and hypocenters are at crustal 411 depths, within the $12-15 \mathrm{~km}$ depth range. The composite focal mechanism indicates strike412 slip faulting (see Supplementary Information) which is consistent with strike-slip at crustal 413 depth; comparable to the repeaters from the same area reported in (Schmittbuhl et al., 414 2016). The major difference between $1 \mathrm{D}$ vs 3D hypocenters is that the events located with 
415 a 1D model are to the south of the fault trace, while those located with the 3D-model are

416 within the shear zone to the north of the MMF. Based on the deep, multi-channel seismic

417 soundings collected during the Seismarmara cruise in 2001, the 3D locations (within the

418 inner basin) appear to be consistent with geology (e.g., Laigle et al., 2008).

\section{$1 D$ versus $3 D$ relative locations}

As expected, for all case studies, differences in relative location results appear to be

424 significant for shallow $(<6 \mathrm{~km})$ seismicity (case studies 1 and 2 ), but relatively minor for 425 deep seismicity (e.g. > $10 \mathrm{~km}$, case study 3). In all cases, both our 1D and 3D relative 426 location results are seismologically "well-constrained" based on the criteria that we had set 427 up (see paragraph: Tools and Methodology). Nevertheless, the computed probability density 428 functions (pdf) indicate that the 3D locations have smaller confidence ellipsoids for each 429 event (see Figures 6b, 9b, 13). RMS errors in travel time differences (|measured 430 calculated|) are displayed in Figure 14.

431 For each case study, our 3D location results are consistent with the geological knowledge 432 that was acquired during the numerous cruises that were conducted in the SoM since 1999. 433 Although our focal mechanisms have been constrained by a limited number of polarities,

434 the systematic geological consistency of our results cannot be due only to pure coincidence: 435 the deep events $(\mathrm{d}>10 \mathrm{~km})$ from the case studies have dominantly strike-slip focal 436 mechanisms, while the majority of shallow events $(\mathrm{d}<5-6 \mathrm{~km})$, have dominantly normal 437 focal mechanisms, except case study 2 where events located near a compressive, flower 438 structure exhibit a reverse focal mechanism. 


\section{Discussion}

\section{Comparison with (Yamamoto's et al., 2017)}

Figure 15 displays the location of the events (14 in total) that were detected in common in

447 this work and in Yamamoto's, during the overlapping period from $19^{\text {th }}$ of September to $14^{\text {th }}$ 448 of November, 2014 (Table 9). The location results provide very different results. West of $44927^{\circ} 50^{\prime} \mathrm{E}$, (Yamamoto et al., 2017) find systematically deep, strike-slip events occurring along 450 the MMF and along EW striking associated structures. These locations are consistent with 451 pure strike-slip motion along the MMF. In contrast our locations suggest normal faulting 452 along SW-NE striking features north of the MMF.

453 Our locations and Yamamoto's are both internally consistent. The differences, though, are 454 due to differences in:

455 i) The location method: linear versus non linear (see discussion in (Husen and $456 \quad$ Hardebeck, 2010)).

457 ii) The network geometry: we used a network of more than 9 OBSs evenly 458 distributed within a circle of less than $10 \mathrm{~km}$ centered on the Western High; 459 (Yamamoto et al., 2017), used an elongated network of 10 OBS stations distributed 460 all along the MMF, with a sparse coverage of only 4 OBSs in our study area (see $461 \quad$ Figures $6 a$ and 6b).

462 iii) The 3D velocity model (see paragraph on: 3D velocity structure of the Western 463 Sea of Marmara) of (Yamamoto et al., 2017) used a large mesh grid $(10 \mathrm{~km} \times 10$ $464 \mathrm{~km} \times 2 \mathrm{~km})$. This naturally induces large effects, particularly due to bathymetry and to lateral variations in surface sediment heterogeneties.

466 In addition to the above-described case study 1, a new case was considered for comparing

467 the results of Figure 15, by taking as reference earthquake 11, of Table 9. This event was 
468 found to be located almost beneath OBS4 in both computations but at a hypocentral depth 469 of $\sim 5 \mathrm{~km}$ in this study and of $\sim 18 \mathrm{~km}$ in (Yamamoto's, et al., 2017) respectively (see 470 Figures 15 and 16). The P-wave arrives first at OBS4 (see Figure 17), compared to all 471 other OBSs, which is consistent with location results, that both propose that earthquake 11 472 is close to OBS4. In contrast, $t_{p}-t_{s}$ was found to be:

$473-$ maximum at OBS6 $(\sim 5 \mathrm{~s})$ located $\sim 14 \mathrm{~km}$ to the east of OBS4.

$474-$ minimum at OBS3 $(\sim 2.78 \mathrm{~s})$ and at OBS1 $(\sim 3.1 \mathrm{~s})$, respectively located $\sim 11 \mathrm{~km}$ 475 to the north and to the south of the MMF.

476 From the above we conclude that:

- There is a very strong velocity anisotropy within the fault zone, with slower 478 velocities along the strike of the MMF.

479 - There are very strong velocity anomalies near the central station OBS4, with low $480 \quad \mathrm{~V}_{\mathrm{P}}$, low $\mathrm{V}_{\mathrm{S}}$ and ultra-high $\mathrm{V}_{\mathrm{p}} / \mathrm{V}_{\mathrm{s}}$ in areas near OBS4 where mud volcanoes and gas$481 \quad$ prone sediment layers are known to be present.

\section{An alternative view of micro-seismicity within the Sea of Marmara}

485 Our 3D location results provide an alternative view of the micro-seismicity within the 486 Western SoM (Figures 18 and 19) compared to the most recent studies by (Yamamoto et 487 al., 2017) and (Schmittbul et al., 2015). Single (e.g. S1 to S4) and composite focal 488 mechanisms (e.g. C1 to C4) calculated within this study are summarized in Table 10 (see 489 also Supplementary Information).

490 In the present study, earthquakes are found to occur not only along the axis of the MMF, 491 but also off-axis, along secondary faults from the NAF System (see Figure 20). The deep 
492 events (d> 8-10 km) occurring along the MMF have a dominantly strike-slip focal

493 mechanism. In contrast, the majority of shallow events $(\mathrm{d}<5-6 \mathrm{~km})$ occur off-axis and have

494 a dominantly normal focal mechanism, except at some specific places characterized by

495 compressive deformation. The diversity of the focal mechanisms is consistent with previous

496 results (e.g., Pinar et al., 2003; Sato et al., 2004; Örgülü et al., 2017).

497 Our results also reveal that there are two categories of shallow $(<6 \mathrm{~km})$ seismicity.

498 - The first category consists of events located within or at the base of the "post499 kinematic", Plio-Quaternary basins (e.g., Bayrakci et al., 2013), at depths of $\sim 2$ to

$500 \quad 6 \mathrm{~km}$ and along tectonically active, structural trends oriented E-W or SW-NE.

501 - The second category includes "ultra-shallow" events, occurring at depths shallower 502 than $\sim 1-2 \mathrm{~km}$ (see for instance Figure 21). Focal focal mechanisms may indicate 503 either normal faulting, either reverse (e.g. earthquakes occurring along the Western 504 High and the Central Basin, respectively), depending on the local context. Based on 505 3D high-resolution seismics (e.g., Thomas et al., 2012) the hypocenters are located 506 within gas prone sediment layers. Such seismicity must be discriminated from the 507 tectonic-related seismicity that occurs at crustal levels.

509 Implication in terms of triggered "ultra-shallow" ( $<2 \mathrm{~km}$ ) seismicity

511 Of particular interest is the swarm of aftershocks triggered by the $M_{1} 5.1$ strike-slip 512 earthquake (see Table 10) that occurred below the Western High on the $25^{\text {th }}$ of July, 2011. 513 (Géli et al., 2018) proposed that part of these aftershocks occurred within gas-prone 514 sediment layers located shallower than $\sim 6 \mathrm{~km}$ depth below seafloor, with a predominantly 
515 normal focal mechanism (see Table 10). In addition, most of the ultra-shallow $(<2 \mathrm{~km})$

516 aftershocks occurred along normal (or reverse) faults within sediment layers.

517 Interestingly, almost all ultra-shallow earthquakes that occurred during the two recording 518 periods of 2011 and 2014 belong to this aftershock sequence, that followed the $\mathrm{M}_{1} 5.1$ 519 earthquake of July, 25 th 2011. In "normal periods" (e.g. in between two successive 520 earthquakes of moderate magnitude) there is hardly any "ultra-shallow" seismicity. This 521 would suggest that the 'ultra-shallow', soft sediments generally considered to behave 522 aseismically can also respond seismically to stress changes caused by nearby deeper 523 earthquakes, which are at least intermediate in size (i.e. $\mathrm{M}_{1}>4.5$ ). This may be explained 524 by observations in rock physics experiments on wet clay-rich sediment where there is a 525 change from velocity strengthening (i.e. an aseismic regime) at slow slip-rates to velocity 526 weakening (i.e. seismic) at high slip-rate (Faulkner et al., 2011; Aretusini et al., 2017). 527 (Faulkner et al., 2011) have postulated that this switch is due to thermal pressurization of 528 pore fluid in the clay. Therefore a possible explanation for the ultra-shallow events are that 529 abrupt stress changes caused by the deeper main shocks may have been large enough to 530 switch the normally aseismic response of the sediment to a seismic one.

531 This could also explain why (Yamamoto et al., 2017) did not detect any "ultra-shallow" 532 seismicity, as no earthquake of magnitude $M_{1}>4$ occurred during the 10 months of 533 recording, from September 2014 to July 2015. (Yamamoto et al., 2017) conclude on page 5342080 that: "Because we recorded no earthquakes of $M_{L}>4$, and no events within the 535 sediment layer of the Western High, we consider that microearthquakes identified in the 536 sedimentary layer by other researchers may be aftershocks triggered by moderate 537 earthquakes in upper crust beneath the Western High, as suggested by (Cros and Géli, 538 2013)”. 


\section{Implications in terms of seismic hazards (creeping versus locked)}

541 Our work underlines the difficulties that prevent the accurate depth determination of low

542 magnitude earthquakes, in absence of numerous, near-fault, sea-bottom stations.

543 Consequently, caution is required for interpreting micro-seismicity maps based on low-

544 magnitude threshold. As an example, the micro-seismicity within the SoM reported by

545 (Schmittbuhl et al., 2015) for the period from 2007 to 2012 is plotted in Figure 22 for

546 different threshold levels. For low magnitude thresholds, the maps of micro-seismicity

547 exhibit swarms of vertically distributed events that could be related to the large uncertainties

548 in depth determinations. These vertical swarms entirely disappear for threshold magnitudes

549 above $M_{1} \sim 3$ (see Figure 22), suggesting that depth determinations for earthquakes of

550 magnitude above $\mathrm{M}_{1} \sim 3$ may be used. Between 2007 and 2012, almost all earthquakes of

$551 \mathrm{M}_{1}>3$ have occurred at a depth greater than $\sim 8 \mathrm{~km}$, along the western segments of the

552 MMF, where most of the gas emissions from the seafloor are found. In contrast only a

553 few earthquakes of magnitude > 3 have occurred along the eastern segments of the MMF,

554 from the Gulf of Izmit to the west of Istanbul.

555 Previous studies (e.g., Schmittbuhl et al., 2015; Schmittbuhl et al., 2016; Yamamoto et al.,

5562017 and Bohnhoff et al., 2017) have proposed that the western part of the MMF could be

557 subject to deep crustal creeping, while the segment crossing the Central High, from the

558 Kumburgas basin to the entrance of the Bosphorus, could be locked. This latter result is

559 based on 6 months of acoustic ranging, which did not reveal any significant steady-state

560 surface creep along the MMF offshore Istanbul (e.g., Sakic et al., 2016).

561 Our results do not contradict this view. Creeping at crustal levels likely induces

562 deformation within the upper sediment layers, which in turn contribute to maintain high

563 permeability within the damage zone, which successively may enhance gas migration up to 
564 the surface. In addition the repeated earthquakes of intermediate magnitude may trigger

565 aftershocks within the uppermost, gas-prone sediment layers, which may result in gas

566 emission from the seafloor.

568 Limitations of our work and perspectives for future research

570 The conflicting depth estimates certainly pose several questions on the accuracy of the

571 locations, regarding the different methods and velocity models, used here versus the ones of

572 previous studies. Finding the correct earthquake locations in submarine environments is quite

573 a challenge, that mostly depends on (i) the methodology used (e.g. linear versus non-linear

574 techniques), (ii) the velocity model and iii) the network geometry.

575 By any means, our approach like any other approach has its limitations and advantages.

576 The assumption of a constant $\mathrm{V}_{\mathrm{p}} / \mathrm{V}_{\mathrm{s}}$ ratio during the location procedure, due to the absence

577 of an S wave velocity model, might have led to a location bias (e.g., Maurer and 578 Kradolfer, 1996). Also, the 3D velocity model of this study does not account for the 579 across-fault variability within the upper sediment structure, which is clearly visible in the 580 seismic sections crossing the Western High (e.g. Figure 8). Specifically, due to technical 581 difficulties, the short scale variability due to the presence of gas below the Western High 582 and the variability between the northern flank and of the southern flank were not 583 considered when building the 3D model of this study.

584 Yet, despite the limitations of the current approach, here we do think that two different 585 types of seismicity (e.g. deep versus shallow seismicity $<6 \mathrm{~km}$ ) occur in the western part 586 of the SoM. The plausible reasons why the previous studies did not find shallow events in 587 their catalogs are the following: (i) a different geometry of the seafloor seismic network 588 and a consideration of only OBS data were considered for this analysis, (ii) our use of a 
589 3D high resolution velocity model, which was build up with all the available geological

590 and geophysical information from the SoM (see paragraph on: 3D velocity-structure of the

591 Western SoM), (iii) only a limited number of earthquakes was used for the analysis (e.g. 20

$592 \%$ ), complying the criteria discussed in Tools and Methodology paragraph catalog, (iv) the

593 use of non-linear methods improved the accuracy of the location solution and (v) additional

594 information based on independent observations (e.g. multi-channel seismics, high-resolution

$5953 \mathrm{D}$ seismics, high-resolution bathymetry) is used for the interpretation of event locations

596 and focal mechanisms.

597 The perspectives for future work are:

598 (i) Merge OBS datasets of (Yamamoto's et al., 2017) and of this study for the $599 \quad$ overlapping observing periods.

600 (ii) Use a variable $\mathrm{V}_{\mathrm{p}} / \mathrm{V}_{\mathrm{s}}$ at every single step of the location procedure by 601 independently solving for a $\mathrm{V}_{\mathrm{s}}$ model.

602 (iii) Implement an OBS network with an appropriate layout allowing the depth 603 determination of shallow earthquakes.

604 (iv) Use land stations for improving the quality of focal mechanisms determinations. 


\section{Conclusions}

611

612 Our results indicate that during the two recording periods $(3.5$ months in 2011 and 2

613 months in 2014), not all earthquakes occurred as strike-slip events at crustal depths (> 8

$614 \mathrm{~km}$ ) along the axis of the MMF. In contrast, a significant number of earthquakes occurred

615 with a predominantly normal focal mechanism, at depths between 2 and $6 \mathrm{~km}$, along

616 tectonically active, structural trends oriented E-W or SW-NE.

617 The $\mathrm{P}$ and $\mathrm{S}$ arrivals, suggest that there are strong velocity anomalies along the Western

618 High, with low $V_{P}$, low $V_{S}$ and ultra-high $V_{P} / V_{S}$ in areas where mud volcanoes and gas-

619 prone sediment layers are known to be present. Finally, we find that a number of

620 earthquakes having a normal-fault focal mechanism occurred within the upper sediment

621 layers (at depths $<2 \mathrm{~km}$ ), particularly in the areas where free gas is suspected to exist,

622 based on high-resolution 3D seismics. Most of this ultra-shallow seismicity appears to be

623 related to the presence of gas in shallow sediments and occurs in response to deep

624 intermediate magnitude $(\mathrm{M} \mathrm{L} \sim 4-5)$ earthquakes.

625 The difficulties to resolve the depth of earthquakes within the SoM, particularly for the 626 shallow seismicity, strongly advocate for the implementation of permanent, seafloor

627 observatories in the close vicinity of the MMF, which represent the only way to conduct 628 high-resolution studies towards a better understanding of the fault behavior. 


\section{Data and Resources}

634

- An unpublished bathymetric grid of the Central Basin and Western High, having a node spacing of $10 \mathrm{~m}$, based on multibeam echosounder system data collected in 2014 with $R / V$ Pourquoi Pas? This $10 \mathrm{~m}$ grid (courtesy of Charline Guérin of Ifremer) is available on request to the authors.

- The two following seismological datasets were analyzed (see details Tables 1 and 2 and in Figure 1b) and are available on request to the authors:

Dataset-1 was recorded from $15^{\text {th }}$ of April to $31^{\text {st }}$ of July, 2011, by 10 autonomous, short-period $(4.5 \mathrm{~Hz})$ OBSs from Ifremer and by 2 permanent, cabled broad-band OBSs operated by KOERI. Unfortunately, the station in the center of the network stopped recording on $1^{\text {st }}$ of July, 2011. 9 autonomous, short-period $(4.5 \mathrm{~Hz})$ from Ifremer and by 1 autonomous, broad-band OBS operated by INGV. Note that two autonomous, short-period OBS were also deployed by Ifremer, from the $1^{\text {st }}$ until the $15^{\text {th }}$ of November near the gas emissions site.

The links to the datasets recorded with the OBSs of Ifremer are indicated below:

- Geli Louis, Pelleau Pascal, Batsi Evangelia, Namik Çagatay (2017). Ocean Bottom (OBS) data of the two the temporary seismic networks of Ifremer in 2011 (4 months). SEANOE. http://doi.org/10.17882/49764

- Geli Louis, Pelleau Pascal, Batsi Evangelia, Nurcan Meral Özel (2017). Ocean

655 Bottom (OBS) data of the two the temporary seismic networks of Ifremer in 2014 656 (2 months). SEANOE. http://doi.org/10.17882/49656 
- High-resolution 3D- and 2D-seismic data collected in 2009 with R/V Le Suroit and with R/V Piri Reis, respectively. The full description of the 3D-acquistion system and dataset is detailed in (Thomas et al., 2012). Multi-channel, deep seismic lines collected in 2001 during the Seismara Cruise of R/V Le Nadir were also used (e.g., Laigle et al., 2008; Bécel et al., 2009; Bécel et al., 2010).

- The Sytmis software package for used for the 2011 OBS dataset: (http://www.ineris.fr/centredoc/3202-fp-sytmisauto-0804-an.pdf)

- The non-linear methods developed by Anthony Lomax were used: (http://alomax.free.fr/alss/)

- The following scientific reports and articles available on-line were used:

Aktar, M., (2017). Fault Structures in Marmara Sea (Turkey) and Their Connection to Earthquake Generation Processes. In: Active Global Seismology. doi:10.1002/9781118944998.ch8 https://agupubs.onlinelibrary.wiley.com/doi/10.1002/9781118944998.ch8

676 Cros, E., and L. Géli, (2013). Caracterization of microseimicity in the Western Sea of Marmara: implications in terms of seismic monitoring, Project Report, Institut Carnot Ifremer-Edrome, Abondement 2011, $\mathrm{N}^{\circ} 06 / 11 / 2013,29$ pages, http://dx.doi.org/10.13155/38916 
681 Géli L., N. Çağatay, L. Gasperini, P. Favali, P. Henry and G. Çifçi, (2011). ESONET 682 WP4 - Demonstration Missions. Marmara-DM final report,

$683 \quad$ http://archimer.ifremer.fr/doc/00032/14324/

684

685 Gürbüz C., S.E. Isik , L. Géli, E. Cross, (2013). High Resolution Micro Earthquake 686 Characterization, Deliverable D8_2, EU MARSITE PROJECT (New Directions in 687 Seismic Hazard Assessment through Focused Earth Observation in the Marmara 688 Supersite), http://archimer.ifremer.fr/doc/00278/38915/.

689

690 Lomax, A., and A. Michelini, (2013). Users Guide for Early-est, Earthquake Rapid $691 \quad$ Location Sytem with Estimation of Tsunamigenesis,

$692 \quad$ http://early-est.rm.ingv.it/early-est_users_guide.pdf

693

694 Lomax, A., (2014). Mise en oeuvre et support pour logiciels de traitement automatisé de 695 données sismologiques acquises dans le cadre du projet Européen FP7 Marsite, 696 Contract report, Reference CNRS, MA201301A,

697 http://alomax.net/projects/marsite/MA201301A_report_v0.2.pdf.

698

699 Husen, S., and J.L. Hardebeck (2010) Earthquake location accuracy, Community Online Re 700 source for Statistical Seismicity Analysis, doi:10.5078/corssa-55815573. Available at $701 \quad$ http://www.corssa.org. 


\section{Acknowledgments}

707 This paper is part of the $\mathrm{PhD}$ of Evangelia Batsi, supported by Ifremer and by Région 708 Bretagne ("bourse ARED”). The OBS data were collected with the ESONET Network of

709 Excellence (contract $\mathrm{N}^{\circ}$ 036851) and the MARSITE Integrated Project (contract $\mathrm{N}^{\circ}$ 308417).

710 Jean-François Rolin and Roland Person, coordinators of ESONET as well as Meral Agualdis

711 project manager of MARSITE are warmly acknowledged. Acknowledgments are also

712 addressed to the Turkish Navy and to the Turkish Hydrographic Service (SHOD) for

713 supporting the operations at sea, particularly our correspondent, Captain Erhan Gezgin; to

714 the personnel of the French Embassy in Ankara, specially Mrs Bonnafous-Boucher; to CNR

715 (Comité National Routier) and to Ifremer for funding operations at sea of R/V Le Suroit,

716 R/V Pourquoi pas? and R/V Urania, respectively; to Giuseppe D'Anna, Giuseppe Passafiume

717 and Stefano Speciale of the Istituto Nazionale di Geofisica e Vulcanologia (INGV) of Italy

718 for assisting in the OBS deployment; to the Institute of Marine Science and Technology of

719 the University of Izmir for support with R/V Piri Reis; to Mireille Laigle of Géoazur of

720 Sophia Antipolis University for providing us the seismic profile SM47 (e.g. Figure 4, by

721 (Bécel, et al., 2010)); to Louis Géli for providing us Figure 2a (e.g. Figure A1-3, by (Géli et 722 al., 2018)); to COST_FLOWS (Action ES1301) for supporting a Short Term Scientific

723 Mission (STSM) for E.B.; to Bruno Marsset for his advices and encouragement; to Pascal

724 Pelleau, Mikaël Roudaut and Ronan Apprioual for their technical support; to Sylvain

725 Bermell and Laetitia Morvan, for drafting some of the figures; to Charline Guerin for 726 providing us the grid of high resolution bathymetry at $10 \mathrm{~m}$; to professor Oguz Özel, for

727 his support for using R/V Yunuz of Istanbul University; to Jean Schmittbuhl, Hayrullah

728 Karabulut and Jean-Robert Grasso for their participation to the $\mathrm{PhD}$ Thesis committee.

729 Intense use was made of Global Mapping Tools (GMT) and ArcGIS. All the data used in 
730 this paper are available on request to the authors.

731

732

733

734

735

736

737

738

739

740

741

742

743

744

745

746

747

748

749

750

751

752

753 


\section{References}

Aktar, M., (2017). Fault Structures in Marmara Sea (Turkey) and Their Connection to Earthquake Generation Processes.

In:

Active

Global Seismology. doi:10.1002/9781118944998.ch8.

Ambraseys, N.N. and C. Finkel, (1987). The Saros-Marmara earthquake of 9 August 1912, J. Earthq. Eng. Struct. Dyn., 15, 189-211.

Ambraseys, N.N and C. Finkel, (1995). The Seismicity of Turkey and adjacent areas. A historical review, 1500-1800, Istanbul: Eren Yayincilik, 240 pp.

Aretusini, S., S., Mittempergher, O. Plümper, E. Spagnuolo, A. F. Gualtieri, and G. Di Toro (2017), Production of nanoparticles during experimental deformation of smectite and implications for seismic slip, Earth and Planet. Sci. Lett., 463, 221-231,

Armijo, R., B. Meyer S. Navarro, G. King, and A. Barka, (2002). Asymetric slip doi:10.1016/j.eps1.2017.01.048.

Armijo, R., N. Pondard, B. Meyer, G.Ucarkus, B. de Lepinay, M., Malavieille, J. Dominguez, S. Gustcher, M. A. Schmidt, S. Beck, C. et al., (2005). Submarine fault scarps in the Sea of Marmara pull-apart (North Anatolian Fault): implications for seismic hazard in Istanbul, Geochem. Geophys. Geosyst., 6, Q06009, doi:10.1029/2004GC000896. 
775 Bayrakci G., M. Laigle, A. Bécel, A. Hirn, T. Taymaz, S. Yolsal-Çevikbilen,, and

776

777

778

779

780

781

782

783

784

785

786

787

788

789

790

791

792

793

794

795

796

797

SEISMARAMARA team (2013). 3-D sediment-basement tomography of the

NorthernMarmara trough by a dense OBS network at the nodes of a grid of controlled source profiles along the North Anatolian fault, Geophys. J. Int., doi: $10.1093 /$ gji/ggt211.

Bécel, A., (2006). Structure Sismique de la Faille Nord Anatolienne en Mer de Marmara, Phd Thesis, Institut de Physique du Globe de Paris.

Bécel, A., M. Laigle, B.De Voogd, A. Hirn, T. Taymaz, A. Galvé, H. Shimamura, Y. Murai, JC Lépine, M. Sapin, andS. Özalaybey, (2009). Moho, crustal architecture and deep deformation under the North Marmara Trough, from the SEISMARMARA Leg 1 offshore-onshore reflection-refraction survey, Tectonophysics 467: 1-21.

Bécel, A., M. Laigle, B. De Voogd, A. Hirn, T. Taymaz,, S. Yolsal-Cevikbilen, H. Shimamura, (2010): North Marmara Trough architecture of basin infill, basement and faults, from PDSM reflection and OBS refractions seismics, Tectonophysics 490: 1-14.

Bourry, C., B. Chazallon, JL Charlou, JP Donval, L. Ruffine, P. Henry, L. Géli, M. Çagatay, S. İnane, and M. Moreau, (2009). Free gas and gas hydrates from the Sea of Marmara, Turkey: Chemical and structural characterization. Chem. Geol., doi:10.1016/j.chemgeo.2009.03.007. 
798 Carton, H., S.C. Singh, A. Hirn, B. Bazin, B. de Voogd, A. Vigner, A. Ricolleau, S. 799 Cetin, N. Oçakoglu, F. Karakoç, V. Sevligen, (2007). Seismic imaging of the three800 dimensional architecture of the Çınarcık Basin along the North Anatolian Fault, $J$. 801 Geophys. Res., 112, B06101, doi: 10.1029/2006JB004548.

802

803 Cros, E., and L. Géli, (2013). Caracterization of microseimicity in the Western Sea of 804 Marmara: implications in terms of seismic monitoring, Project Report, Institut 805 Carnot Ifremer-Edrome, Abondement 2011, $\mathrm{N}^{\circ} 06 / 11 / 2013,29$ pages.

806

807 De Landro, G., O. Amoroso, TA Stabile, E. Martullo, A. Lomax and A. Zollo, (2015). 808 High precision Differential Earthquake Location in 3D models: Evidence for a 809 rheological barrier controlling the microseismicity at the Irpinia fault zone in 810 southern Apennines, Geophys. J. Int., 203 (3): 1821-1831,

811 doi:10.1093/gji/ggv397

813 Dupré S., C. Scalabrin C., C. Grall, J-M Augustin, P. Henry, A. M. C Sengor, N. Görür, M. 814 N. Cagatay andL. Géli (2015). Tectonic and sedimentary controls for widespread gas 815 emissions in the Sea of Marmara, Results from systematic, ship-borne multibeam 816 echosounder water column imageries, J. Geophys. Res., doi: 10.1002/2014JB011617.

818 Faulkner, D. R., T. M. Mitchell, J. Behnsen, T. Hirose, and T. Shimamoto (2011). Stuck in 819 the mud? Earthquake nucleation and propagation through accretionary forearcs, Geophys. $820 \quad$ Res. Lett, 38 (18), doi:10.1029/2011GL048552.

822 Géli, L., P. Henry, T. Zitter, S. Dupré, M. Tryon, M.N. Çağatay, B. Mercier de Lépinay,, 

X. Le Pichon, A.M.C. Şengör, N. Görür , et al., (2008). Gas emissions and active tectonics within the submerged section of the North Anatolian Fault zone in the Sea of Marmara. Earth Planet. Sci. Lett., 274(1-2): 34-39.

827 Géli L., N. Çağatay, L. Gasperini, P. Favali, P. Henry and G. Çifçi, (2011). ESONET WP4 828 Demonstration Missions. Marmara-DM final report.

830 Géli, L., J. Piau, M., Dziak, R., Maury, V., Fitzenz, D., Coutellier, Q., and P. Henry, (2014), Seismic Precursors linked to Highly Compressible Fluids at Oceanic Transform Faults, Nature Geoscience, doi:10.1038/NGEO2244

Géli, L., P. Henry, C. Grall, J.B. Tary, A. Lomax, E. Batsi, C. Cros, C. Gürbüz, S.E. Isik, A.M.C. Şengör et al., (2018). Gas related seismicity within the Istanbul seismic gap, Nature Scientific Reports.

838 Grall, C., P. Henry, D. Tezcan, B. Mercier de Lepinay, A. Bécel, L. Géli, J-L. Rudkiewicz, T. Zitter, F. Harmegnies, (2012). Heat flow in the Sea of Marmara Central Basin, possible implications for the tectonic evolution of the North Anatolian Fault, Geology, 40:3-6, doi:10.1130/G32192.32191.

843 Grall, C., P. Henry, Y. Thomas, G.K. Westbrook, .M. N. Çağatay, B. Marsset, H. Saritas, G. Çifçi, and L. Géli, (2013). Slip rate estimation along the western 
segment of the Main Marmara Fault over the last 330 ka by correlating Mass Transport Deposits, Tectonics, 10.1002/2012TC003255.

847 Gürbüz C., M. Aktar, H. Eyidogan, A. Cisternas, H. Haessler, A. Barka, M. Ergin, N. 848 Türkelli, O. Polat, S.B Üçer, S. Kuleli, et al., (2000). The seismotectonics of the Marmara region (Turkey): results from a micro-seismic experiment. Tectonophysics

852 Gürbüz C.,S.E. Isik L. Géli, E. Cross, (2013). High Resolution Micro Earthquake 316, 1-17.

Hausmann, H., S. Hoyer, B. Schurr, E. Brückl, G. Houseman, and G. Stuart, (2010).

Hardebeck, J.L. and P.M. Shearer, (2003). Using S/P Amplitude Ratios to Constrain the 866

867 Hardebeck, J.L. and P.M Shearer, (2008). HASH : A Fortran program for computing 868 Earthquake First-Motion Focal Mechanisms -v1.2 - January 31 
870

871

872

873

874

875

876

877

878

879

880

881

882

883

884

885

886

887

888

889

890

891

892

893

894

Helmstetter A., (2002). Is Earthquake Triggering Driven by Small Earthquakes, Phys. Rev. Lett. 91, 058501.

Husen, S., and J.L. Hardebeck (2010). Earthquake location accuracy, Community Online Resource for Statistical Seismicity Analysis, doi:10.5078/corssa-55815573.

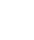

Imren, C., X. Le Pichon, C. Rangin, E. Demirbağ, B. Ecevitoğlu,, N. Görür, (2001). The North Anatolian Fault within the Sea of Marmara: a new interpretation based on multichannel seismic and multi-beam bathymetry data,

Earth Plan. Sci. Lett., 186,143-158, doi:10.1016/S0012-821X(01)00241-2.

Karabulut, H., J. Schmittbuhl, S. Özalaybey, O. Lengliné, A. Kömeç-Mutlu, V.

Durand, M. Bouchon, G. Daniel, M.P Bouin,. (2011). Evolution of the seismicity in the eastern Marmara Sea a decade before and after the 17 August 1999 Izmit earthquake, Tectonophysics, 510, 17-27.

King G.C.P., S. Ross, J. Lin, (1994). Static stress changes and the triggering of earthquakes, Bull. Seism. Soc. Am. 84, 3, 935-953.

Kuscu, I.,M. Okamura, H. Matsuoka, E. Gökaşan, Y. Awata, H. Tur, Şimşek and M. Keçer, (2005). Seafloor gas seeps and sediment failures triggered by the August 17, 1999 earthquake in the Eastern part of the Gulf of Izmit, Sea of Marmara, NW Turkey. Mar. Geol. 215, 193-214.

Laigle M., A. Becel, B. De Voogd, A. Hirn, T. Taymaz, S. Ozalaybey, and Members of SEISMARA Leg1 Team (2008). A first seismic survey in the Sea of Marmara: Deep 
897 Le Pichon, X., A.M.C. Şengör , E. Demirbăg , C. Rangin, C. Imren, R. Armijo, Görür, N. 898 Çağatay, B. Mercier de Lepinay, et al., (2001). The active Main Marmara Fault, Earth 899 Planet. Sci. Lett., 192, 595-616.

900

901 Lomax, A. (2008), Location and Tectonics of the Focal Region of the California Earthquake 902 of 18 April 1906, Bull. Seism. Soc. Am., 98, 846-860.

903

904 Lomax, A., A. Michelini, and A. Curtis,, (2009). Earthquake Location, Direct, Global-Search 905 Methods, in Complexity In Encyclopedia of Complexity and System Science, Part 5, 906 Springer, New York, pp. 2449-2473, doi:10.1007/978-0-387-30440-3.

907

908 Lomax, A., C. Satriano, and M. Vassallo, (2012). Automatic picker developements and 909 optimazation: FilterPicker - a robust broadband picker for real - time seismic monitoring and earthquake early - warning, Seism. Res. Lett., 83, 531-540, doi :

913 Lomax, A., and A. Michelini, (2013). Users Guide for Early-est, Earthquake Rapid Location 914 Sytem with Estimation of Tsunamigenesis, see link in «Data and Resources » section.

916 Lomax, A., (2014). Mise en oeuvre et support pour logiciels de traitement automatisé de 917 données sismologiques acquises dans le cadre du projet Européen FP7 Marsite, Contract 918 report, Reference CNRS, MA201301A. 
920 Maurer, H., and U. Kradolfer (1996). Hypocentral parameters and velocity estimation in the 921 western Swiss Alps by simultaneous inversion of P- and S-wave data, Bull. Seism. Soc. $922 \quad A m ., 86,32-42$.

923

924 Örgülü, G., (2011). Seismicity and source parameters for small-scale earthquakes along the 925 splays of the North Anatolian Fault (NAF) in the Marmara Sea, Geophys. J. Int. 184, 926 385-404 doi:10.1111/j.1365-246X.2010.04844.x

927

928 Parsons T., (2004). Recalculated probability of $M>7$ earthquakes beneath the Sea of Marmara. 929 J. Geophys. Res., 109, doi:10.1029/2003JB002667.

931 Pinar A., K. Kuge, and Y. Honkura,. (2003). Moment tensor inversion of recent small to 932 moderate sized earthquakes: implications for seismic hazard and active tectonics 933 beneath the Sea of Marmara, Geophys. J. Int., 153, 133-145.

934

935 Pondard N., R. Armijjo, G.C.P. King, and B. Meyer, (2007). Fault interactions in the Sea of 936 Marmara pull-apart (North Anatolian Fault): earthquake clustering and propagating 937 earthquake sequences, Geophys. J. Int. (2007), 171, 1185-1197, doi: 10.1111/j.1365$938 \quad$ 246X.2007.03580.x.

939

Rangin, C., E. Demirbag, C. Imren., A. Crusson,, E. Le Drezen, A. Le Bot, (2001). Marine Atlas of the Sea of Marmara (Turkey). Data collected on board R.V Le Suroît, September 2000.

940

941 Rangin, C., X. Le Pichon, E. Demirbag, and C. Imren, (2004). Strain localization in the Sea 
of Marmara: Propagation of the North Anatolian Fault in a now inactive pull-apart, Tectonics, 23, TC2014, doi:10.1029/2002TC001437.

944 Ruffine, L., Y. Germain, A. Polonia, A. De Prunelé, C. Croguennec, J-P Donval., M. Pitel-

945

946

947

948

949

950

951

952

953

954

955

956

957

958

959

960

961

962

963

964

965

966

967 Roudaut, E. Ponzevera, J-C. Caprais, C. Brandily, (2015). Pore water geochemistry at two seismogenic areas in the Sea of Marmara, Geochem. Geophys. Geosyst., 16, 2038-2057, doi:10.1002/2015GC005798.

Ruffine, L., O. Fandino, J. Etoubleau, S. Chéron,, J-P. Donval, Y. Germain, E. Ponzevera, V. Guyader, B. Dennielou, Etiope, et al., (2012). Geochemical dynamics of the naturalgas hydrate system in the Sea of Marmara, offshore Turkey, Advances in Natural Gas Technology, ISBN 978-953-51-0507-7, pp. 29-56.

Sakic, P., H. Piété, V. Ballu, J.-Y. Royer, H. Kopp, D. Lange, F. Petersen, S. Özeren, S. Ergintav, L. Géli, P. Henry, A. Deschamps (2016). No significant steady state surface creep along the North Anatolian Fault offshore Istanbul: Results of 6 months of sea floor acoustic ranging,

Geophys. Res. Lett., 43, 6817-6825, doi:10.1002/2016GL069600.

Sato, T., J. Kasahara, T. Taymaz, M. Ito, A. Kamimura, T. Hayakawa, andO. Tan, (2004). A study of microearthquake seismicity and focal mechanisms within the Sea of Marmara (NW Turkey) using ocean bottom seismometers (OBSs), Tectonophysics, 391:303, 314. doi:10.1016/j.tecto.2004.07.018.

Schmittbuhl, J.,H. Karabulut, O. Lengliné, and M. Bouchon, (2015). Seismicity distribution and locking depth along the Main Marmara Fault, Turkey, Geochemistry, Geophysics, 
970 Schmittbuhl, J., H. Karabulut, O. Lengliné, and M. Bouchon, (2016). Long-lasting seismic repeaters in the Central Basin of the Main Marmara Fault, Geophys. Res. Lett., 43, 9527-9534, doi:10.1002/2016GL070505.

973

974 Shillington, D. J., L., Seeber, C. C. Sorlien, M. S. Steckler, H. Kurt, D. Dondurur, G. Çifçi, 975 C. İmren, M.-H. Cormier, C.M.G. McHugh, S. Gürçay, D. Poyraz, S. Okay, O. Atgın , 976 J.B. Diebold (2012). Evidence for widespread creep on the flanks of the Sea of Marmara transform basin from marine geophysical data. Geology; 40 (5): 439-442.

978

979 Şengör, A. M. C.,O. Tüysüz, C. İmren, M. Sakınç, H. Eyidoğan, N. Görür, X. Le Pichon, 980 and C. Rangin, (2005). The North Anatolian Fault: A new look, Annu. Rev. Earth Planet. Sci., 33, 37-112, doi:10.1146/annurev.earth.32.101802.120415.

982

983 Şengör, A.M.C., C. Grall, C. Imren, X. Le Pichon, Görür, P. Henry, H. Karabulut, and M. 984 Siyako (2014). The geometry of the North Anatolian transform fault in the Sea of 985 Marmara and its temporal evolution: Implications for the development of intracontinental transform faults, Can. J. Earth Sci., 51(3), 222-242, doi:10.1139/cjes-2013-

989 Steacy, S., J. Gomberg, and M. Cocco, (2005). Introduction to special section: Stress transfer, 990 earthquake triggering, and time-dependent seismic hazard, J. Geophys. Res., 110, B05S01, doi:10.1029/2005JB003692. 
993 Stein, R. S., A.A. Barka, and H. Dieterich, (1997). Progressive failure on the North Anatolian 994 fault since 1939 by earthquake stress triggering, Geophys. J. Int., 128, 594-604.

995 Tary, J.-B, L. Géli, P. Herny, B. Natalin, L. Gasperini, M. Çomoğlu, N. Çağatay, and T. 996 Bardainne, (2011). Sea-Bottom Observations from the Western Escarpment of 997 the Sea of Marmara, Bull. Seism. Soc. Am.,

999 Thomas, Y., B. Marsset, G. Westbrook, C. Grall, L. Géli, G.Cifci, A. Rochat and H. 1000 Sartas, (2012). Contribution of high-resolution 3D seismic near-seafloor imaging to 1001 reservoir scale studies: application to the active north Anatolian Fault, Sea of Marmara, 1002 Near Surface Geophysics, 10, 291-301, doi:10.3997/1873-0604.2012019

1004 Waldhauser, F., and W.L. Ellsworth, (2000). A double-difference earthquake location 1005 algorithm: Method and application to the northern Hayward fault, Bull. Seismol. Soc. $1006 \quad$ Am., 90, 1353-1368.

1008 Yamamoto, Y., N. Takahashi, A. Pinar, D. Kalafat, S. Citak, M. Comoglu, R. Polata, and 1009 Y. Kaneda, (2017). Geometry and segmentation of the North Anatolian Fault beneath 1010 the Marmara Sea, Turkey, deduced from long-term ocean bottom seismographic 1011 observations, JGR, doi:10.1002/2016JB013608 
1018 MAILING LIST OF AUTHORS

1019

1020 Order of Authors:

1021 Corresponding Author Dr. Evangelia Batsi (E-Mail: Evangelia.Batsi@ifremer.fr)

1022 Dr. Anthony Lomax (E-Mail: alomax@free.fr)

1023 Dr. Jean-Baptiste Tary (E-Mail: jb.tary@uniandes.edu.co)

1024 Dr. Frauke Klingelhoefer (E-Mail: Frauke.Klingelhoefer@ifremer.fr)

1025 Dr. Vincent Riboulot (E-Mail: Vincent.Riboulot@ifremer.fr)

1026 Dr. Shane Murphy (E-Mail: Shane.Murphy@ifremer.fr)

1027 Dr. Stephen Monna (E-Mail: stephen.monna@ingv.it)

1028

1029

1030

1031

1032

1033

1034

1035

1036

1037

1038

1039 
1043 LIST OF FIGURE CAPTIONS (1 to 22)

1046 Figure 1: (1a) General view of the SoM between the Black Sea and the Aegean Sea. 1047 Black lines indicate the main structural features of the MMF (e.g., Şengör et al., 2005). 1048 Black box correspond to Fig. 1b. Abbreviations: TB: Tekirdag basin; WH: Western High; 1049 CB: Central Basin; KB: Kumburgaz basin; CH: Central High; ÇB: Çinarcik Basin.

1050 (1b) Bathymetric map of the study area within the Western SoM, displaying the position of 1051 the OBSs used for this study, along with the delimitation of the boxes shown in Figures 3, 1052 6b, 9b, and 13. Temporary seismic networks of Ifremer in 2011 and 2014 are shown with 1053 yellow and red triangles, respectively, while the one of INGV (in 2014) is represented by a 1054 purple triangle. The permanent OBS stations of KOERI (green triangles) were operating in 10552011 but not in 2014. Black lines are for active faults (e.g., Şengör et al., 2005). Green 1056 dots indicate acoustically detected gas emission sites, after (Dupré et al., 2015). White 1057 circles show the center of the clusters of case study 1 (CS1), 2 (CS2) and 3 (CS3), 1058 respectively.

1059

1060 Figure 2: (2a) From (Cros and Géli, 2013). See also Appendix 1 in (Géli et al., 2018). 1061 Contours of the pre-kinematic basement depth, from Figure 13a of (Bayrakci et al., 2013), 1062 are here super-imposed on the bathymetric map of the Western SoM, based on the high 1063 resolution, $38 \mathrm{~m}$ grid from (Le Pichon et al., 2001). Red dots indicate grid nodes from the 1064 low-resolution $(6 \mathrm{~km} \times 6 \mathrm{~km} \times 2 \mathrm{~km})$ grid of (Bayrakci et al., 2013). Black dots indicate 
1065 the nodes of the high-resolution grid $(0.75 \mathrm{~km} \times 0.75 \mathrm{~km} \times 0.2 \mathrm{~km})$ used in this study. 1066 Labels from 1 to 9 on the basement iso-depth contours indicate 9 different velocity 1067 domains: red dots within iso-contour 1 share the same 1D-velocity profile within the pre1068 kinematic basement; so do all red dots located between iso-contours 2 and 3 , etc. The 1069 velocity profile below the pre-kinematic basement is based on (Bécel et al., 2009), as 1070 described in (Cros and Géli, 2013). Finally, the 1D velocity profile below each black dot is 1071 obtained by interpolating the velocity profile from the surrounding red nodes.

1072 (2b) 1D-velocity models used in previous studies of seismicity within the SoM (where 1073 dash-dot line, plus sign, circle and solid line correspond to the models by ((Tary et al., 1074 2011); (Gürbüz et al., 2000) and (Karabulut et al., 2011)) respectively, along with the 1D1075 model used in this study (solid line) and described in (Cros and Géli, 2013).

1077 Figure 3: Detailed bathymetric map of the Western High having a node spacing of $10 \mathrm{~m}$ 1078 (contour interval: $100 \mathrm{~m}$, see Data and Resource section). The bathymetric grid is still 1079 unpublished and available on request to the authors (Courtesy of Charline Guérin, Ifremer). 1080 Dashed black line A2-08 is the 2D-high resolution seismic line displayed in Figure 8. 1081 Black boxes correspond to Figures 6b, 20 and 21. Continuous black lines indicate the main 1082 structural features of the MMF. Temporary seismic networks of Ifremer in 2011 and 2014 1083 are shown with yellow and red triangles, respectively, while the one of INGV (in 2014) is 1084 represented by a purple triangle. The permanent OBS stations of KOERI (green triangles) 1085 were operating in 2011 but not in 2014.

1087 Figure 4: Matrix of cross correlation for all events recorded during the 2014 deployment, 1088 by the central station OBS4, on the vertical component. White arrows indicate highly 1089 correlated events, e.g: the triplet $(\mathrm{cc}>0.9)$ of $25^{\text {th }}$ of October 2014, selected for Case 
1092 Figure 5: Case study 1. Seismograms from the vertical (left panel) and horizontal 1 (right 1093 panel) components corresponding to the triplet (with cc>0.9) recorded by the central OBS4 1094 station of the 2014 network on the $25^{\text {th }}$ of October 2014.

1096 Figure 6: Case study 1. 6a) Distribution of OBSs (shown by black triangles) used in this 1097 study for the location of earthquake 2 of case study 1 (see seismograms in Figure 7). 1098 White star, circle and diamond indicate the 1D (this study), the 3D (this study) and the 1099 (Yamamoto et al., 2017) locations, respectively. The distances (in kilometers) from the 3D 1100 location of earthquake 2 to each OBS are indicated in black. Note that OBS10 (e.g. shown 1101 with a black cross) stopped working 3 days before the occurrence of the events of case 1102 study 1 . Note that paths to OBS4 necessarily cross mud volcanoes and gas-prone sediment 1103 layers. Black box corresponds to Fig. 6b. Black lines indicate the main structural features 1104 of the MMF (e.g., Şengör et al., 2005).

1105 6b) Left panel indicates the relocated epicenters for the triplet shown in Figure 5, obtained 1106 using respectively the 1D (stars), the 3D (circles) velocity models of this study and the 3D 1107 velocity model by (Yamamoto et al., 2017) (white diamonds). The right panel indicates the 1108 N-S cross-section with the relocated hypocenters. The probabilistic, relative location 1109 uncertainties obtained by NLDiffLoc are displayed by black ellipsoids showing the 1110 projection of the $68 \%$ confidence ellipsoid for each earthquake with their pdf (probability 1111 density functions) indicated by blue and red dots, for the 1D and 3D velocity models 1112 respectively. Red beachballs show the composite focal mechanism solution calculated for the 1113 triplet events. Numbers 1 to 3 correspond to the number of each individual event listed in 1114 Table 4. Line A2-08 is the 2D-high resolution seismic line displayed in Figure 8. Green 
1115 dots correspond to gas emissions sites, after (Dupré et al., 2015). Note that OBS10 (e.g.

1116 shown with a yellow cross) stopped working 3 days before the occurrence of the events of

1117 case study 1. See polarities and characteristics of composite focal mechanisms of 3D

1118 locations in Supplementary Information.

1120 Figure 7: Seismograms from earthquake $2\left(25^{\text {th }}\right.$ of October, 2014) of case study 1 recorded 1121 at seafloor stations $1,8,4,7,5$ and 3 of the 2014 OBS network. Dotted lines indicate $t_{p}$ 1122 and $t_{s}$ arrivals at each different OBS. The upper panel displays the vertical component (e.g. 1123 Z) and the bottom panel is for Horizontal-1 (e.g. H1).

1125 Figure 8: (a) Upper panel: 2D-high resolution seismic section along line A2-08 (see track 1126 line location in Figure 3) collected in 2009 with Piri Reis. (b) Bottom panel: Interpretation 1127 of seismic profile A2-08 (this study).

1129 Figure 9: Case Study 2, presented for a triplet of highly correlated events (cc > 0.8) that 1130 occurred on the $19^{\text {th }}$ of May 2011 and on the $23^{\text {rd }}$ of June 2011. 9a) Distribution of OBSs 1131 (shown by black triangles) used in this study for the location of earthquake 3 of case study 11322 (see seismograms in Figure 10). White star and white circle indicate the 1D (this study) 1133 and the 3D (this study) locations, respectively. Black lines indicate the distance of 3D 1134 location to each OBS station. Dashed black line indicated the profile SM47 shot during the 1135 Seismarmara cruise in 2001 across the eastern side of the Central Basin. Black box 1136 corresponds to figure Fig. 9b. Black lines indicate the main structural features of the MMF 1137 (e.g., Şengör et al., 2005).

1138 9b) Left panel indicates the relocated epicenters obtained using respectively the 1D (stars), 1139 the 3D (circles) velocity models of this study. Upper right panels indicate N-S cross-section 
1140 with the relocated hypocenters. The probabilistic, relative location uncertainties obtained by

1141 NLDiffLoc are displayed by black ellipsoids showing the projection of the $68 \%$ confidence 1142 ellipsoid for each earthquake with their pdf (probability density functions) indicated by blue 1143 and red dots, for the "this study 1D" and 3D velocity models respectively. Numbers 1 to 3

1144 correspond to the number of each individual event listed in Table 5. Red beachball shows 1145 the composite focal mechanism solution calculated for the triplet. Green dots correspond to 1146 gas emissions sites, after (Dupré et al., 2015). See polarities and characteristics of 1147 composite focal mechanisms of 3D locations in Supplementary Information.

1149 Figure 10: Seismograms for event 3 of case study 2, recorded at OBSs 7, 8, 9 and 10 on 1150 the $23^{\text {rd }}$ of June 2011. Horizontal arrows indicate the $t_{s}-t_{p}$ arrival at each different OBS. 1151 The upper panel displays the vertical component (e.g. Z) and the bottom panel is for 1152 Horizontal-1 (e.g. H1).

1154 Figure 11: (after Figure 4, of (Bécel et al., 2010)): Relocated hypocenters (orange circles) 1155 of 2011 recording period, projected along the pre-stack depth migrated section (Line SM47) 1156 shot during the Seismarmara cruise in 2001 across the eastern side of the Central Basin. 1157 Line track is indicated in Figure 9a. Interpretations (yellow, red and brown lines) are from 1158 (Bécel et al., 2010). Note that the most shallow (at depths $<3 \mathrm{~km}$ ) hypocenters are near 1159 or within to the positive flower structure underlined by the black box (see case study 2 , 1160 Figure 9b).

1162 Figure 12: Schematic diagram showing the steps that were followed for the synthetic test 1163 of case study 2. 
1165 Figure 13: Case study 3. Left panel indicates the relocated epicenters of the cluster of 1166 events that occurred from the $26^{\text {th }}$ of April 2011 until the $18^{\text {th }}$ of May 2011, obtained 1167 using respectively the 1D (stars), the 3D (circles) velocity models of this study. The right 1168 panel indicates the N-S cross-section with the relocated hypocenters. The probabilistic, 1169 relative location uncertainties obtained by NLDiffLoc are displayed by black ellipsoids 1170 showing the projection of the $68 \%$ confidence ellipsoid for each earthquake with their pdf 1171 (probability density functions) indicated by blue and red dots, for the "this study 1D" and 1172 3D velocity models respectively. Red beachball shows the composite focal mechanism 1173 solution calculated for the cluster events. Numbers 1 to 10 correspond to the number of 1174 each individual event listed in Table 8. Green dots correspond to gas emissions sites, after 1175 (Dupré et al., 2015). See polarities and characteristics of composite focal mechanisms of 1176 3D locations in Supplementary Information.

1178 Figure 14: Comparison of RMS errors of absolute location (e.g. use of NonLinLoc) 1179 obtained for the case studies 1 to 3, for the velocity models 1D (black bins) and 3D (gray 1180 bins) of this study. Event number for each case study is indicated (see Tables 4, 5 and 8).

1182 Figure 15: Comparison of location results for the common events, listed both in 1183 (Yamamoto et al., 2017) (light green diamonds) and in this work (salmon circles), that 1184 occurred during the overlapping period, from $19^{\text {th }}$ of September to $14^{\text {th }}$ of November, 2014. 1185 Labels (from 1 to 14 ) correspond to the number of each individual event listed in Table 9 1186 and are connected with yellow lines. Red beachball shows the focal mechanism solution of 1187 the triplet of case study 1 (see Table 10). Green dots correspond to gas emissions sites, after 1188 (Dupré et al., 2015). Bathymetric map of upper left panel with a node spacing of $10 \mathrm{~m}$ 1189 and contour interval of $20 \mathrm{~m}$ (see Data and Resource section). Black lines indicate main 
structural features, after (Şengör et al., 2005).

1192 Figure 16: Distribution of OBSs (shown by black triangles) used in this study for the 1193 location of earthquake 11 of Figure 15 (see seismograms in Figure 17). White circle and 1194 diamond indicate the 3D (this study) and the (Yamamoto et al., 2017) locations, 1195 respectively. The distances (in kilometers) from the 3D location of earthquake 11 to each 1196 OBS are indicated in black. Note that OBS10 (e.g. shown with a black cross) stopped 1197 working 3 days before the occurrence of the earthquake 11. Note that paths to OBS4 1198 necessarily cross-mud volcanoes and gas-prone sediment layers. Black lines indicate the 1199 main structural features of the MMF (e.g., Şengör et al., 2005).

1201 Figure 17: Seismograms from earthquake $11\left(25^{\text {th }}\right.$ of October, 2014) of Figure 17, recorded 1202 at seafloor stations $1,3,4,5,6,7$ and 8 of the 2014 OBS network. Dotted lines indicate 1203 tp and ts arrivals at each different OBS. The upper panel displays the vertical component 1204 (e.g. Z) and the bottom panel is for Horizontal-1 (e.g. H1).

1206 Figure 18: Upper left panel indicates the relocated epicenters (obtained using the 3D 1207 velocity model) for the 2011 recording period, including also the mainshock of the $25^{\text {th }}$ of 1208 July and its sequence of aftershocks (e.g. $15^{\text {th }}$ of April until the $31^{\text {st }}$ of July 2011). The 1209 lower left and upper right panels indicate E-W and N-S cross-sections of the relocated 1210 hypocenters. Red beachballs show the focal mechanisms solutions, with white labels 1211 indicating the name, local magnitude and depth for each case (see Table 10). Yellow 1212 triangles show the temporary OBS stations of Ifremer during the 2011 recording. Green 1213 dots correspond to gas emissions sites, after (Dupré et al., 2015). Black lines are for active 1214 faults (e.g., Şengör et al., 2005). The size of the orange circles is proportional to their 
1215 local magnitude (e.g. $0.5<\mathrm{M}<5.1$ ). Bathymetric map in upper left panel is with node 1216 spacing of $10 \mathrm{~m}$ (see Data and Resource section). See polarities and characteristics of 1217 composite focal mechanisms of 3D locations in Supplementary Information.

1219 Figure 19: Upper left panel indicates the relocated epicenters (obtained using the 3D 1220 velocity model) for the recording period from September $19^{\text {th }}$ to November $14^{\text {th }}, 2014$. The 1221 lower left and upper right panels indicate E-W and N-S cross-sections of the relocated 1222 hypocenters. Red beachballs show the focal mechanisms solutions with white labels 1223 indicating the name, local magnitude and depth for each case (see Table 10). Red and 1224 orange (OLD-OBS) triangles show the temporary OBS stations of Ifremer during the 2014 1225 recording, while the purple triangle show the temporary OBS station of INGV. Green dots 1226 correspond to gas emissions sites, after (Dupré et al., 2015). Black lines are for active 1227 faults (e.g., Şengör et al., 2005). The size of the salmon circles is proportional to their 1228 local magnitude (e.g. $0.5<\mathrm{M}<3.3$ ). Bathymetric map (upper left panel) with node spacing 1229 of $10 \mathrm{~m}$ (see Data and Resource section). See polarities and characteristics of composite 1230 focal mechanisms of 3D locations in Supplementary Information.

1232 Figure 20: A synthesis map of the relocated epicenters (using our 3D velocity model) 1233 during the 2011 (orange circles) and 2014 (salmon circles) recording periods. Red triangles 1234 show the temporary OBS stations of Ifremer during the 2014 recording period. Green dots 1235 correspond to gas emissions sites, after (Dupré et al., 2015). The bathymetric map of the 1236 Western High is with a node spacing of $10 \mathrm{~m}$ (see Data and Resource section). Black 1237 dashed line indicates seismic line A2-08 (see Figure 8).

1239 Figure 21: Map presenting the shallower (depth $<4 \mathrm{~km}$ ), well constrained, relocated 
1240 aftershocks (using our 3D velocity model) that followed the M5.1 earthquake of the $25^{\text {th }}$ of 1241 July, 2011. Green dots correspond to gas emissions sites, after (Dupré et al., 2015). The 1242 bathymetric map of the Western High is with a node spacing of $10 \mathrm{~m}$ and contour interval of $124320 \mathrm{~m}$ (see Data and Resource section). Red beachball shows the composite focal 1244 mechanism solution of the aftershocks (see Table 10). See polarities and characteristics of 1245 composite focal mechanisms of 3D locations in Supplementary Information. 1246

1247 Figure 22: Thresholded" seismicity maps between 2007 and 2012, after (Schmittbuhl et al., 1248 2015) displaying events of magnitude $\left(\mathrm{M}_{\mathrm{l}}\right)$ above 3.0 (top); 2.6 (middle) and 2.0 (bottom), 1249 respectively. The "vertical" swarms of seismicity disappear for a threshold magnitude of $\mathrm{M}_{1}$ $1250 \sim 3$. 
Table 1: Table of coordinates and operation period of the temporary and permanent OBS stations of data-set 1.

\begin{tabular}{|c|c|c|c|c|}
\hline OBS code & Latitude $\left({ }^{\circ} \mathbf{N}\right)$ & Longitude $\left({ }^{\circ} \mathbf{E}\right)$ & Depth $(\mathbf{m})$ & Recording period \\
\hline OBS1 & 40.8848 & 27.6996017 & 1024 & 15 Apr. - 31 July \\
\hline OBS2 & 40.817055 & 27.7804433 & 652 & 15 Apr. - 30 June \\
\hline OBS3 & 40.750405 & 27.700185 & 516 & 15 Apr. - 31 July \\
\hline OBS4 & 40.8611483 & 28.580295 & 328 & 15 Apr. - 31 July \\
\hline OBS5 & 40.733415 & 27.920655 & 775 & 15 Apr. - 31 July \\
\hline OBS6 & 40.84155 & 27.9155833 & 906 & 15 Apr. - 31 July \\
\hline OBS7 & 40.786225 & 28.040535 & 1100 & 15 Apr. - 31 July \\
\hline OBS8 & 40.88608 & 28.0778767 & 1181 & 15 Apr. - 31 July \\
\hline OBS9 & 40.7344117 & 28.143615 & 634 & 15 Apr. - 31 July \\
\hline OBS10 & 40.8343517 & 28.2122183 & 720 & 15 Apr. - 31 July \\
\hline KOERI03 & 40.884783 & 27.975100 & 1204 & permanent \\
\hline KOERI04 & 40.828184 & 27.535460 & 1144 & permanent \\
\hline
\end{tabular}

Where: OBS1 to OBS10 are the temporary OBS stations of Ifremer, during the 2011 recording period and KOERI-03 and KOERI-04:are the permanent OBS stations of KOERI used here 
Table 2: Table of coordinates and operation period of the temporary OBS stations of dataset 2 .

\begin{tabular}{|c|c|c|c|c|}
\hline OBS code & Latitude $\left({ }^{\circ} \mathbf{N}\right)$ & Longitude $\left({ }^{\circ} \mathbf{E}\right)$ & Depth (m) & Recording period \\
\hline OBS1 & 40.91677 & 27.764366 & 443 & 19 Sep. - 14 Nov. \\
\hline OBS2 & 40.81528 & 27.7769 & 661 & 19 Sep. - 21 Sep. \\
\hline OBS3 & 40.71292 & 27.787066 & 481 & 19 Sep. - 14 Nov. \\
\hline OBS4 & 40.81267 & 27.7717 & 665 & 19 Sep. - 14 Nov. \\
\hline OBS5 & 40.77940 & 27.848133 & 918 & 19 Sep. - 14 Nov. \\
\hline OBS6 & 40.83143 & 27.947 & 1191 & 19 Sep. - 14 Nov. \\
\hline OBS7 & 40.77620 & 27.708516 & 598 & 19 Sep. - 14 Nov. \\
\hline OBS8 & 40.85125 & 27.708 & 1024 & 19 Sep. - 14 Nov. \\
\hline OBS9 & 40.81977 & 27.60506 & 1106 & 19 Sep. - 14 Nov. \\
\hline OBS10 & 40.84997 & 27.845516 & 401 & 19 Sep. - 23 Oct. \\
\hline OBS11 & 40.812946 & 27.768004 & 658 & 01 Nov. -14 Nov. \\
\hline OBS12 & 40.813015 & 27.768516 & 657 & 01 Nov. -14 Nov. \\
\hline OBS13 & 40.795116 & 27.83906 & 1016 & 06 Oct. 2013- 14 Nov. 2014 \\
\hline
\end{tabular}

Where: OBS1 to OBS12 are the temporary OBS stations of Ifremer, and OBS13 is the temporary OBS station of INGV, during the 2014 recording period 
Table 3: Results for synthetic tests on the 1D-models and the $3 \mathrm{D}$ velocity model of this study, for Trials 1 and 2 .

\begin{tabular}{|c|c|c|c|c|c|c|}
\hline \multirow{2}{*}{ Velocity models } & \multicolumn{3}{|c|}{ Trial 1 } & \multicolumn{3}{c|}{ Trial 2 } \\
\cline { 2 - 7 } & Latitude 1 $\left(^{\circ}\right)$ & Longitude 1 $\left(^{\circ}\right)$ & Depth 1 (km) & Latitude 2 $\left(^{\circ}\right)$ & Longitude 2 $\left(^{\circ}\right)$ & Depth 2 (km) \\
\hline Initial location & 40.80 & 28.00 & 12 & 40.80 & 28.00 & 2 \\
\hline 1D - this study & 40.7677 & 28.0008 & 15.2 & 40.7627 & 27.996 & 11.2 \\
\hline 1D - (Karabulut et al., & 40.7674 & 27.995 & 21.5 & 40.7611 & 27.9918 & 17.4 \\
\hline 2011) & & & & & & 2.09 \\
\hline 3D-this study & 40.7985 & 27.9956 & 10.75 & 40.7965 & 27.9997 & 2.09 \\
\hline
\end{tabular}


Table 4: Location results for triplet of case study 1.

\begin{tabular}{|c|c|c|c|c|c|c|c|c|c|c|c|c|}
\hline \multicolumn{4}{|c|}{ Case study 1} & \multicolumn{9}{|c|}{ Velocity Models } \\
\hline & & & & \multicolumn{3}{|c|}{ 1D - this study } & \multicolumn{3}{|c|}{ 3D - this study } & \multicolumn{3}{|c|}{ 3D - (Yamamoto, et al., 2017) } \\
\hline No & Date-Time & OBS used & Ml & Lat $\left({ }^{\circ}\right)$ & Long $\left({ }^{\circ}\right)$ & Depth bsf (km) & Lat $\left({ }^{\circ}\right)$ & Long $\left({ }^{\circ}\right)$ & Depth bsf $(\mathbf{k m})$ & Lat $\left({ }^{\circ}\right)$ & Long $\left({ }^{\circ}\right)$ & Depth bsl (km) \\
\hline 1 & 25 October 2014 01:46:52 & $01,04,05,07,13$ & 1.50 & 40.8080 & 27.8032 & 10.77 & 40.8452 & 27.8120 & 6.21 & 40.8174 & 27.7668 & 18.62 \\
\hline 2 & 25 October 2014 03:05:00 & $03,04,05,06,07,08,13$ & 1.93 & 40.8036 & 27.7999 & 9.61 & 40.8484 & 27.8104 & 6.29 & 40.8171 & 27.7691 & 18.38 \\
\hline 3 & 25 October 2014 04:21:38 & $01,03,04,05,07$ & 1.54 & 40.8035 & 27.8039 & 10.52 & 40.8421 & 27.8096 & 6.59 & 40.8152 & 27.7667 & 18.61 \\
\hline
\end{tabular}


Table 5: Location results for triplet of case study 2.

\begin{tabular}{|c|c|c|c|c|c|c|c|c|c|}
\hline \multicolumn{4}{|c|}{ Case study 2} & \multicolumn{6}{|c|}{ Velocity Models } \\
\hline & & & & & ID - this & & & 3D - this & udy \\
\hline No & Date-Time & OBS used & MI & Lat $\left({ }^{\circ}\right)$ & Long $\left({ }^{\circ}\right)$ & Depth bsf $(\mathbf{k m})$ & Lat $\left({ }^{\circ}\right)$ & Long $\left({ }^{\circ}\right)$ & Depth bsf $(\mathbf{k m})$ \\
\hline 1 & 19 May 2011 04:44:05 & $01,02,05,06,07,08,09,10$ & 1.15 & 40.8159 & 28.0985 & 2.71 & 40.8277 & 28.1154 & 0.003 \\
\hline 2 & 19 May 2011 05:05:38 & $07,08,10,09$ & 0.54 & 40.8377 & 28.0958 & 15.65 & 40.8340 & 28.1246 & 1.46 \\
\hline 3 & 23 June 2011 20:25:11 & $07,08,10,09$ & 0.93 & 40.8558 & 28.1189 & 19.64 & 40.8361 & 28.1303 & 0.7 \\
\hline
\end{tabular}

Where the relocation was obtained by the two velocity models (1D versus 3D). 
Table 6: Comparison of the synthetic $P$ and $S$ arrivals for triplet of case study 2 with the real data.

\begin{tabular}{|c|c|c|c|c|}
\hline \multicolumn{3}{|c|}{ Case study 2 } & $\begin{array}{c}\text { Synthetic } \\
\text { ts-tp (s) } \\
\text { Station }\end{array}$ \\
\cline { 2 - 5 } & \multicolumn{4}{|c|}{$\begin{array}{c}\text { Real data } \\
\text { ts-tp (s) }\end{array}$} \\
\cline { 2 - 5 } & Earthquake 1 & Earthquake 2 & Earthquake 3 \\
\hline OBS07 & 3.5 & 3.2 & 3.6 & 4.0 \\
\hline OBS08 & 3.2 & 2.6 & 2.9 & 3.0 \\
\hline OBS09 & 4.1 & 3.7 & 4.0 & 3.9 \\
\hline OBS10 & 3.8 & 3.0 & 3.1 & 3.4 \\
\hline
\end{tabular}


Table 7: Comparison of the 3D location results for triplet of case study 2 with the synthetic test.

\begin{tabular}{|c|c|c|c|c|c|c|}
\hline \multicolumn{9}{|c|}{ Case study 2 } \\
\hline \multirow{2}{*}{ No } & \multicolumn{3}{|c|}{ Synthetic Location } & \multicolumn{3}{c|}{ Real data location with 3D model } \\
\cline { 2 - 7 } & Lat $\left(^{\circ}\right)$ & Long $\left(^{\circ}\right)$ & Depth bsf $(\mathbf{k m})$ & Lat $\left(^{\circ}\right)$ & Long $\left(^{\circ}\right)$ & Depth bsf $(\mathbf{k m})$ \\
\hline 1 & 40.8327 & 28.1152 & 0.057 & 40.8277 & 28.1154 & 0.003 \\
\hline 2 & 40.838 & 28.1258 & 0.96 & 40.8340 & 28.1246 & 1.46 \\
\hline 3 & 40.84 & 28.1318 & 0.34 & 40.8361 & 28.1303 & 0.7 \\
\hline
\end{tabular}


Table 8: Location results for the 10-events cluster of case study 3 .

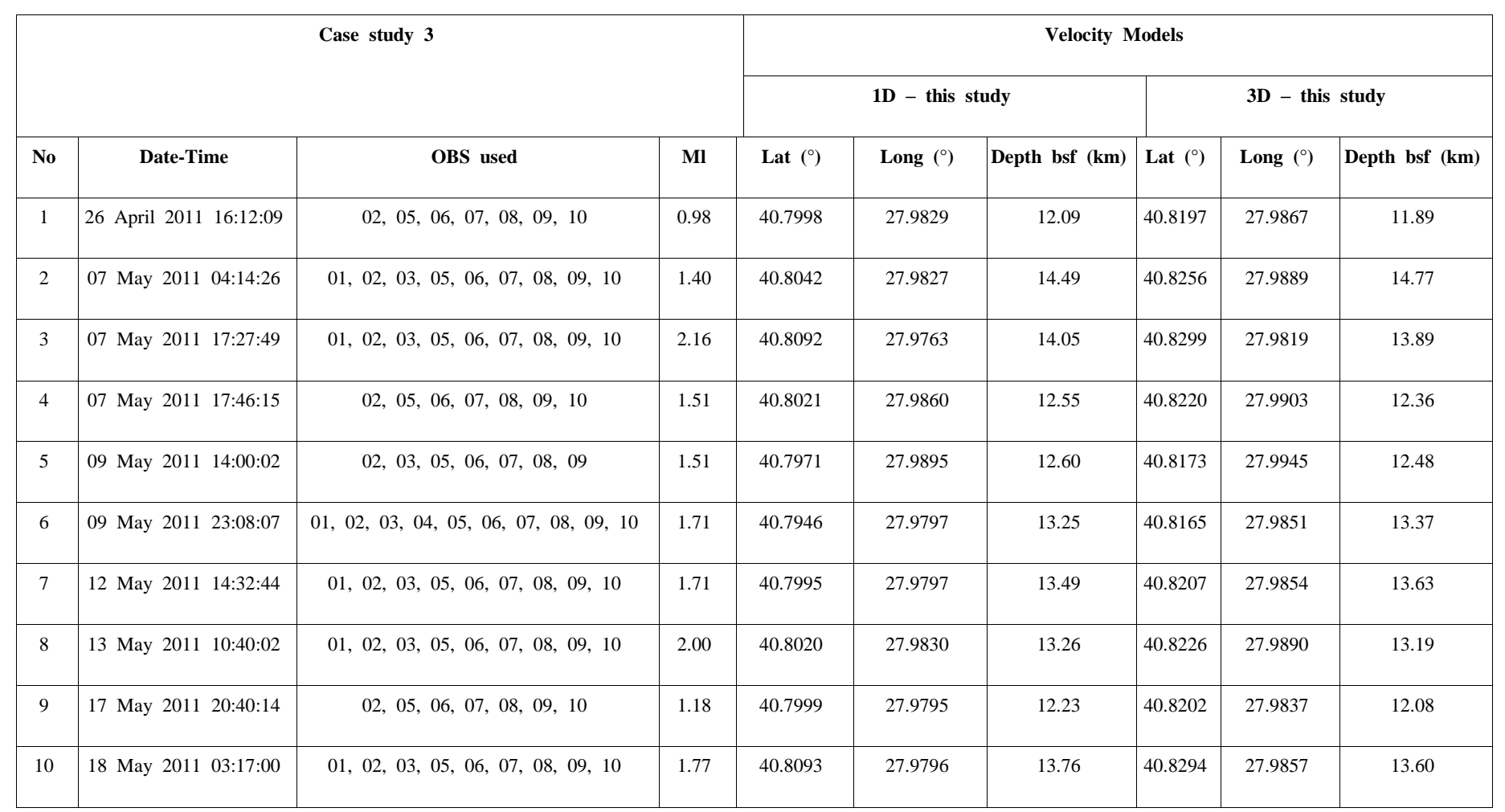

Where the relocation was obtained by the two velocity models (1D versus 3D). 
Table 9: Common events used for comparison of locations from for this study (2014 period) and from (Yamamoto's et al., 2017) and displayed in Figure 15.

\begin{tabular}{|c|c|c|c|c|c|c|c|c|c|}
\hline \multirow[b]{2}{*}{ No } & \multirow[b]{2}{*}{ Date-Time (2014) } & \multicolumn{4}{|c|}{ This study } & \multicolumn{4}{|c|}{ (Yamamoto et al., 2017) } \\
\hline & & $\begin{array}{c}\text { Latitude } \\
\left({ }^{\circ}\right)\end{array}$ & $\begin{array}{c}\text { Longitude } \\
\left(^{\circ}\right)\end{array}$ & $\begin{array}{c}\text { Depth } \\
(\mathbf{k m})\end{array}$ & Mag & $\begin{array}{c}\text { Latitude } \\
\left({ }^{\circ}\right)\end{array}$ & $\begin{array}{c}\text { Longitude } \\
\left(^{\circ}\right)\end{array}$ & $\begin{array}{c}\text { Depth } \\
\text { (km) }\end{array}$ & Mag \\
\hline 1 & 26 September 06:02:55 & 40.8309 & 27.7308 & 5.25 & 0.9 & 40.8091 & 27.6466 & 15.46 & 1.7 \\
\hline 2 & 01 October 14:44:49 & 40.8509 & 27.8905 & 3.55 & 0.7 & 40.8710 & 27.9218 & 10.00 & 1.3 \\
\hline 3 & 03 October 21:40:22 & 40.8340 & 27.8769 & 5.59 & 0.7 & 40.8497 & 27.9223 & 18.2 & 1.7 \\
\hline 4 & 04 October 11:58:34 & 40.8243 & 27.7265 & 7.00 & 1.9 & 40.8247 & 27.6696 & 14.54 & 2.2 \\
\hline 5 & 17 October 19:52:52 & 40.8295 & 27.8642 & 4.90 & 0.8 & 40.8041 & 27.8832 & 13.54 & 1.4 \\
\hline 6 & 18 October 10:17:43 & 40.8471 & 27.8087 & 6.61 & 1.1 & 40.8310 & 27.8056 & 21.07 & 1.9 \\
\hline 7 & 24 October 14:18:24 & 40.8356 & 27.7383 & 5.41 & 0.7 & 40.8241 & 27.6531 & 14.89 & 1.4 \\
\hline 8 & 25 October 01:46:52 & 40.8452 & 27.812 & 6.21 & 0.9 & 40.8174 & 27.7668 & 18.62 & 1.5 \\
\hline 09 & 25 October 03:05:00 & 40.8484 & 27.8104 & 6.29 & 1.7 & 40.8171 & 27.7691 & 18.38 & 1.9 \\
\hline 10 & 25 October 04:21:38 & 40.8421 & 27.8096 & 6.59 & 0.9 & 40.8152 & 27.7667 & 18.61 & 1.5 \\
\hline 11 & 25 October 09:28:57 & 40.8242 & 27.7754 & 5.22 & 0.5 & 40.8165 & 27.7706 & 18.19 & 1.6 \\
\hline 12 & 26 October 03:21:34 & 40.8303 & 27.7331 & 5.19 & 0.9 & 40.8089 & 27.6489 & 15.46 & 1.6 \\
\hline 13 & 26 October 07:41:51 & 40.8463 & 27.7379 & 6.68 & 0.7 & 40.8236 & 27.6907 & 20.28 & 2.0 \\
\hline 14 & 27 October 21:22:10 & 40.8240 & 27.8023 & 4.59 & 0.7 & 40.8134 & 27.6734 & 20.52 & 1.4 \\
\hline
\end{tabular}


Table 10: Single (for $M>3$ ) and composite (for $M<2$ ) focal mechanisms solutions for selected earthquakes from the two data-sets.

\begin{tabular}{|c|c|c|c|c|c|c|c|c|c|}
\hline No & Number of events used & Date-Time & Lat $\left({ }^{\circ} \mathbf{N}\right)$ & Long $\left({ }^{(} \mathbf{E}\right)$ & $\begin{array}{c}\text { Depth }(\mathrm{km}) \\
\text { below } \\
\text { seafloor }\end{array}$ & $\mathbf{M}_{\mathbf{l}}$ & Strike $\left(^{\circ}\right)$ & Dip $\left(^{\circ}\right)$ & Rake $\left(^{\circ}\right)$ \\
\hline S1 & 1 & 01 May 2011 08:36 & 40.8266 & 28.1355 & 14.2 & 3.3 & 312 & 63 & 135 \\
\hline S2 & 1 & 19 May 2011 04:38 & 40.8340 & 28.1442 & 4.3 & 3.1 & 70 & 20 & -125 \\
\hline S3 & 1 & 25 July $2011 \quad 17: 57$ & 40.82 & 27.741 & 11.5 & 5.1 & 113 & 83 & -148 \\
\hline S4 & 1 & 19 Sept 2014 10:52 & 40.837 & 27.8722 & 4.4 & 3.3 & 97 & 20 & -86 \\
\hline $\mathrm{C} 1$ & 10 & $\begin{array}{c}\text { Aftershock Sequence } \\
\text { See supplementary Information }\end{array}$ & 40.82 & 27.75 & 2.5 & 1.2 & 300 & 34 & -145 \\
\hline $\mathrm{C} 2$ & 10 & See Case Study 3 & 40.82 & 27.98 & 13.1 & 1.5 & 78 & 58 & 151 \\
\hline $\mathrm{C} 3$ & 3 & See Case Study 2 & 40.83 & 28.12 & 0.7 & 1.5 & 233 & 67 & 101 \\
\hline $\mathrm{C} 4$ & 3 & See Case Study 1 & 40.84 & 27.81 & 6.4 & 1.65 & 190 & 59 & -80 \\
\hline
\end{tabular}

Where $\mathrm{S} 1$ to $\mathrm{S} 4$ and $\mathrm{C} 1$ to $\mathrm{C} 4$ correspond to single and composite focal mechanisms respectively. 


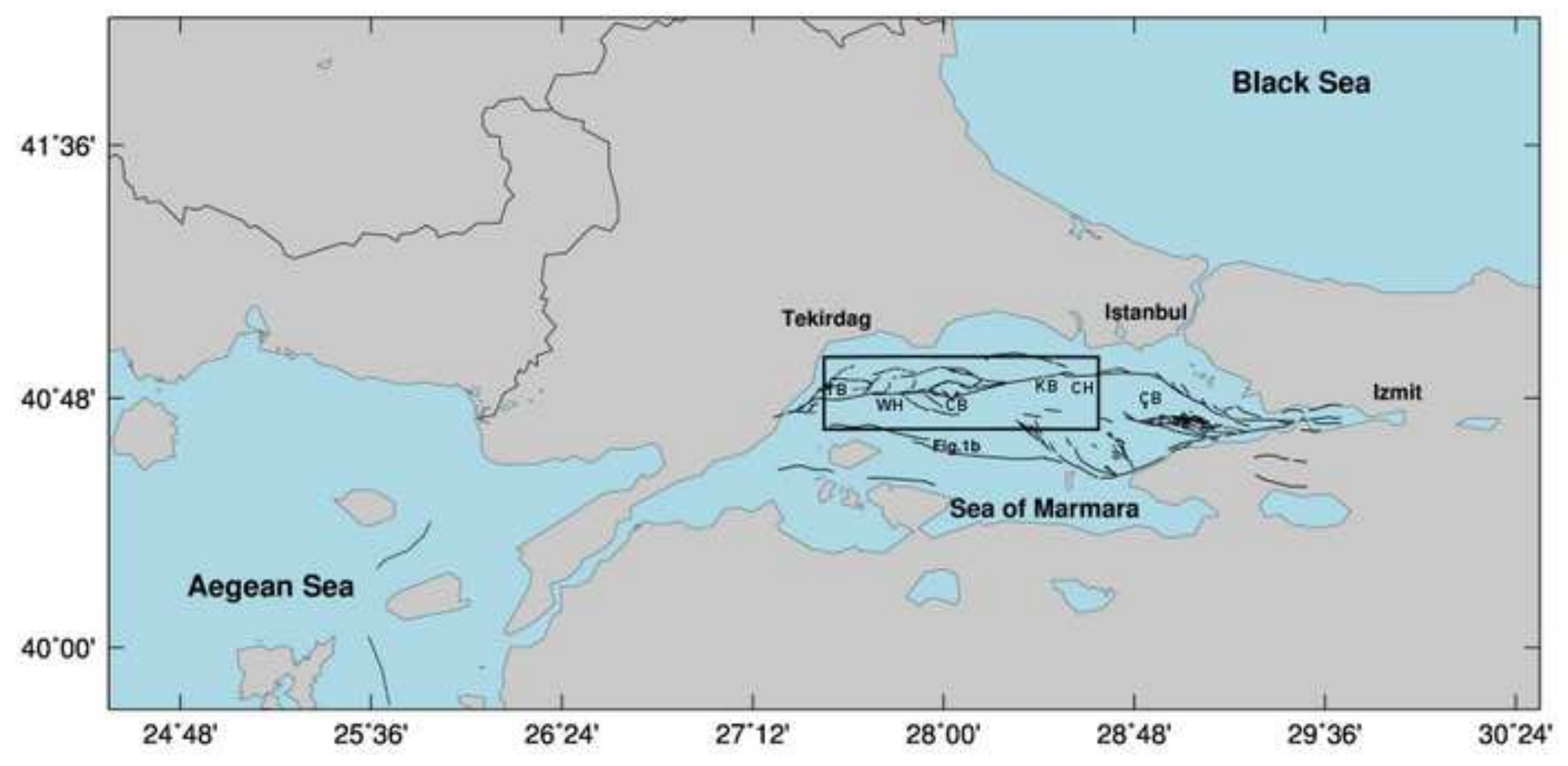




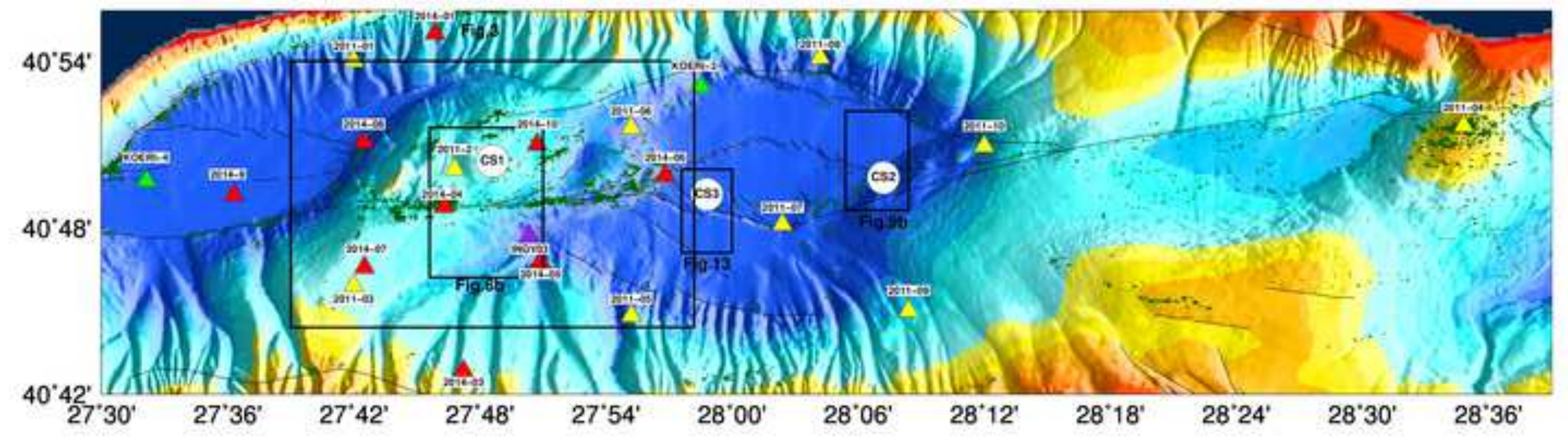




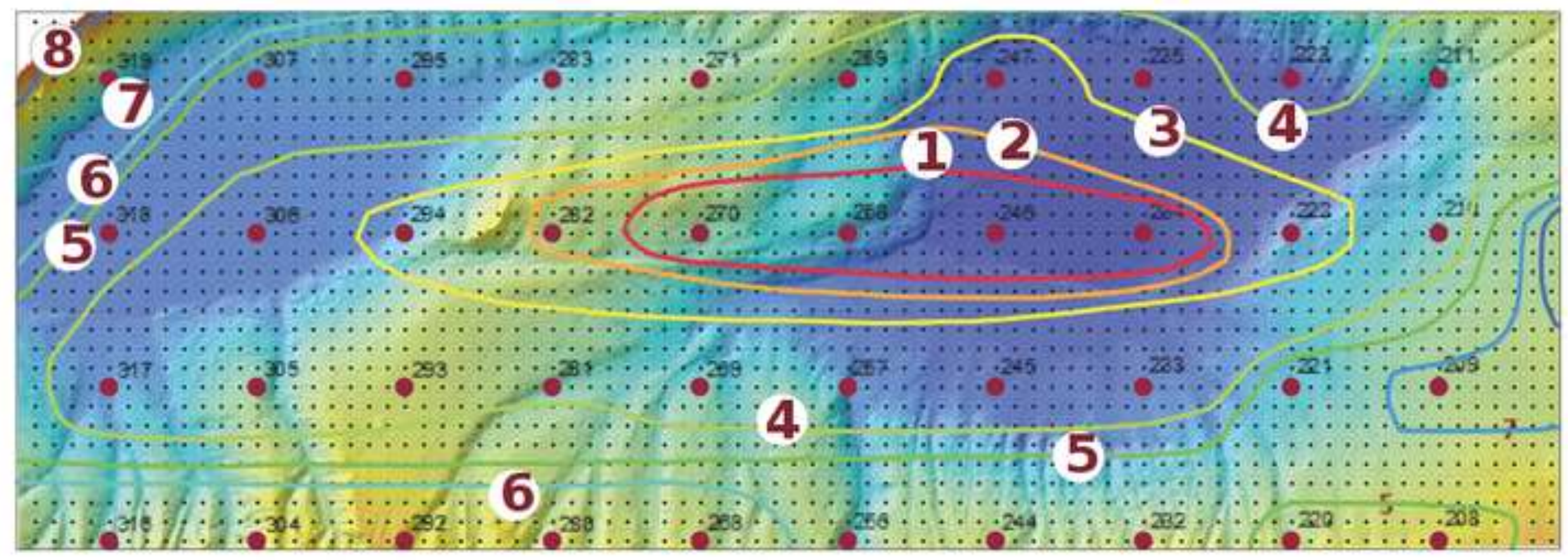




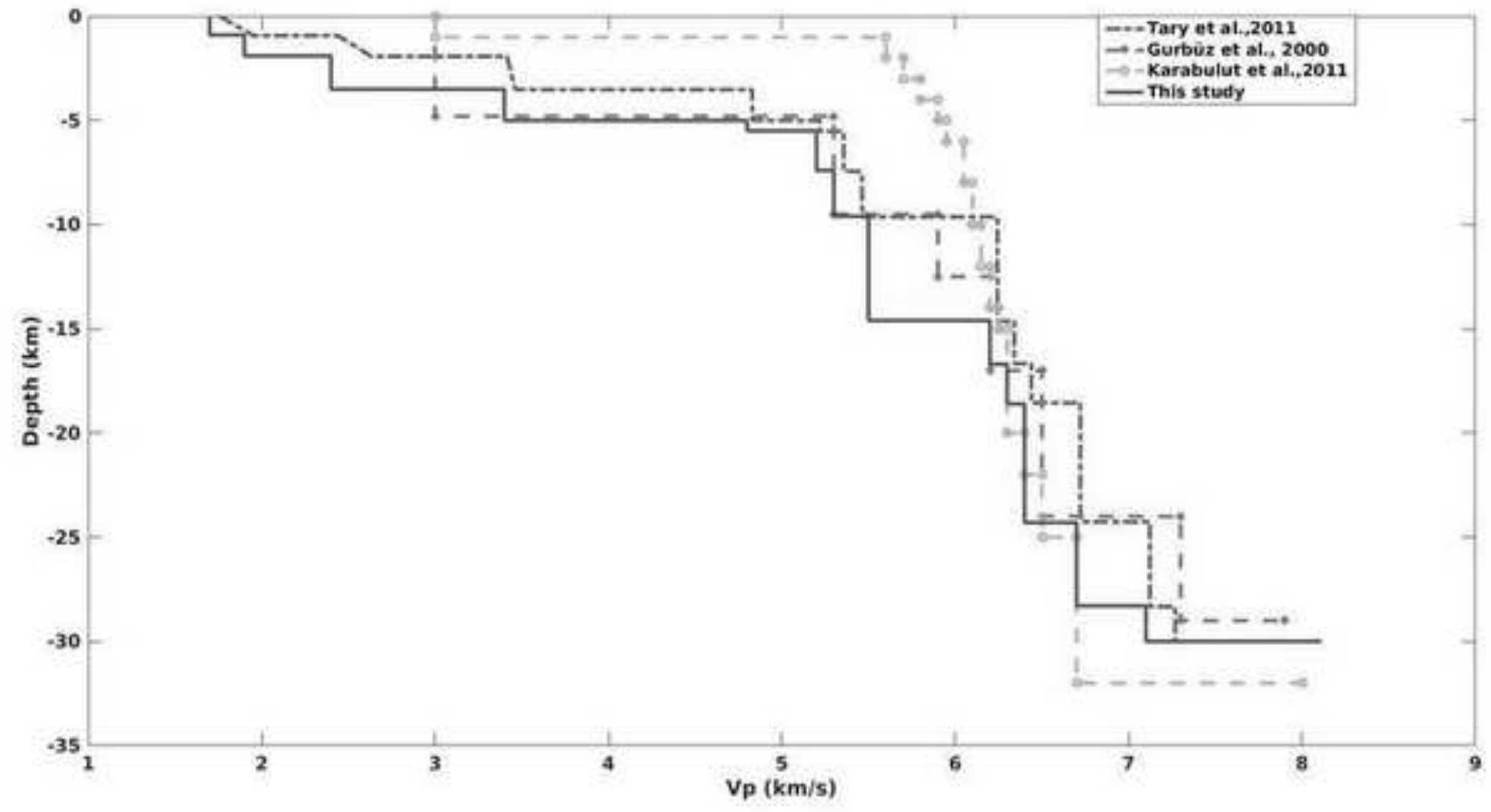




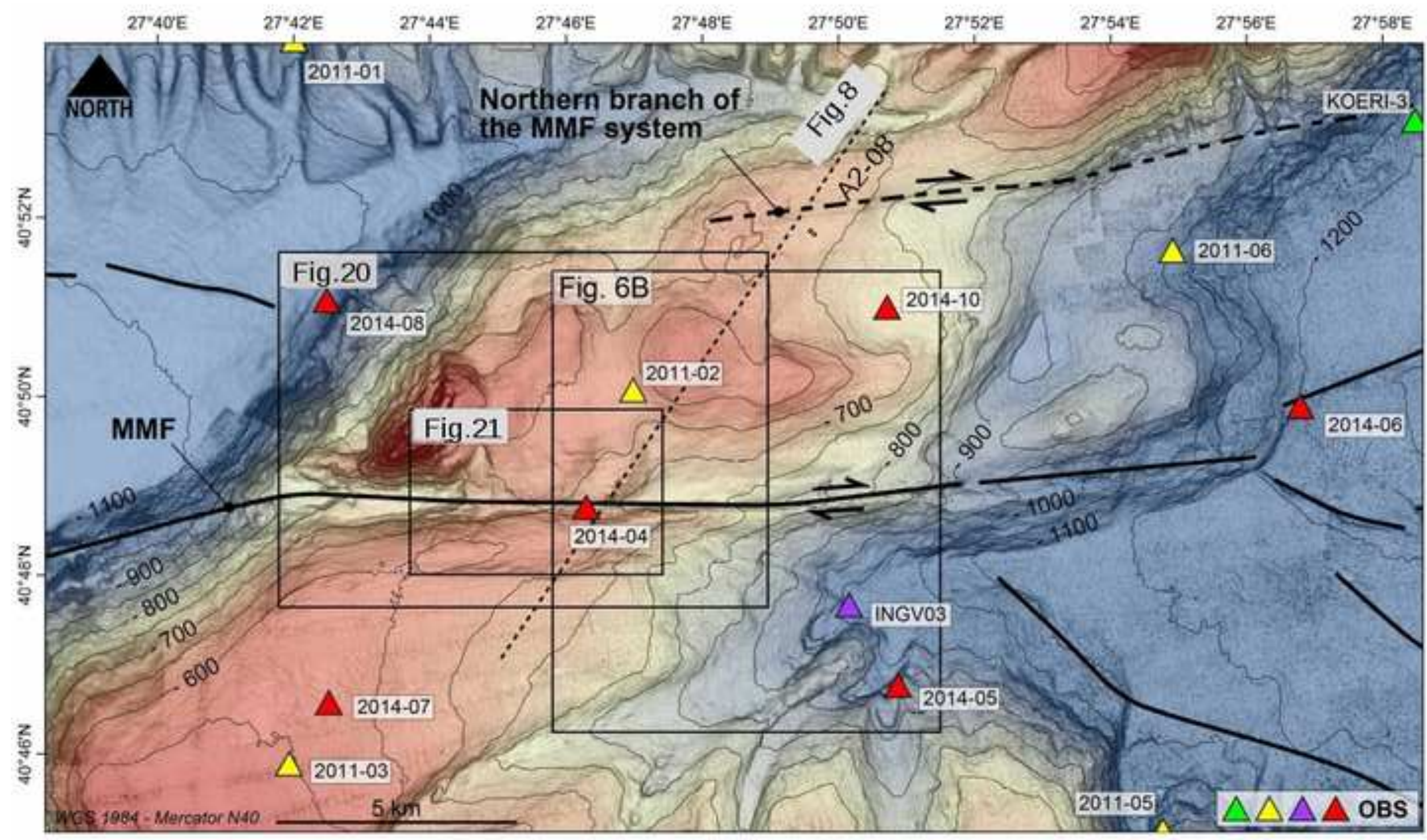




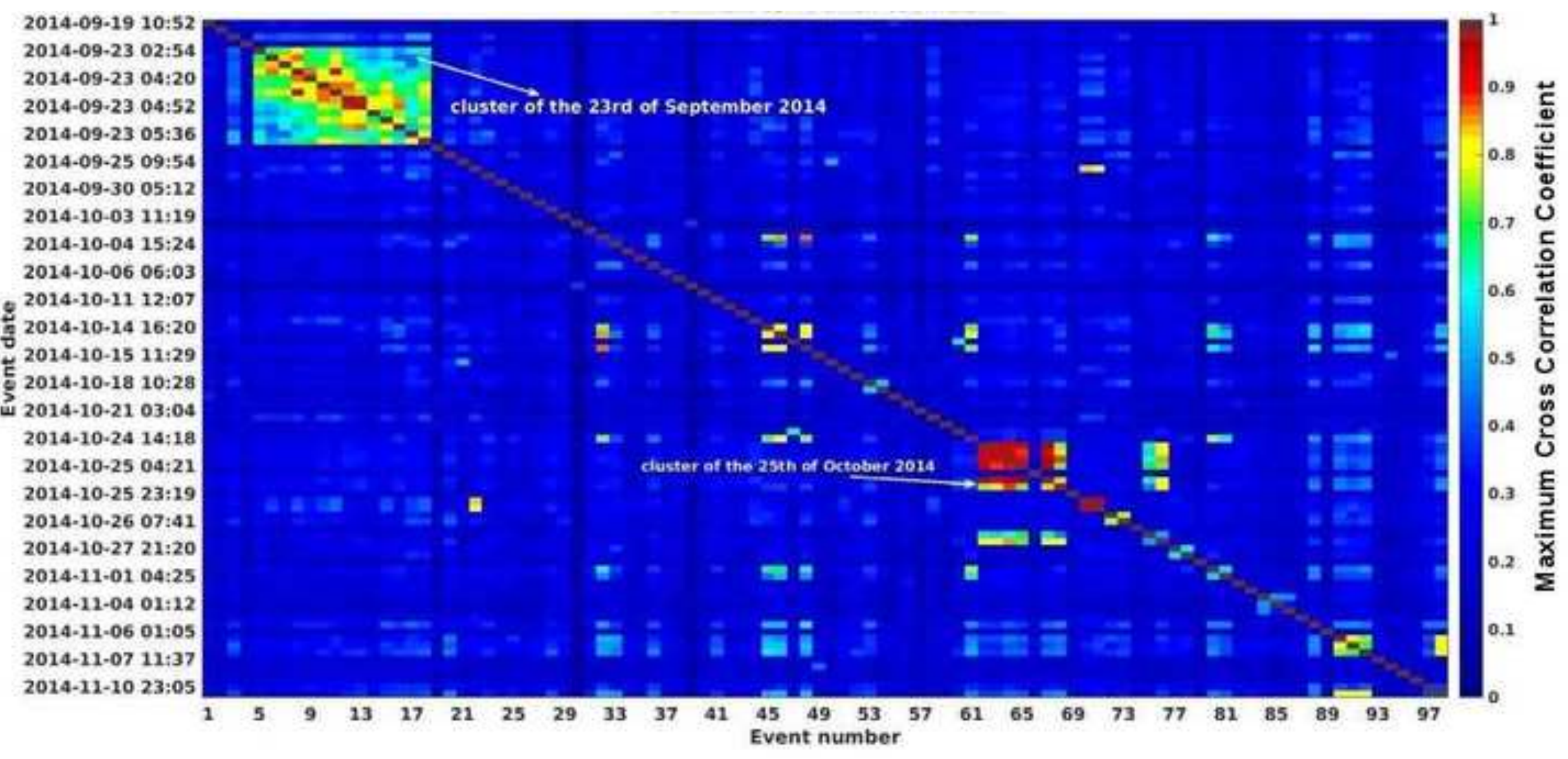

.



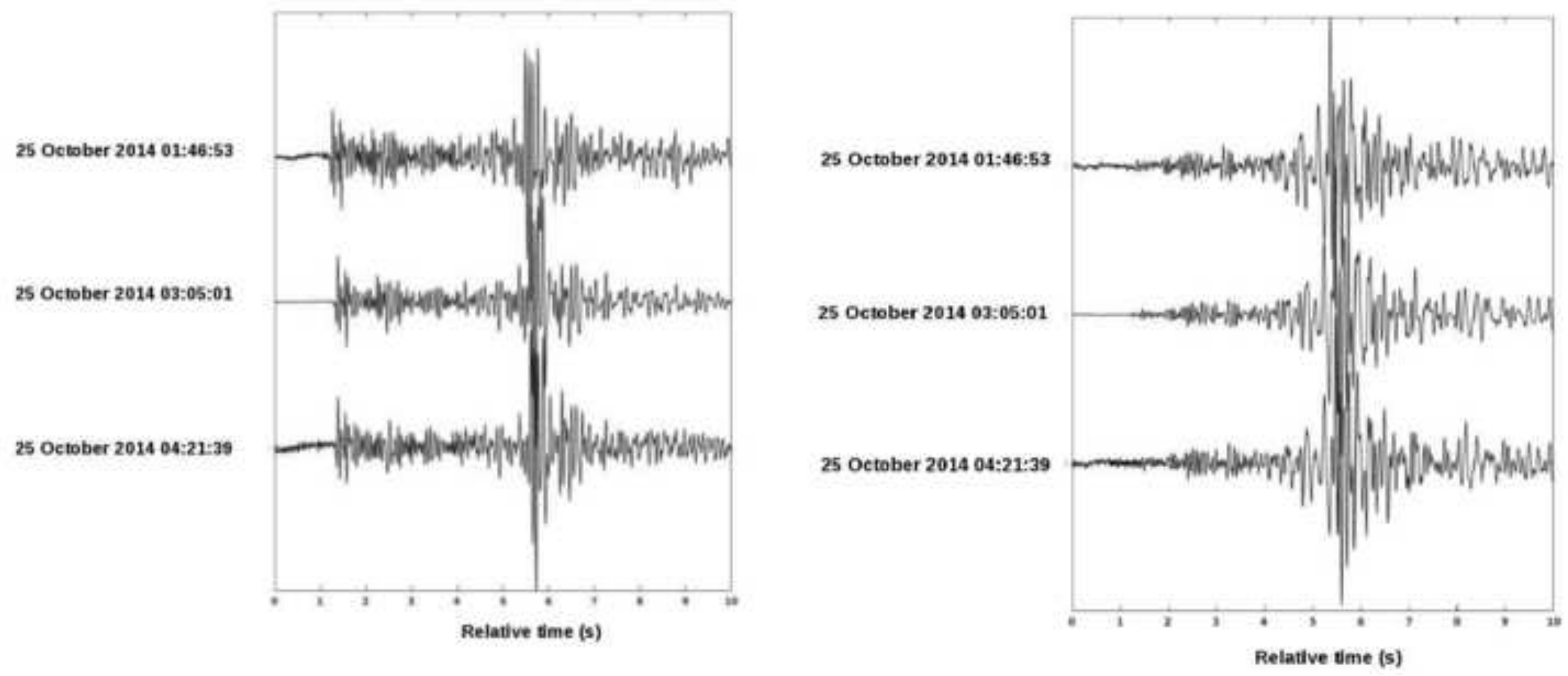


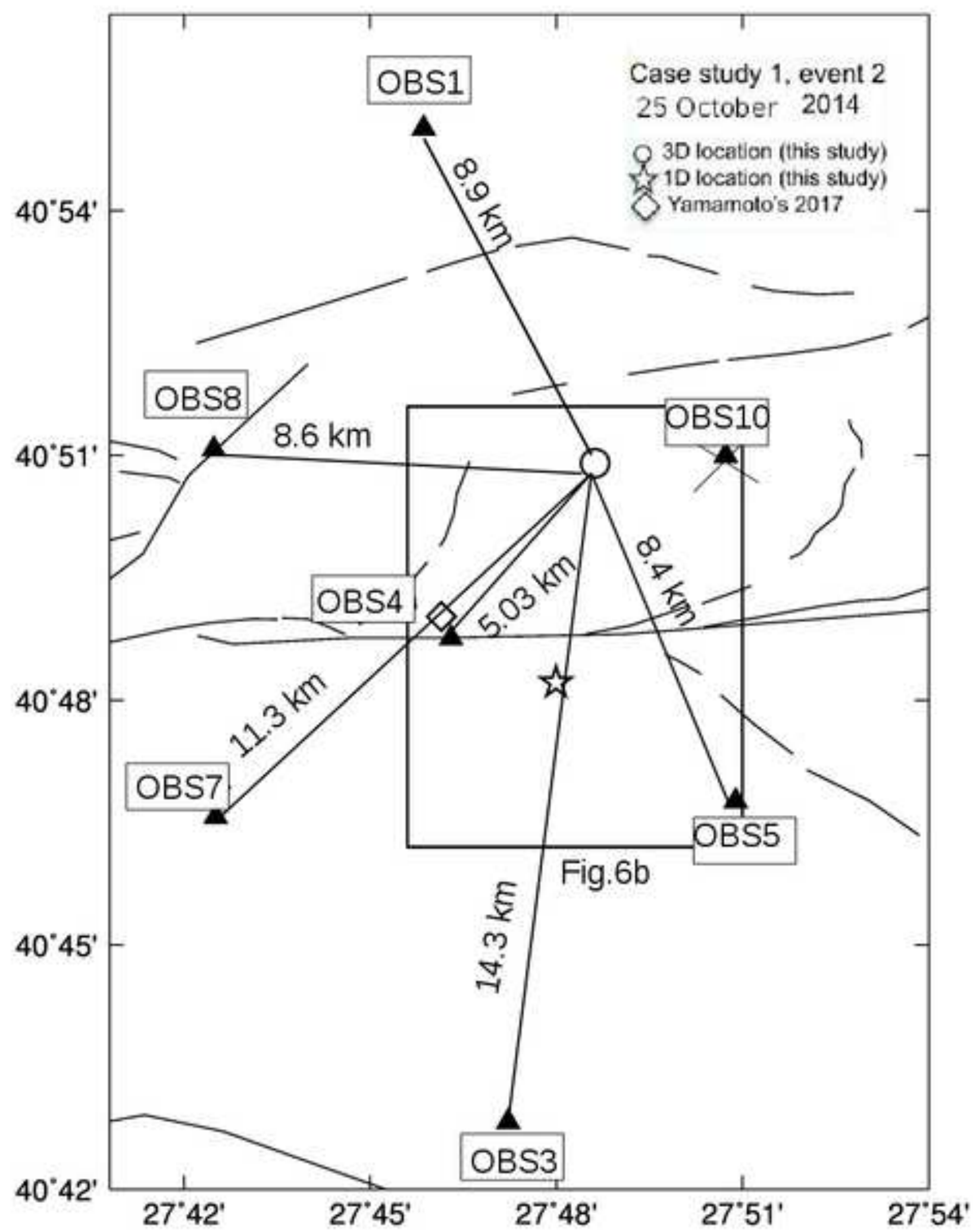




\section{Depth $(\mathrm{km})$}
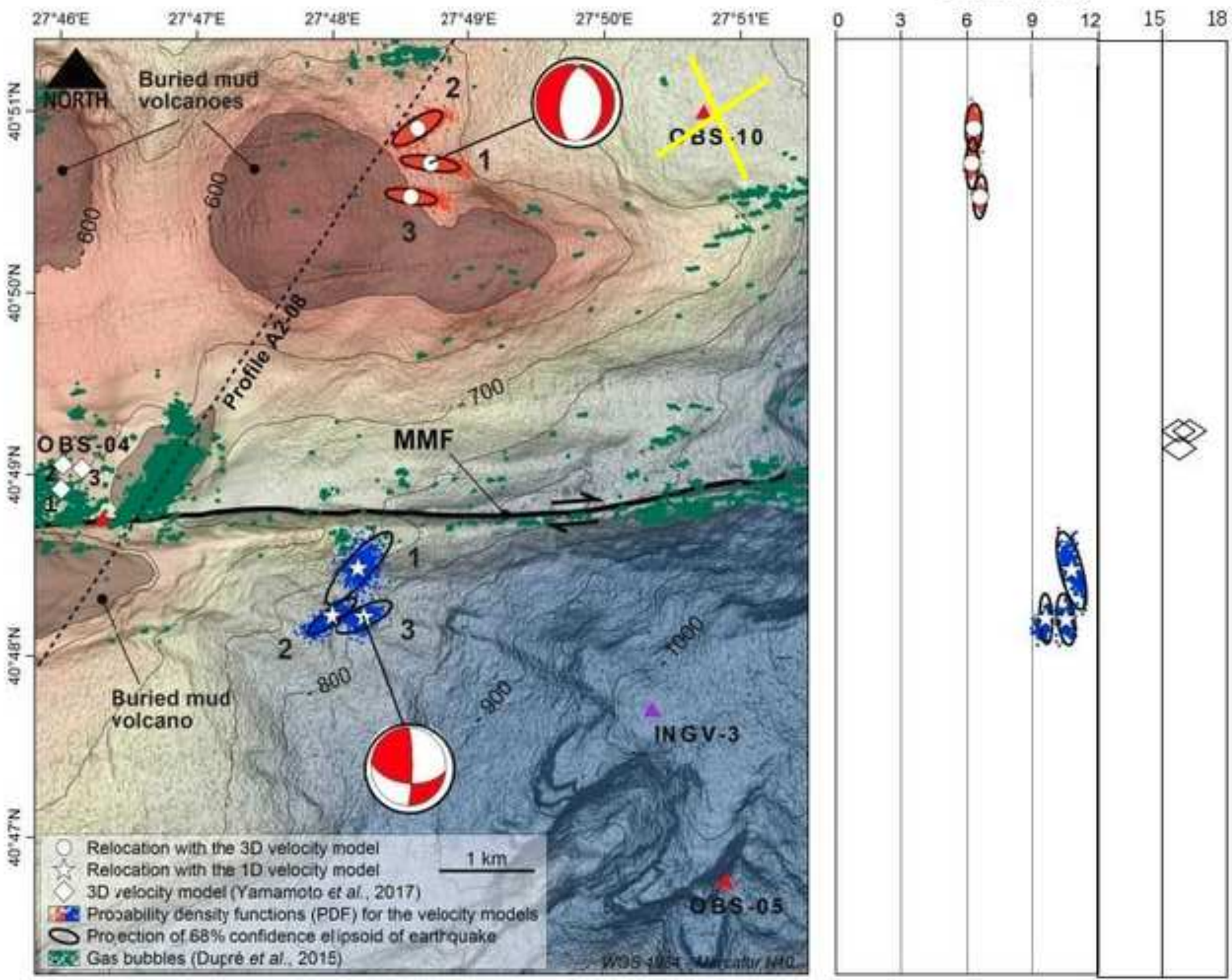

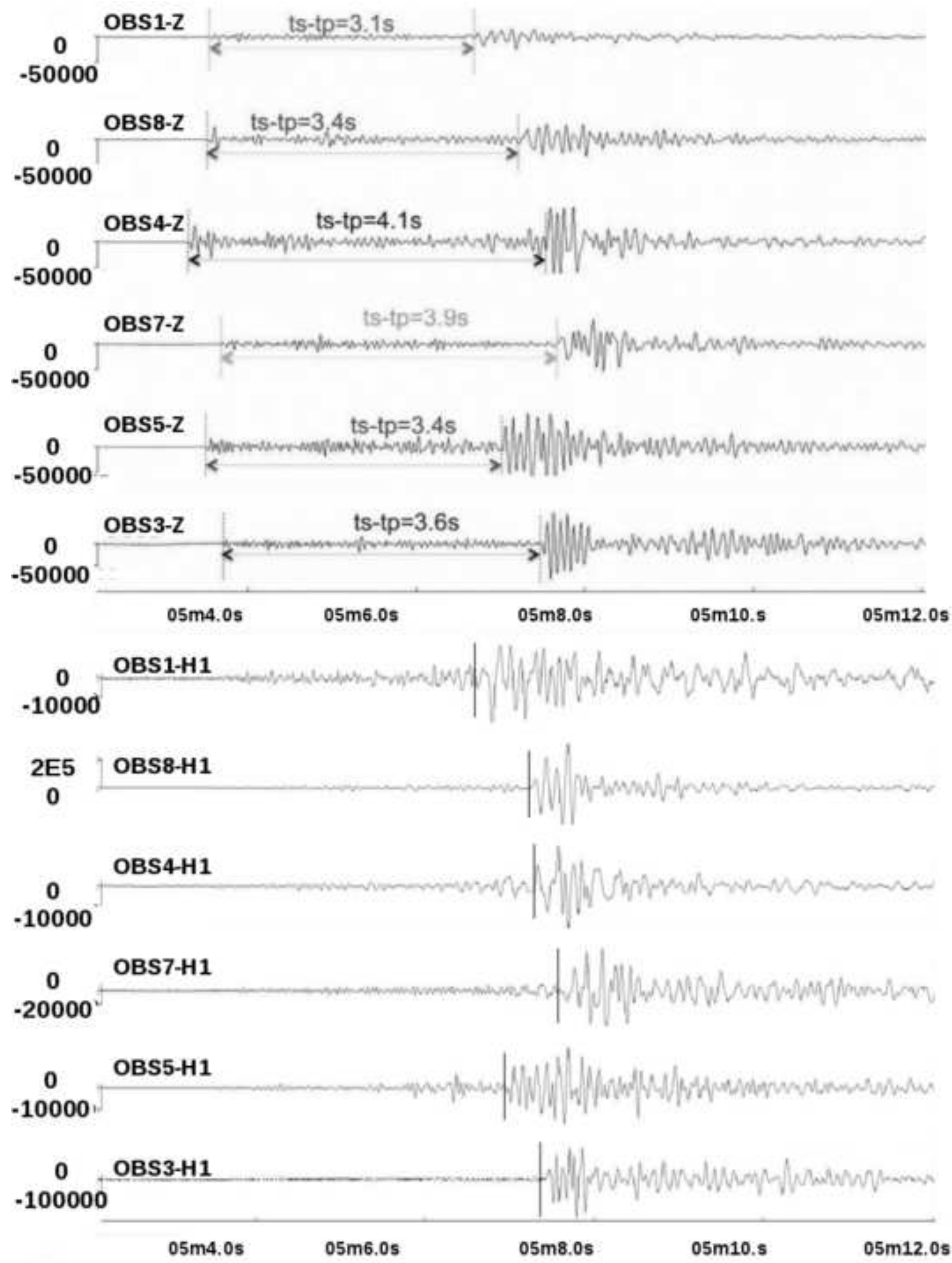


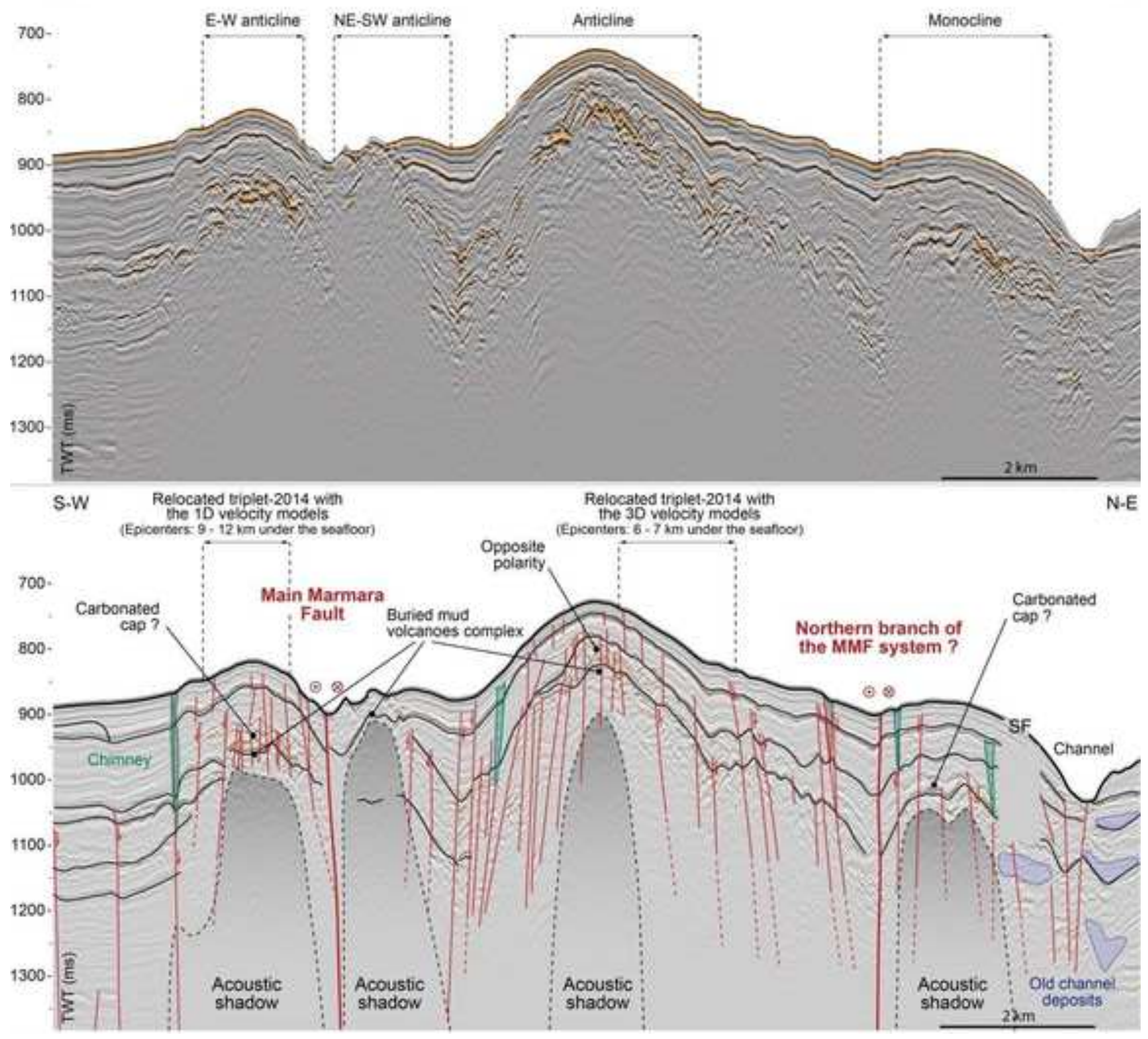




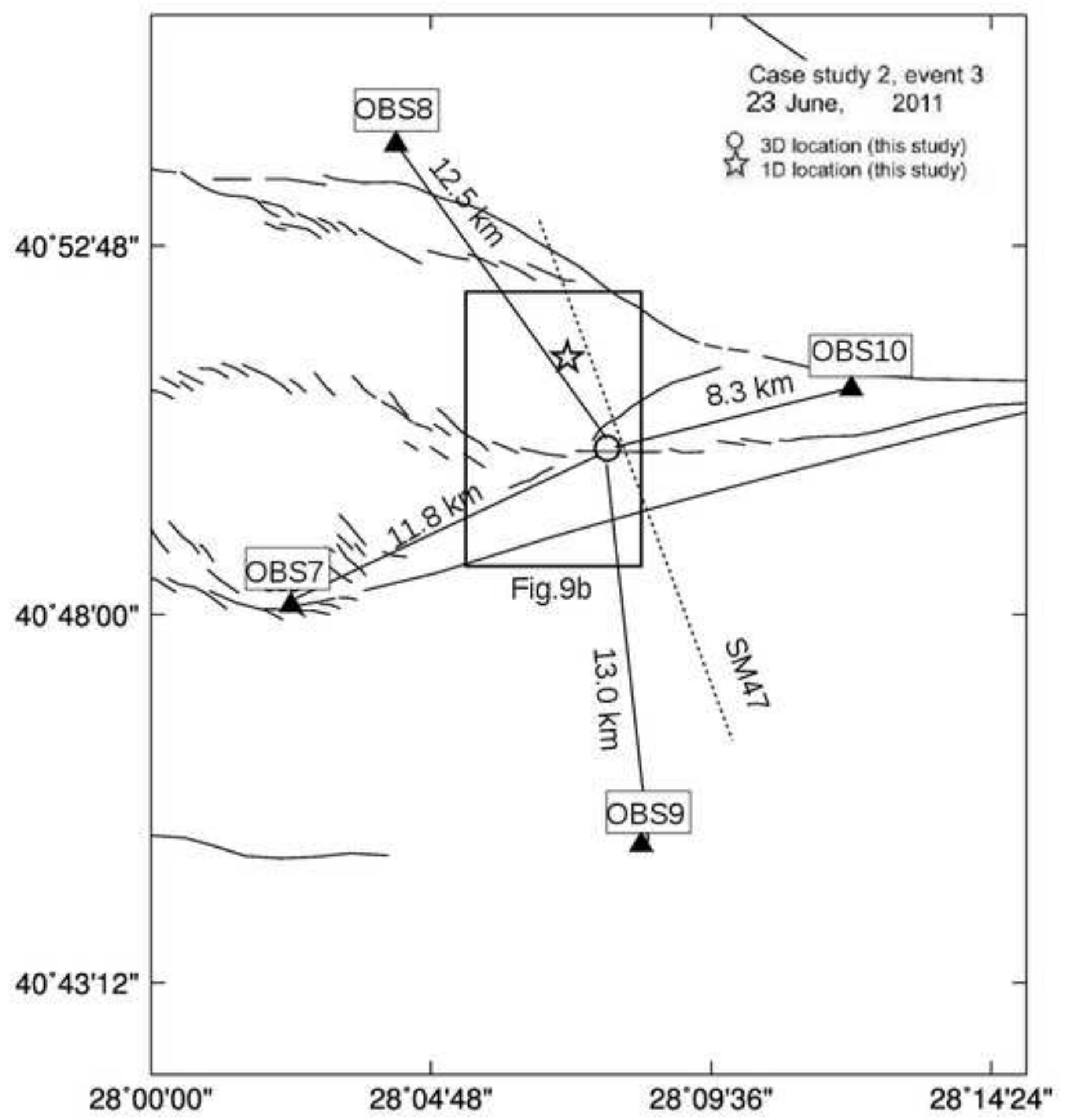


Depth $(\mathrm{km})$
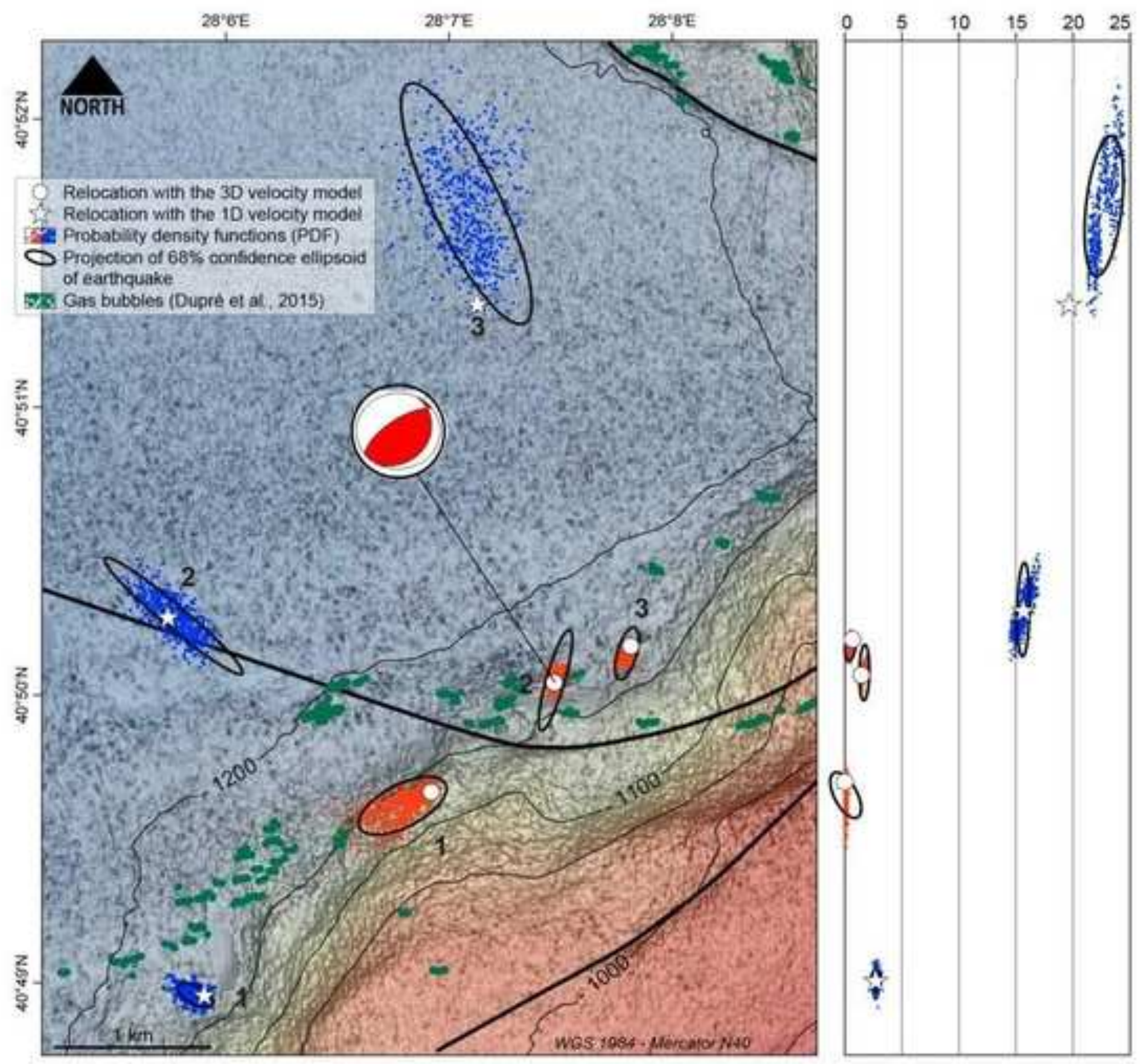

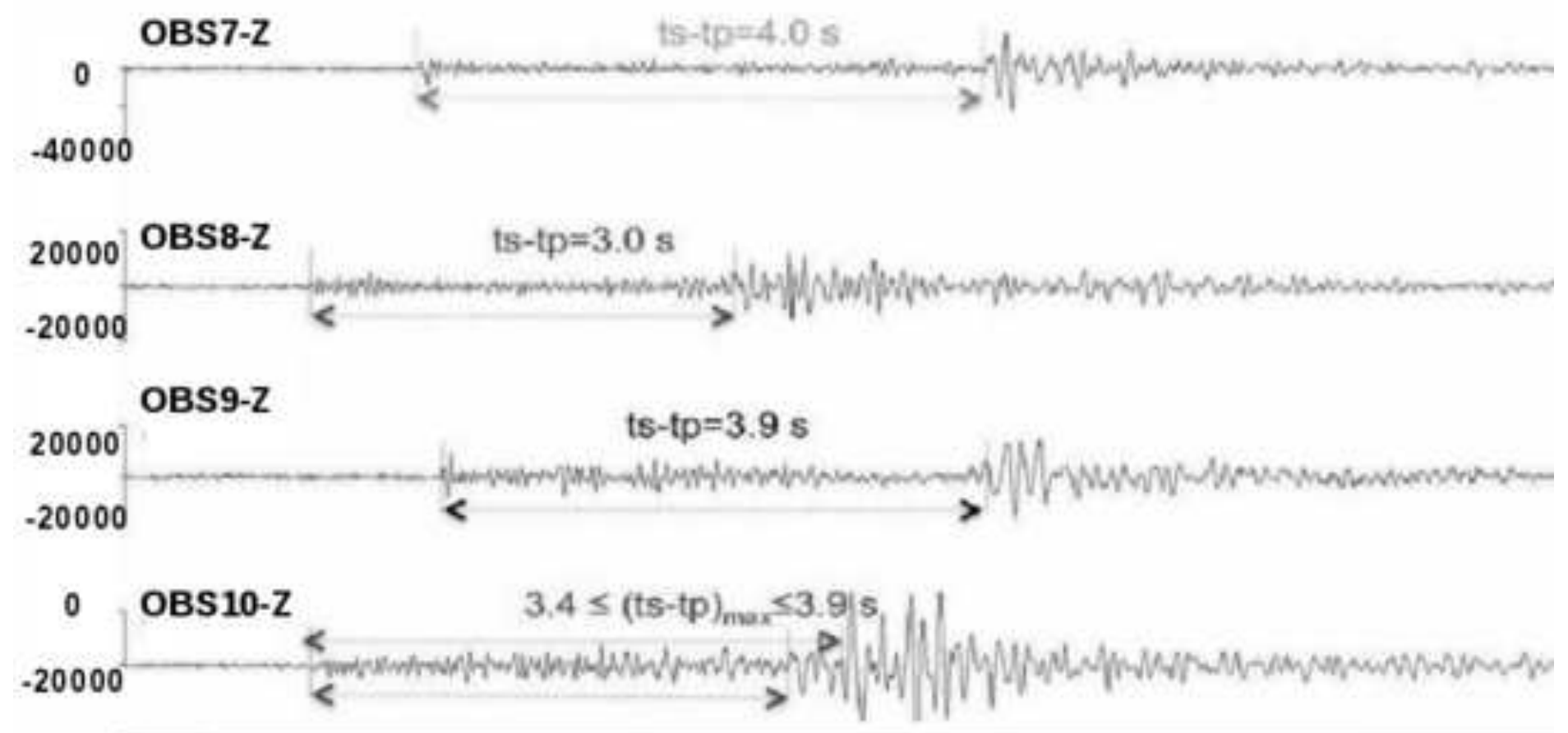

\begin{tabular}{lllll}
\hline $25 \mathrm{~m} 22.0 \mathrm{~s}$ & $25 \mathrm{~m} 24.0 \mathrm{~s}$ & $25 \mathrm{~m} 26.0 \mathrm{~s}$ & $25 \mathrm{~m} 28 . \mathrm{s}$ & $25 \mathrm{~m} 30.0 \mathrm{~s}$
\end{tabular}
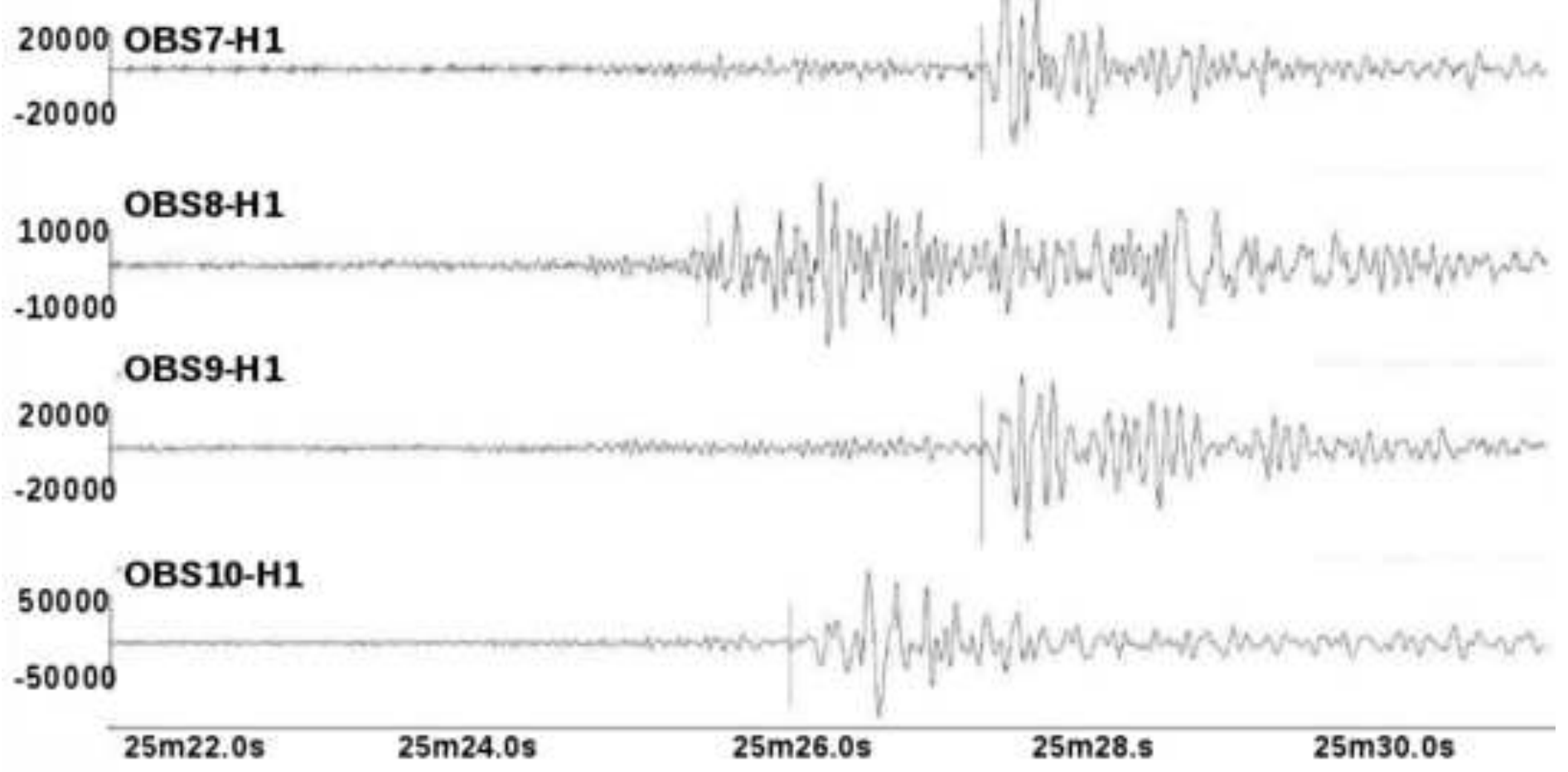


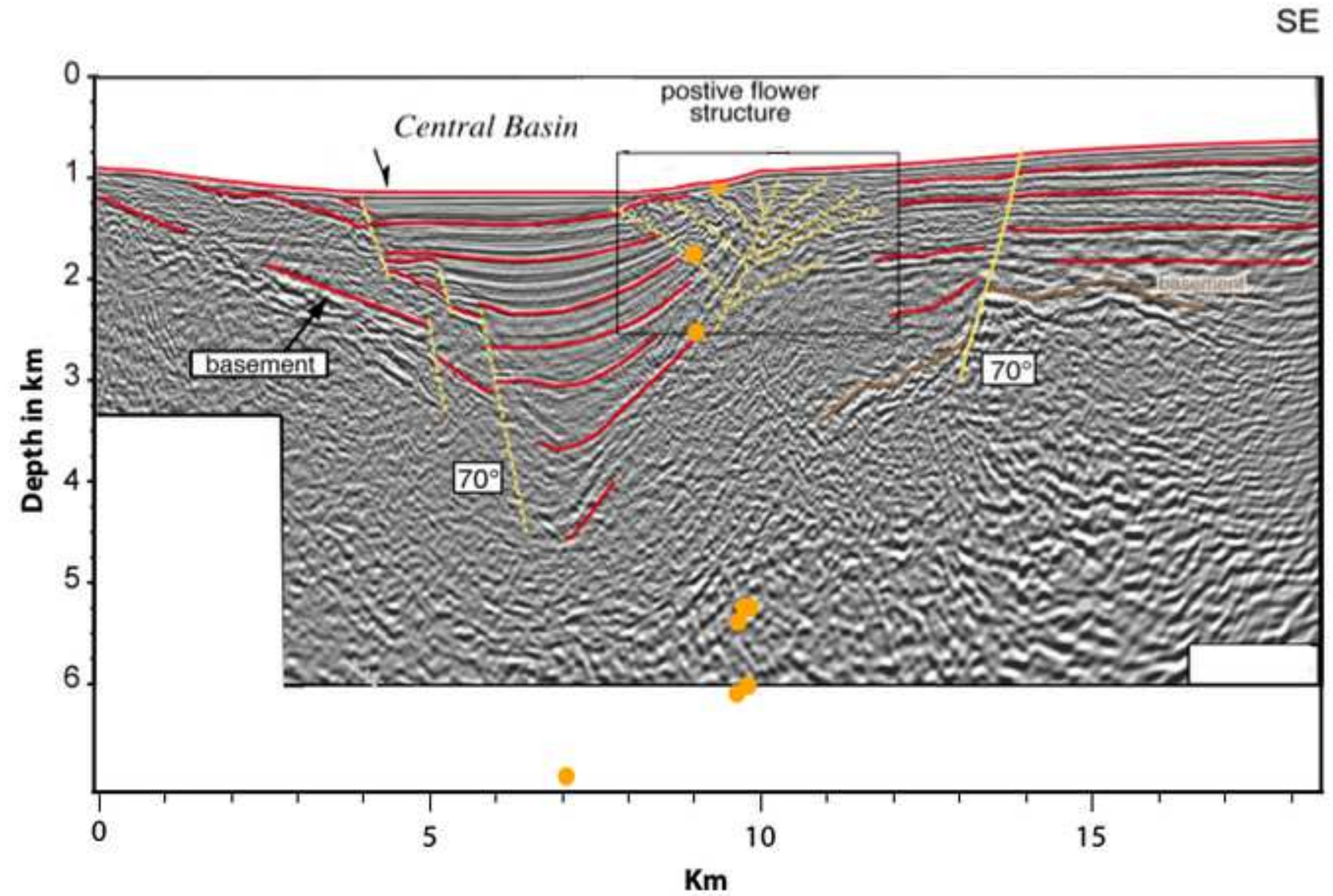




\section{Reference location by Batsi et al., (this study)}

$$
\text { lat } t_{r}, \operatorname{lon}_{r}, d_{r}
$$

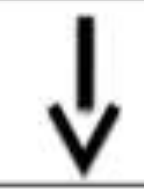

\section{Synthetic arrival times}

(computed using Time2Eq, Lomax package)

$$
t_{p, s}, t_{s, s}, t_{s, s}-t_{p, s}
$$

Table 6

Synthetic, absolute Locations

(using 3D model by Géli et al., (2018) and NonLinLoc, Lomax Package)

$$
\text { lat }, \text { lon }_{\mathrm{s}}, \mathrm{d}_{\mathrm{s}}
$$

Table 7 
Depth (km)
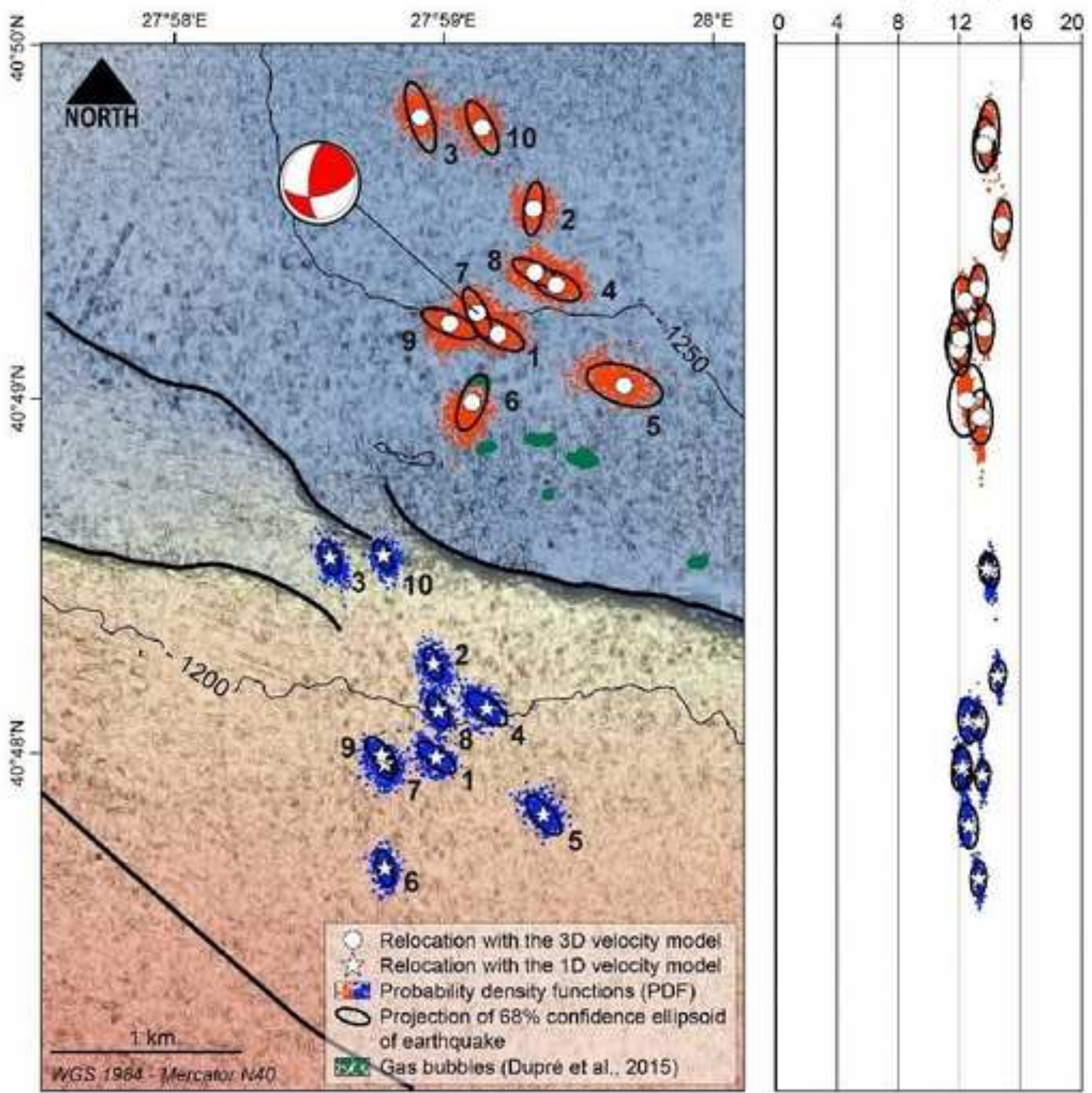


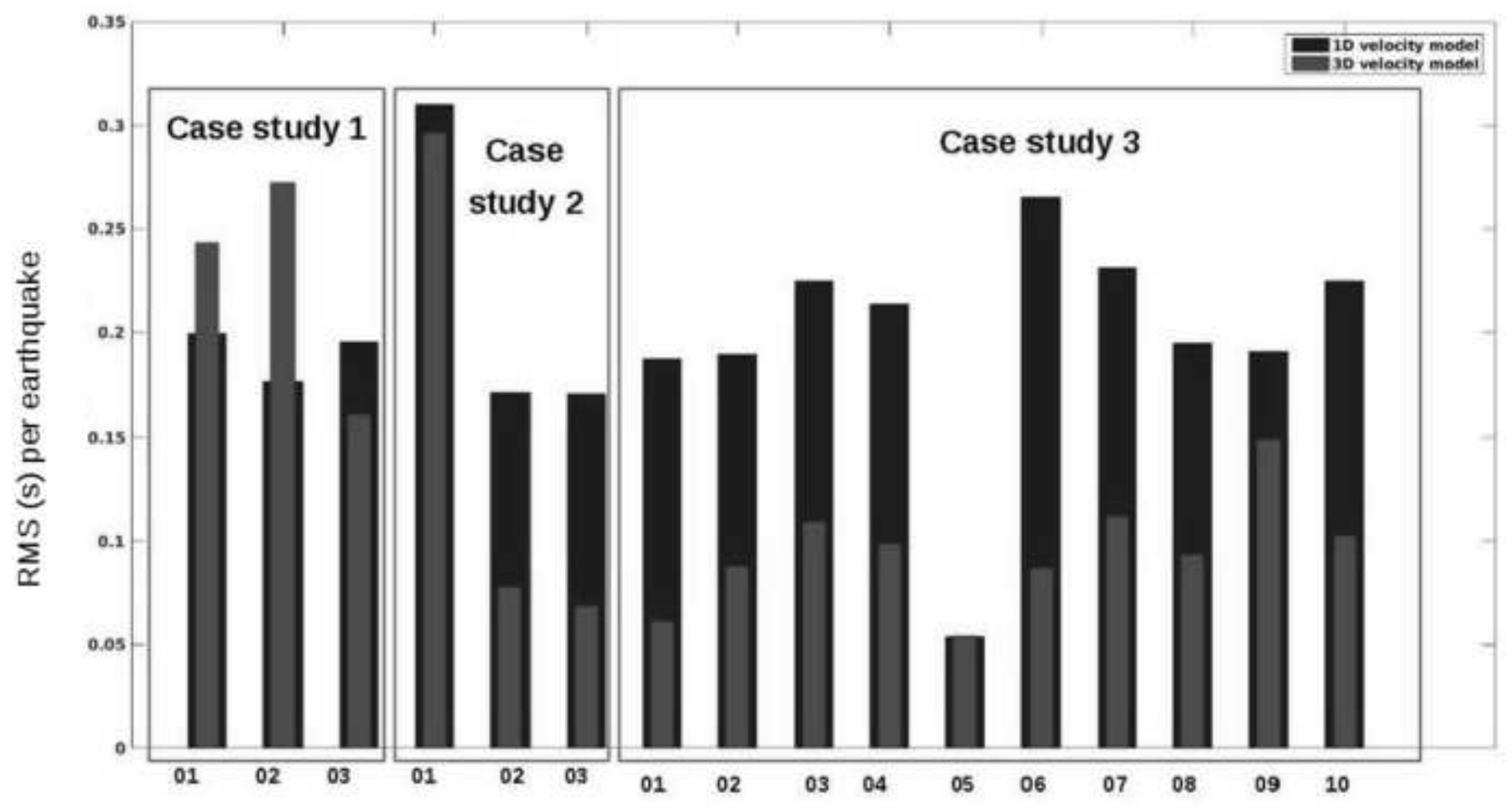



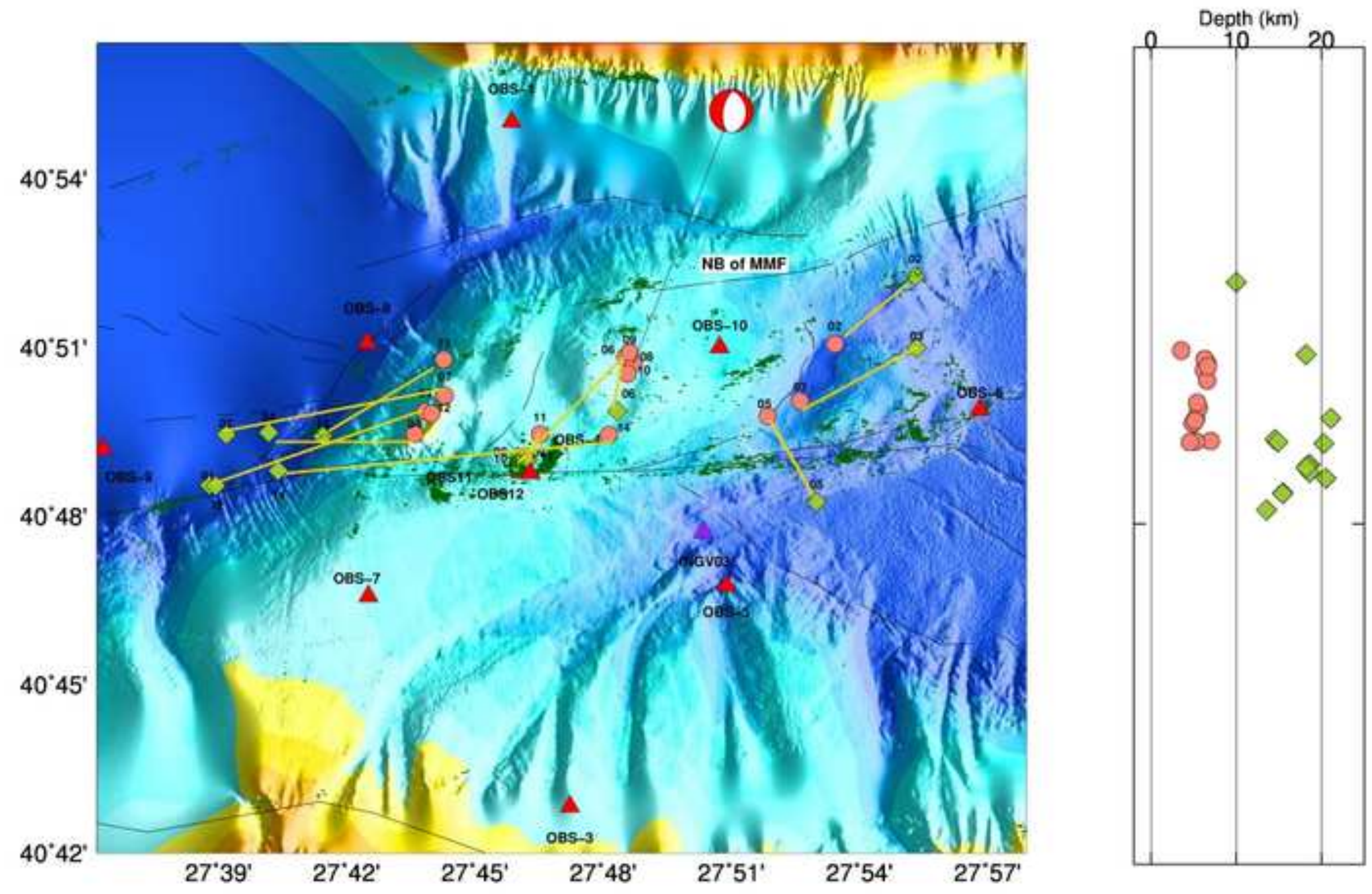


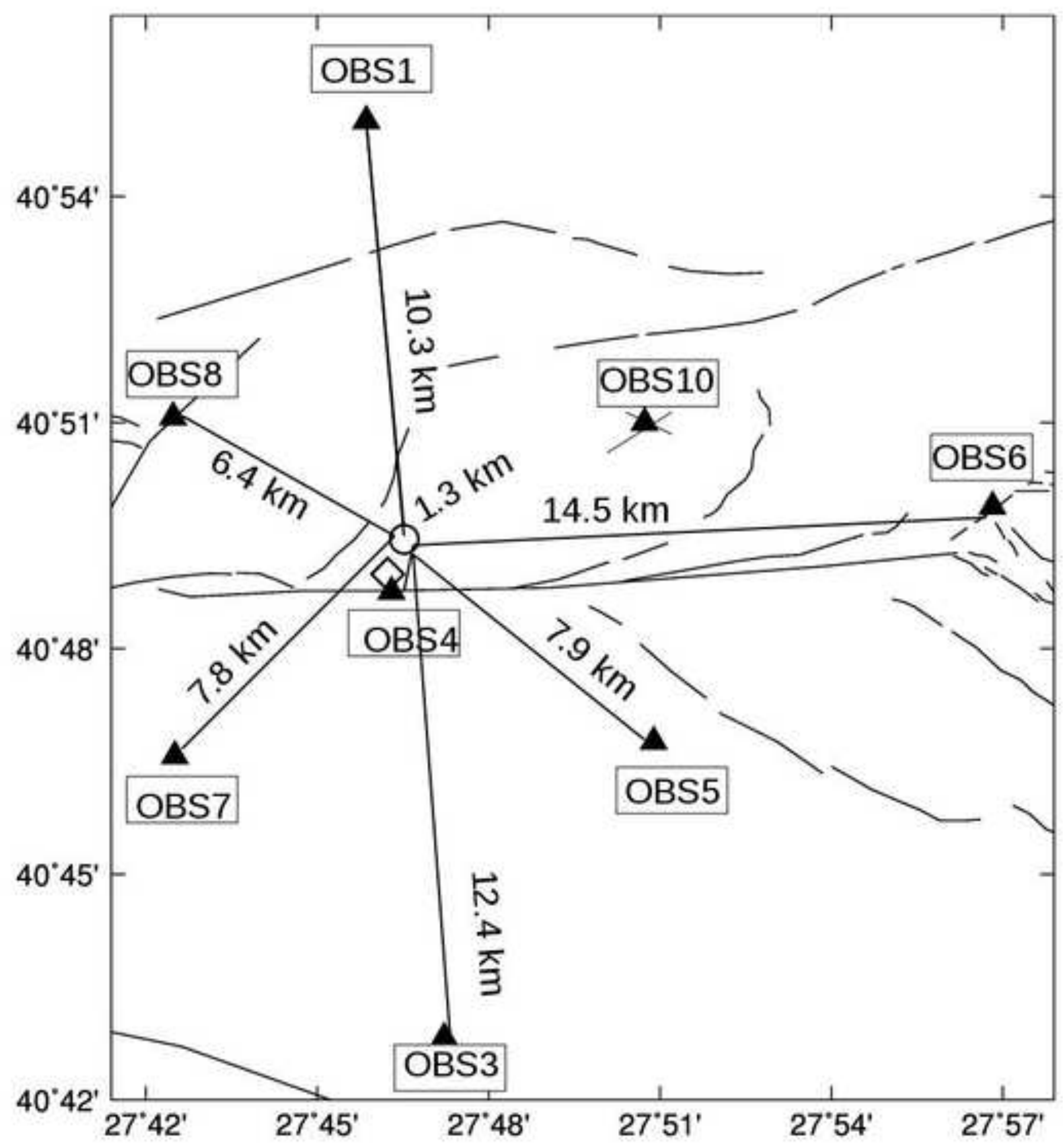




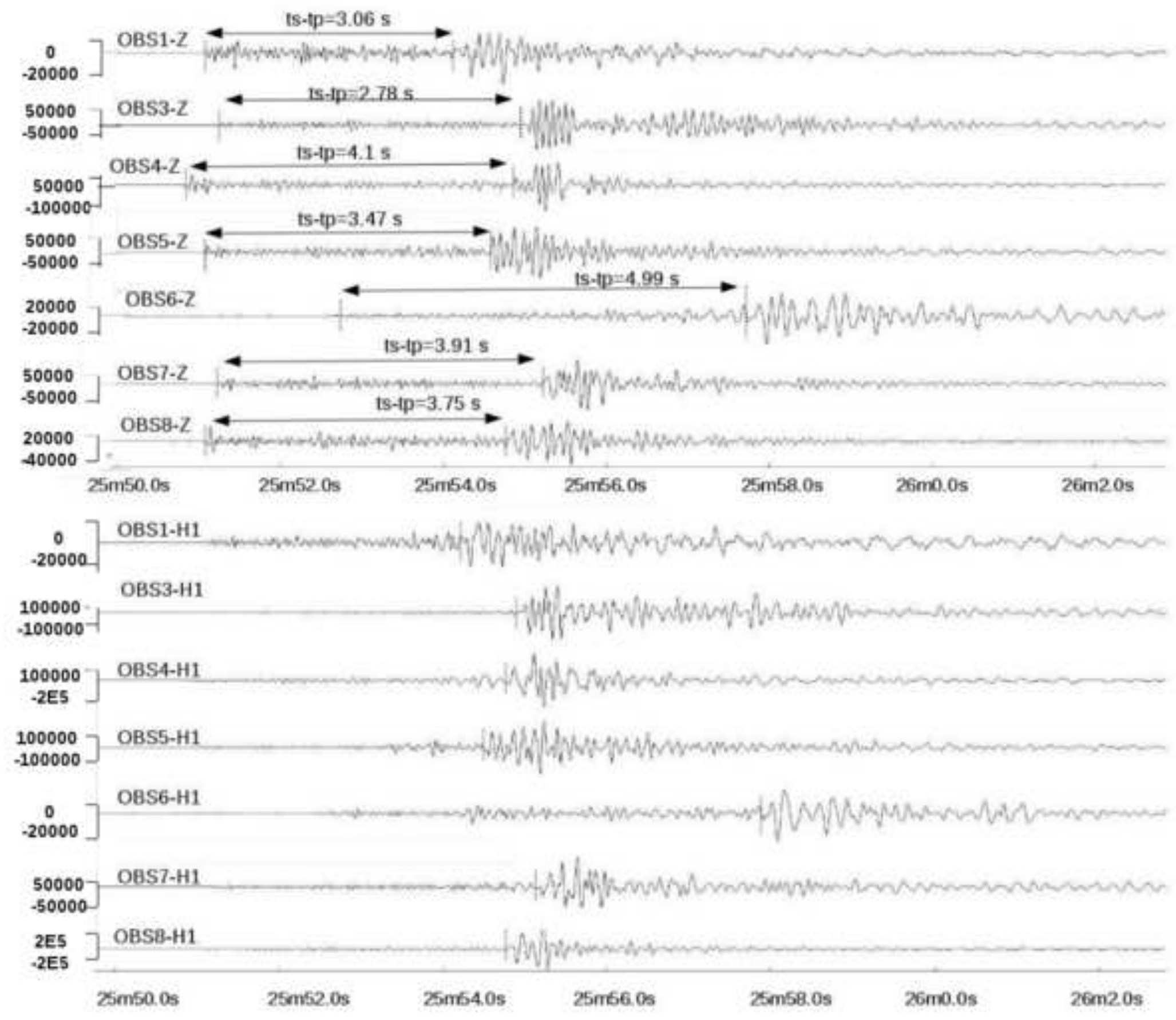



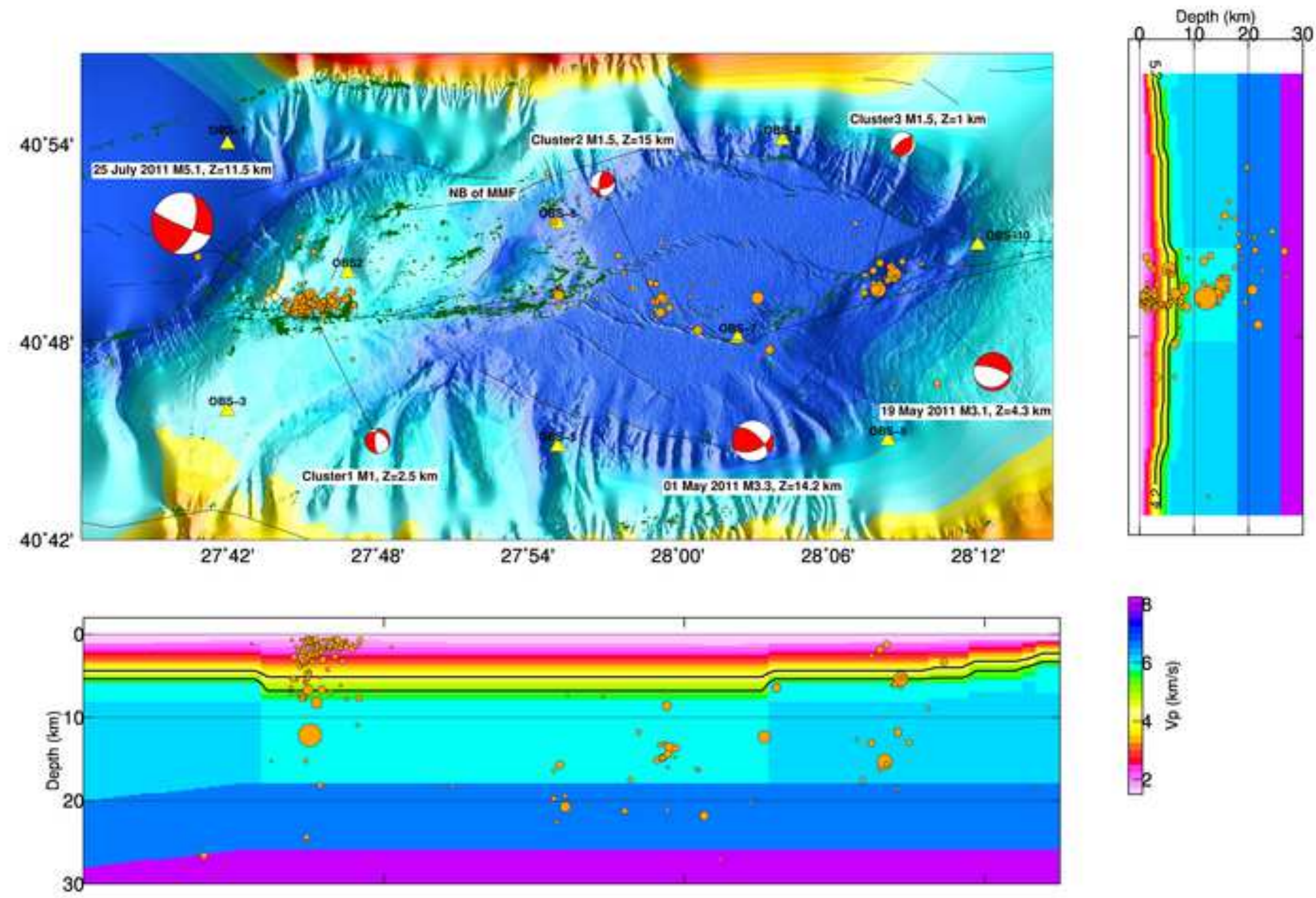

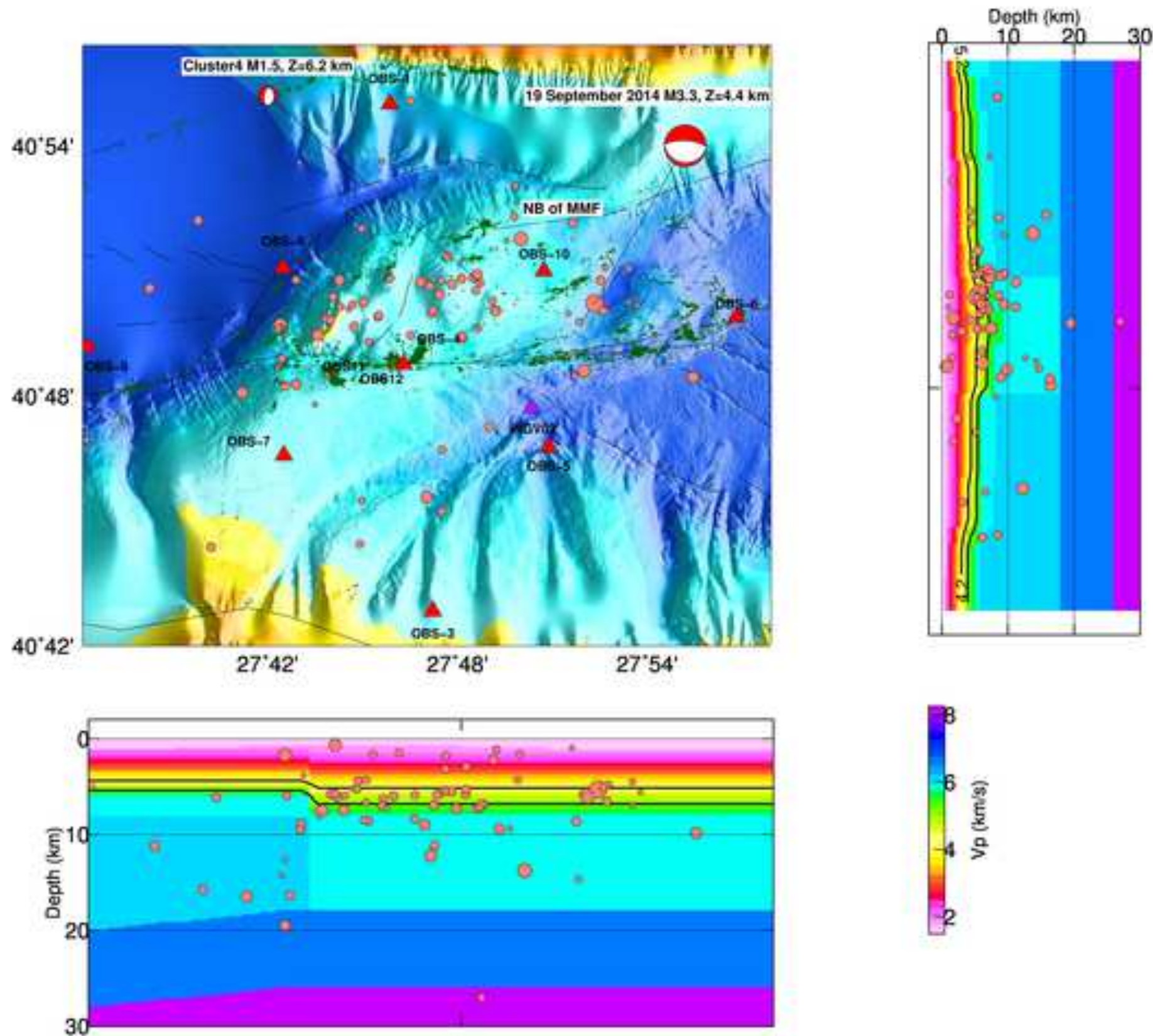


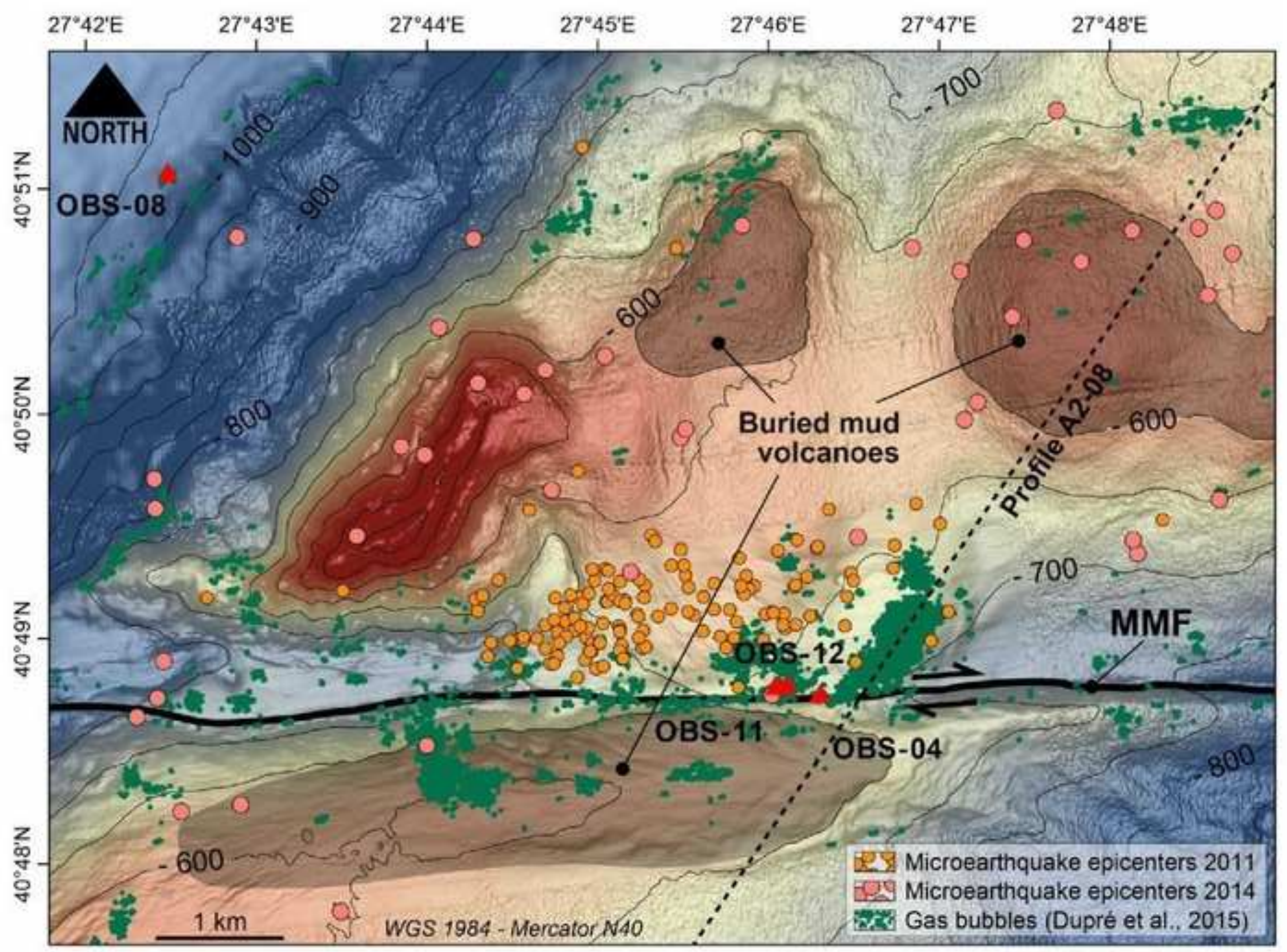




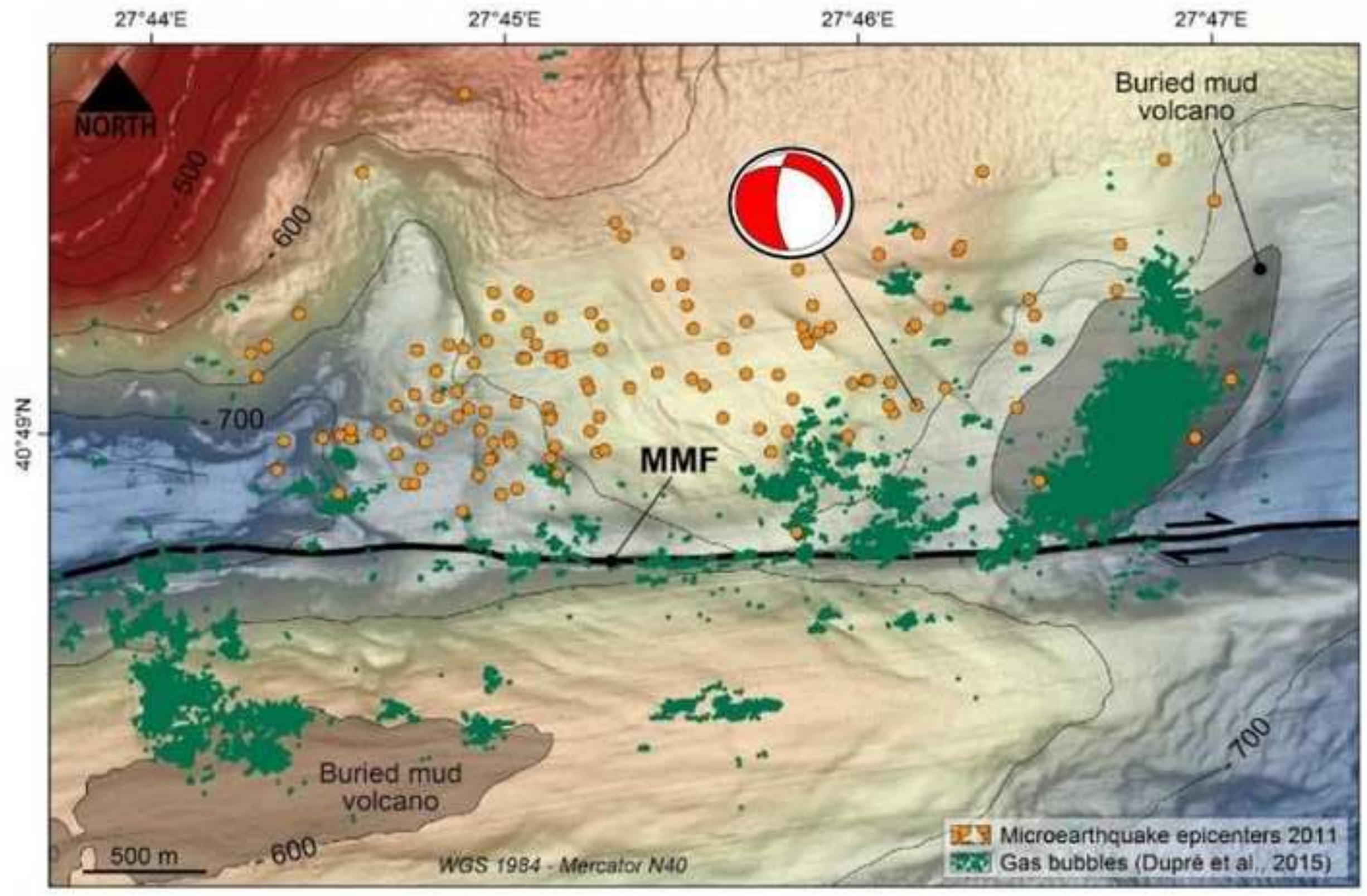



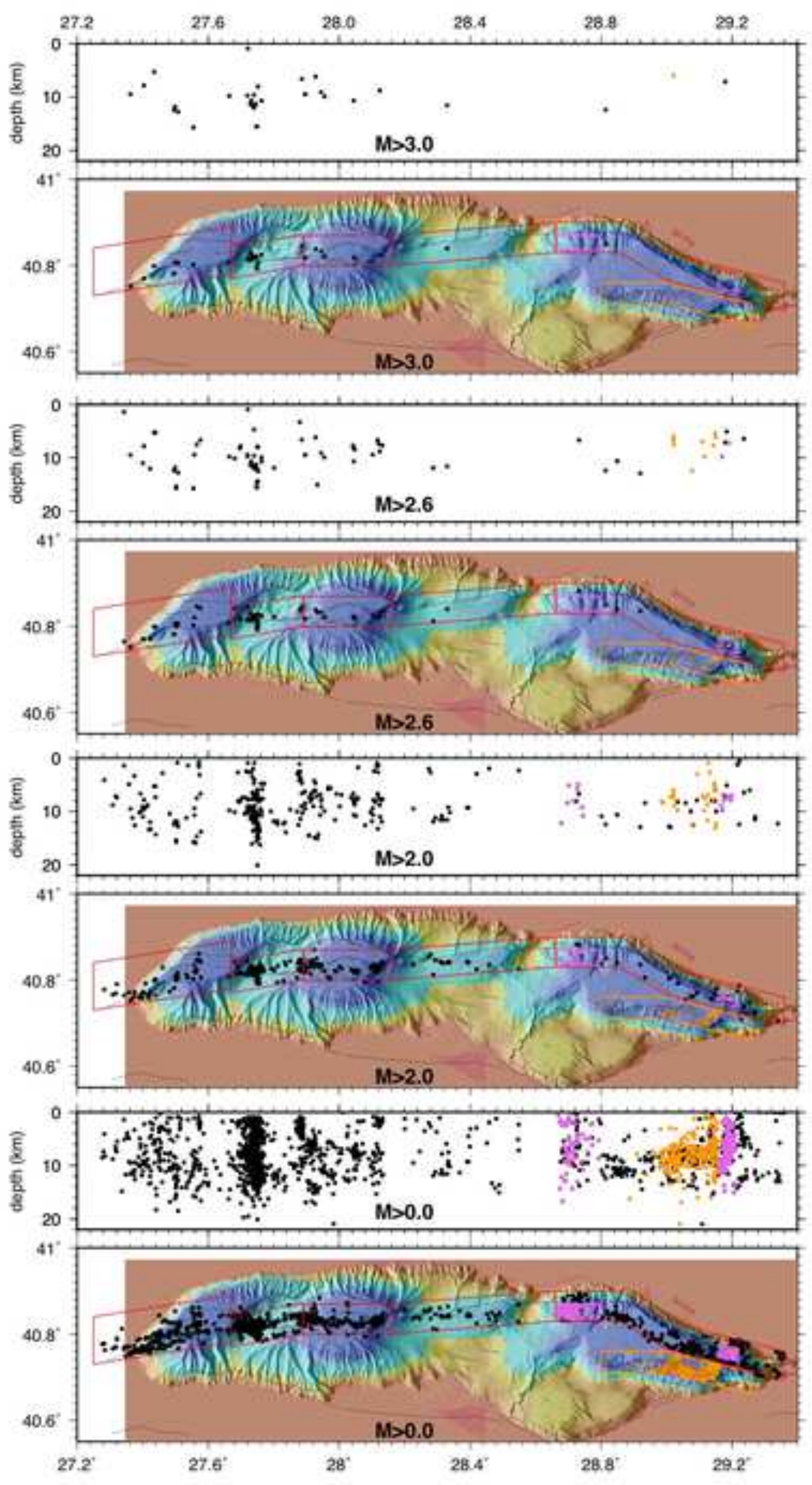


\section{Supplementary information for «An alternative view of}

\section{2 the micro-seismicity along the Western Main Marmara}

\section{Fault»}

6 Evangelia Batsi, Anthony Lomax, Jean-Baptiste Tary, Frauke Klingelhoefer, Vincent Riboulot,

7 Shane Murphy, Stephen Monna, Nurcan Meral Özel, Dogan Kalafat, Hakan Saritas, Günay Cifçi,

8 Namik Çagatay, Luca Gasperini, Louis Géli

12 This electronic supplement contains: (i) Earthquake Catalogs of relative locations, including the

13 station correction values and the time delays obtained by the $1 \mathrm{D}$ and $3 \mathrm{D}$ velocity models of this

14 study; (ii) Characteristics of the calculated composite focal mechanisms and (iii) Seismograms of

15 the triplet of case study 2, recorded on the vertical and horizontal components of different OBS

16 stations. 
22 Catalogs of relocated events (Tables S1 to S4)

24 Station correction values for $\mathbf{P}$ and $\mathbf{S}$ phases (Tables S5 to S8)

26 Station corrections were applied by considering all the detected earthquakes of 2011 and 2014 as

27 described (Lomax et al., 2008). Events that were not meeting the criteria of well-constrained 28 earthquakes were eliminated from our catalogue (see paragraph on: Location procedure). 
35 Characteristics of Focal Mechanisms (Figures S2 to S5 and Table

36 S10)

38 Case Study 1: composite focal mechanism derived from the 3D-locations (Figure S2)

39 Case study 2: composite focal mechanism derived from the 3D-locations (Figure S3)

40 Case study 3: composite focal mechanism derived from the 3D-locations (Figure S4)

41 Composite focal mechanism computed for 10 events triggered by the

42 M 5.1 earthquake of the $25^{\text {th }}$ of July, 2011 (Figure S5 and Table S10).

44 Seismograms of the triplet of case study 2 (Figures S6 to S9). 


\section{List of Table Captions}

53 Table S1: Catalogue of relocated events (Step 5: see main text) with statistics obtained with

54 the NLDiffLoc, using the 1D velocity model of this study (2011 data set).

55 Table S2: Catalogue of relocated events (Step 5: see main text) with statistics obtained with

56 the NLDiffLoc, using the 3D velocity model of this study after applying station corrections 57 (2011 data set).

58 Table S3: Catalogue of relocated events (Step 5: see main text) with statistics obtained with

59 the NLDiffLoc, using the 1D velocity model of this study (2014 data set).

60 Table S4: Catalogue of relocated events (Step 5: see main text) with statistics obtained with

61 the NLDiffLoc, using the 3D velocity model of this study after applying station corrections 62 (2014 data set).

63 Table S5: Station correction values for $\mathrm{P}$ and $\mathrm{S}$ phases for the 1D-velocity model of this 64 study for the 2011 data-set 1.

65 Table S6: Station correction values for $\mathrm{P}$ and $\mathrm{S}$ phases for the 3D-velocity model of this 66 study for the 2011 data-set 1.

67 Table S7: Station correction values for $\mathrm{P}$ and $\mathrm{S}$ phases for the 1D-velocity model of this 68 study for the 2014 data-set 2 .

69 Table S8: Station correction values for $\mathrm{P}$ and $\mathrm{S}$ phases for the $3 \mathrm{D}$-velocity model of this 70 study for the 2014 data-set 2 .

71 Table S9: List of selected events detected by all 10 OBSs (2011 dataset), displayed in 72 Figure S1.

73 Table S10: Table of the 10 events triggered by the M 5.1 earthquake of the $25^{\text {th }}$ of July, 2011 used

74 for calculating the composite focal mechanism of Figure S5. 


\section{List of Figures Captions}

77 Figure S1: P-wave travel-time residuals (observed-predicted) in seconds at 10 OBS (of

78 2011) for $1 \mathrm{D}$ (blue) and 3D (red) locations of 10 selected events (see Table S9).

80 Figure S2: Composite focal mechanism of case study 1, computed with HASH software 81 (Hardebeck and Shearer, 2008), with the measured polarities represented with red and black circles,

82 down and up motions respectively, calculated with the 3D velocity model of this study. Resulting 83 focal mechanism: Strike/Dip/rake $=190^{\circ} / 59^{\circ} /-80^{\circ}$.

85 Figure S3: Composite focal mechanism of case study 2, computed with HASH software 86 (Hardebeck and Shearer, 2008), with the measured polarities represented with red and black 87 circles, down and up motions respectively, calculated with the 3D velocity model of this 88 study. Resulting focal mechanism: Strike/Dip/rake=233\% $/ 67^{\circ} / 101^{\circ}$.

90 Figure S4: Composite focal mechanism of case study 3, computed with HASH software 91 (Hardebeck and Shearer, 2008), with the measured polarities represented with red and black 92 circles, down and up motions respectively, calculated with the $3 \mathrm{D}$ velocity model of this 93 study. Resulting focal mechanism: Strike/Dip/rake $=78 \% / 58 \% 151^{\circ}$.

95 Figure S5: Composite focal mechanism computed for 10 events triggered by the M 5.1 96 earthquake of the $25^{\text {th }}$ of July, 2011 (see Table S10). Computation with HASH software 97 (Hardebeck and Shearer, 2008), with the measured polarities represented with red and black

98 circles, down and up motions respectively, calculated with the $3 \mathrm{D}$ velocity model of this 99 study. Resulting focal mechanism: Strike/Dip/rake=300\% $34 \%-145^{\circ}$. 
101 Figure S6: Seismograms of the triplet of case study 2, recorded on the vertical and horizontal 102 components of OBS07.

103

104 Figure S7: Seismograms of the triplet of case study 2, recorded on the vertical and horizontal 105 components of OBS08.

106

107 Figure S8: Seismograms of the triplet of case study 2, recorded on the vertical and horizontal 108 components of OBS09.

109

110 Figure S9: Seismograms of the triplet of case study 2, recorded on the vertical and horizontal 111 components of OBS10. 


\section{References}

124

125 Hardebeck, J.L. and Shearer, P.M., (2008). HASH : A Fortran program for computing 126 Earthquake First-Motion Focal Mechanisms -v1.2 - January 31.

127

128 Lomax, A. (2008), Location and Tectonics of the Focal Region of the California Earthquake of 18 129 April 1906, Bull. Seism. Soc. Am., 98, 846-860. 
Table S1. Catalogue of relocated events (Step 5: see main text) with statistics obtained with the NLDiffLoc, using the $1 \mathrm{D}$ velocity model of this study (2011 data set).

\begin{tabular}{|c|c|c|c|c|c|c|c|c|c|c|c|c|c|c|c|c|}
\hline No & yy & mo & dd & hh & $\mathbf{m m}$ & Ss & Lat & Long & Depth & Ml & Exx & Eyy & Ezz & RMS & Nph & Gap \\
\hline & & & & & & & $\left({ }^{\circ}\right)$ & $\left(^{\circ}\right)$ & (km) & & (km) & $(\mathbf{k m})$ & (km) & (s) & & $\left(^{\circ}\right)$ \\
\hline 1 & 2011 & 4 & 16 & 16 & 30 & 25 & 40.7995 & 28.0017 & 15.47 & 0.9 & 0.165 & 0.16 & 0.368 & 0.039 & 90 & 119 \\
\hline 2 & 2011 & 4 & 20 & 5 & 4 & 49 & 40.8091 & 28.0051 & 14.82 & 0.6 & 0.08 & 0.075 & 0.155 & 0.046 & 127 & 107 \\
\hline 3 & 2011 & 4 & 26 & 16 & 12 & 10 & 40.7998 & 27.9829 & 12.09 & 1 & 0.047 & 0.046 & 0.126 & 0.028 & 141 & 93 \\
\hline 4 & 2011 & 4 & 29 & 4 & 58 & 40 & 40.7990 & 27.9446 & 3.74 & 0.8 & 0.049 & 0.056 & 0.081 & 0.076 & 130 & 78 \\
\hline 5 & 2011 & 4 & 30 & 15 & 21 & 53 & 40.8112 & 27.9600 & 15.89 & 1.1 & 0.05 & 0.07 & 0.154 & 0.037 & 164 & 96 \\
\hline 6 & 2011 & 5 & 1 & 8 & 36 & 17 & 40.8266 & 28.1355 & 13.69 & 3.3 & 0.057 & 0.064 & 0.093 & 0.027 & 187 & 115 \\
\hline 7 & 2011 & 5 & 2 & 15 & 31 & 6 & 40.7147 & 28.1004 & 10.22 & 0.8 & 0.274 & 0.283 & 0.445 & 0.034 & 19 & 177 \\
\hline 8 & 2011 & 5 & 4 & 5 & 3 & 19 & 40.8030 & 27.9136 & 19.28 & 0.7 & 0.143 & 0.326 & 0.771 & 0.072 & 97 & 78 \\
\hline 9 & 2011 & 5 & 7 & 4 & 14 & 26 & 40.8042 & 27.9 & 14.49 & 1.4 & 0.04 & 0.048 & 0.089 & 0.027 & 170 & 95 \\
\hline 10 & 2011 & 5 & 7 & 17 & 27 & 50 & 40.8092 & 27.9763 & 14.05 & 2.2 & 0.036 & 0.049 & 97 & 0.029 & 182 & 97 \\
\hline 11 & 2011 & 5 & 7 & 17 & 46 & 15 & 40.80 & 27.9860 & .55 & 1.5 & 0.051 & 0.047 & & & 49 & 100 \\
\hline 12 & 2011 & 5 & 9 & 14 & 0 & 3 & 40.79 & & & 0.9 & 0.0 & 0.05 & & & 40 & 98 \\
\hline 13 & 201 & 5 & 9 & 23 & 8 & 7 & 40.79 & 27.9 & .25 & 1 & 0.031 & 0.048 & & & 57 & 101 \\
\hline 14 & 2011 & 5 & 12 & 14 & 32 & 44 & 40.7995 & 27.9797 & .49 & 1.7 & 0.034 & 0.045 & & 0.028 & 76 & 93 \\
\hline 15 & 2011 & 5 & 13 & 10 & 40 & 3 & 40.8020 & 27.9 & 13.26 & 2 & 0.034 & 0.048 & & 0.025 & 168 & 93 \\
\hline 16 & 2011 & 5 & 14 & 15 & 23 & 24 & 40.7892 & 27.9927 & 8.74 & 0.5 & 0.048 & 0.055 & 0.1 & 0.058 & 124 & 103 \\
\hline 17 & 2011 & 5 & 14 & 18 & 38 & 4 & 40.7927 & 27.9216 & 7.06 & 0.8 & 0.09 & 0.104 & 0.7 & 0.0 & 59 & 104 \\
\hline 18 & 2011 & 5 & 15 & 3 & 39 & 1 & 40.8305 & 28.0 & 18.48 & 1. & 0.273 & 0.209 & & $0.0^{\prime}$ & 45 & 111 \\
\hline 19 & 2011 & 5 & 17 & 20 & 40 & 15 & 40.7999 & 27.9795 & 12.23 & 1.2 & 0.045 & 0.05 & 0.12 & 0.032 & 143 & 4 \\
\hline 20 & 2011 & 5 & 18 & 3 & 17 & 0 & 40.8093 & 27.9796 & 13.76 & 1.8 & 0.03 & 0.042 & 0.089 & 0.029 & 180 & 104 \\
\hline 21 & 2011 & 5 & 19 & 4 & 38 & 37 & 40.8251 & 28.1330 & 11.64 & 3.1 & 0.056 & 0.057 & 0.1 & 0.026 & 191 & 110 \\
\hline 22 & 2011 & 5 & 19 & 4 & 44 & 7 & 40.8159 & 28.0985 & 2.71 & 1.1 & 0.061 & 0.045 & 0.129 & 0.075 & 168 & 5 \\
\hline 23 & 2011 & 5 & 19 & 5 & 5 & 38 & 40.8377 & 28.0958 & 15.65 & 0.5 & 0.124 & 0.124 & 0.5 & 0.014 & 86 & 145 \\
\hline 24 & 2011 & 5 & 22 & 22 & 39 & 26 & 40.8229 & 28.1370 & 11.12 & 2.3 & 0.067 & 0.061 & 0.198 & 0.024 & 174 & 106 \\
\hline 25 & 2011 & 5 & 25 & 23 & 43 & 19 & 40.7918 & 27.9235 & 18.56 & 0.9 & 0.252 & 0.426 & 0.426 & 0.045 & 37 & 110 \\
\hline 26 & 2011 & 5 & 29 & 7 & 24 & 20 & 40.8265 & 28.1468 & 13.62 & 1.1 & 0.066 & 0.076 & 0.106 & 0.022 & 170 & 108 \\
\hline 27 & 2011 & 5 & 30 & 19 & 53 & 12 & 40.7872 & 27.9203 & 16.84 & 1.4 & 0.201 & 0.344 & 0.369 & 0.033 & 30 & 84 \\
\hline 28 & 2011 & 6 & 9 & 20 & 43 & 27 & 40.8179 & 28.1227 & 10.65 & 1.8 & 0.039 & 0.043 & 0.123 & 0.021 & 185 & 96 \\
\hline 29 & 2011 & 6 & 9 & 20 & 53 & 41 & 40.8194 & 28.1125 & 12.74 & 1.1 & 0.045 & 0.063 & 0.159 & 0.018 & 142 & 95 \\
\hline 30 & 2011 & 6 & 10 & 3 & 54 & 24 & 40.8336 & 28.0822 & 15.22 & 0.6 & 0.12 & 0.13 & 0.281 & 0.023 & 65 & 135 \\
\hline 31 & 2011 & 6 & 10 & 4 & 28 & 29 & 40.8202 & 28.1196 & 10.58 & 1.9 & 0.037 & 0.043 & 0.131 & 0.02 & 176 & 97 \\
\hline 32 & 2011 & 6 & 10 & 5 & 52 & 19 & 40.7763 & 28.0507 & 4.94 & 1.4 & 0.127 & 0.147 & 0.115 & 0.139 & 61 & 109 \\
\hline 33 & 2011 & 6 & 10 & 17 & 43 & 13 & 40.8205 & 28.1181 & 14.38 & 1.4 & 0.052 & 0.066 & 0.108 & 0.021 & 169 & 102 \\
\hline 34 & 2011 & 6 & 12 & 6 & 9 & 29 & 40.8181 & 27.9563 & 18.93 & 0.9 & 0.081 & 0.105 & 0.29 & 0.044 & 168 & 101 \\
\hline 35 & 2011 & 6 & 14 & 5 & 37 & 33 & 40.8229 & 28.1316 & 10.82 & 1.5 & 0.053 & 0.05 & 0.166 & 0.022 & 181 & 105 \\
\hline 36 & 2011 & 6 & 23 & 20 & 25 & 11 & 40.8558 & 28.1189 & 19.64 & 0.9 & 0.181 & 0.324 & 0.87 & 0.018 & 71 & 137 \\
\hline 37 & 2011 & 6 & 24 & 12 & 37 & 45 & 40.8439 & 27.9134 & 16.17 & 1.2 & 0.19 & 0.249 & 0.542 & 0.027 & 29 & 146 \\
\hline 38 & 2011 & 6 & 24 & 12 & 58 & 48 & 40.8557 & 27.9150 & 19.48 & 1.7 & 0.192 & 0.292 & 0.807 & 0.014 & 22 & 152 \\
\hline 39 & 2011 & 6 & 24 & 13 & 20 & 26 & 40.8369 & 27.9171 & 15.7 & 1 & 0.105 & 0.188 & 0.393 & 0.041 & 56 & 98 \\
\hline 40 & 2011 & 7 & 2 & 3 & 30 & 53 & 40.8256 & 27.8485 & 12.45 & 1 & 0.198 & 0.298 & 0.894 & 0.021 & 19 & 143 \\
\hline 41 & 2011 & 7 & 6 & 12 & 45 & 53 & 40.8254 & 27.9805 & 19.28 & 0.7 & 0.071 & 0.071 & 0.153 & 0.029 & 130 & 115 \\
\hline 42 & 2011 & 7 & 7 & 9 & 42 & 35 & 40.8021 & 28.0094 & 22.49 & 0.7 & 0.093 & 0.075 & 0.387 & 0.033 & 109 & 95 \\
\hline 43 & 2011 & 7 & 10 & 10 & 11 & 39 & 40.7531 & 28.1297 & 10.56 & 0.6 & 0.184 & 0.321 & 0.564 & 0.058 & 59 & 136 \\
\hline 44 & 2011 & 7 & 14 & 9 & 15 & 41 & 40.7771 & 28.0119 & 18.43 & 1.6 & 0.124 & 0.103 & 0.335 & 0.036 & 100 & 118 \\
\hline 45 & 2011 & 7 & 22 & 15 & 16 & 12 & 40.8062 & 28.0953 & 15.28 & 1.1 & 0.07 & 0.09 & 0.145 & 0.032 & 148 & 87 \\
\hline 46 & 2011 & 7 & 23 & 5 & 14 & 59 & 40.8050 & 28.0950 & 12.68 & 1.5 & 0.087 & 0.102 & 0.475 & 0.029 & 126 & 91 \\
\hline
\end{tabular}

Where: yy, mo, dd, hh, mm,ss, lat, lon stand for year, month, day, hour, minute, second, latitude, longitude

Exx, eyy, ezz, Nph for horizontal1, horizontal2, vertical location errors, respectively, and number of phases used 
Table S2. Catalogue of relocated events (Step 5: see main text) with statistics obtained with the NLDiffLoc, using the 3D velocity model of this study after applying station corrections (2011 data set).

\begin{tabular}{|c|c|c|c|c|c|c|c|c|c|c|c|c|c|c|c|c|}
\hline No & year & month & day & hh & $\mathrm{mm}$ & ss & Lat & Long & Depth & MI & Exx & Eyy & Ezz & RMS & Nphs & Gap \\
\hline & & & & & & & $\left(^{\circ}\right)$ & $\left({ }^{\circ}\right)$ & $(\mathrm{km})$ & & $(\mathrm{km})$ & $(\mathrm{km})$ & (km) & (sec) & & $\left(^{\circ}\right)$ \\
\hline 1 & 2011 & 4 & 16 & 16 & 30 & 26 & 40.8231 & 28.0082 & 14.99 & 0.9 & 0.061 & 0.091 & 0.146 & 0.051 & 103 & 120 \\
\hline 2 & 2011 & 4 & 20 & 5 & 4 & 50 & 40.8293 & 28.0100 & 15.07 & 0.6 & 0.12 & 0.079 & 0.294 & 0.052 & 122 & 122 \\
\hline 3 & 2011 & 4 & 26 & 16 & 12 & 10 & 40.8197 & 27.9867 & 11.89 & 1 & 0.163 & 0.081 & 0.307 & 0.035 & 132 & 118 \\
\hline 4 & 2011 & 4 & 29 & 4 & 58 & 40 & 40.8220 & 27.9461 & 6.19 & 0.8 & 0.065 & 0.053 & 0.156 & 0.118 & 53 & 81 \\
\hline 5 & 2011 & 4 & 30 & 15 & 21 & 54 & 40.8349 & 27.9641 & 16.26 & 1.1 & 0.166 & 0.134 & 0.166 & 0.055 & 165 & 131 \\
\hline 6 & 2011 & 5 & 1 & 15 & 18 & 41 & 40.8656 & 28.1636 & 5.85 & 3.3 & 0.063 & 0.086 & 0.271 & 0.086 & 62 & 146 \\
\hline 7 & 2011 & 5 & 2 & 15 & 31 & 6 & 40.7194 & 28.1148 & 11.96 & 0.8 & 0.359 & 0.505 & 0.747 & 0.075 & 11 & 130 \\
\hline 8 & 2011 & 5 & 4 & 5 & 3 & 20 & 40.8330 & 27.9150 & 21.69 & 0.7 & 0.935 & 0.446 & 0.685 & 0.047 & 58 & 95 \\
\hline 9 & 2011 & 5 & 7 & 4 & 14 & 26 & 40.8256 & 27.9889 & 14.77 & 1.4 & 0.14 & 0.195 & 0.541 & 0.034 & 157 & 125 \\
\hline 10 & 2011 & 5 & 7 & 17 & 27 & 50 & 40.8299 & 27.9819 & 13.89 & 2.2 & 0.048 & 0.055 & 0.147 & 0.033 & 143 & 130 \\
\hline 11 & 2011 & 5 & 7 & 17 & 46 & 16 & 40.8220 & 27.9903 & 12.36 & 1.5 & 0.054 & 0.066 & 0.202 & 0.035 & 138 & 122 \\
\hline 12 & 2011 & 5 & 9 & 14 & 0 & 3 & 40.8173 & 27.9945 & 12.48 & 0.9 & 0.072 & 0.053 & 0.143 & 0.049 & 126 & 113 \\
\hline 13 & 2011 & 5 & 9 & 23 & 8 & 8 & 40.8165 & 27.9851 & 13.37 & 1.7 & 0.103 & 0.066 & 0.216 & 0.031 & 143 & 113 \\
\hline 14 & 2011 & 5 & 12 & 14 & 32 & 45 & 40.8207 & 27.9854 & 13.63 & 1.7 & 0.056 & 0.069 & 0.165 & 0.036 & 149 & 123 \\
\hline 15 & 2011 & 5 & 13 & 10 & 40 & 3 & 40.8226 & 27.9890 & 13.19 & 2 & 0.052 & 0.056 & 0.149 & 0.035 & 157 & 122 \\
\hline 16 & 2011 & 5 & 14 & 15 & 23 & 25 & 40.8150 & 27.9884 & 7.37 & 0.5 & 0.053 & 0.052 & 0.138 & 0.075 & 118 & 110 \\
\hline 17 & 2011 & 5 & 14 & 18 & 38 & 4 & 40.8047 & 27.9225 & 6.21 & 0.8 & 0.111 & 0.173 & 0.392 & 0.024 & 19 & 105 \\
\hline 18 & 2011 & 5 & 15 & 3 & 39 & 1 & 40.8505 & 28.0441 & 18.92 & 1.1 & 0.181 & 0.361 & 0.513 & 0.063 & 72 & 128 \\
\hline 19 & 2011 & 5 & 17 & 20 & 40 & 15 & 40.8202 & 27.9837 & 12.08 & 1.2 & 0.284 & 0.173 & 0.463 & 0.041 & 136 & 115 \\
\hline 20 & 2011 & 5 & 18 & 3 & 17 & 1 & 40.8294 & 27.9857 & 13.6 & 1.8 & 0.065 & 0.054 & 0.165 & 0.039 & 157 & 129 \\
\hline 21 & 2011 & 5 & 19 & 4 & 38 & 37 & 40.8340 & 28.1442 & 4.33 & 3.1 & 0.054 & 0.062 & 0.16 & 0.048 & 117 & 130 \\
\hline 22 & 2011 & 5 & 19 & 4 & 44 & 6 & 40.8277 & 28.1154 & 0 & 1.1 & 0.072 & 0.063 & 0.265 & 0.15 & 96 & 107 \\
\hline 23 & 2011 & 5 & 19 & 5 & 5 & 38 & 40.8340 & 28.1246 & 1.46 & 0.5 & 0.145 & 0.099 & 0.072 & 0.017 & 63 & 120 \\
\hline 24 & 2011 & 5 & 22 & 22 & 39 & 26 & 40.8330 & 28.1463 & 4.19 & 2.3 & 0.027 & 0.038 & 0.177 & 0.041 & 110 & 149 \\
\hline 25 & 2011 & 5 & 25 & 23 & 43 & 20 & 40.8236 & 27.9208 & 19.68 & 0.9 & 0.17 & 0.08 & 0.477 & 0.039 & 40 & 125 \\
\hline 26 & 2011 & 5 & 29 & 7 & 24 & 21 & 40.8396 & 28.1628 & 7.96 & 1.1 & 0.211 & 0.381 & 0.87 & 0.034 & 98 & 151 \\
\hline 27 & 2011 & 5 & 30 & 19 & 53 & 12 & 40.8174 & 27.9206 & 18.33 & 1.4 & 0.187 & 0.126 & 0.469 & 0.051 & 52 & 70 \\
\hline 28 & 2011 & 6 & 9 & 20 & 43 & 28 & 40.8312 & 28.1399 & 4.95 & 1.8 & 0.121 & 0.19 & 0.306 & 0.034 & 108 & 122 \\
\hline 29 & 2011 & 6 & 9 & 20 & 53 & 41 & 40.8380 & 28.1421 & 10.75 & 1.1 & 0.096 & 0.054 & 0.411 & 0.028 & 89 & 119 \\
\hline 30 & 2011 & 6 & 10 & 3 & 54 & 24 & 40.8599 & 28.1184 & 16.32 & 0.6 & 0.087 & 0.1 & 0.346 & 0.024 & 72 & 173 \\
\hline 31 & 2011 & 6 & 10 & 4 & 28 & 30 & 40.8323 & 28.1381 & 5.03 & 1.9 & 0.123 & 0.169 & 0.344 & 0.036 & 108 & 125 \\
\hline 32 & 2011 & 6 & 10 & 5 & 52 & 19 & 40.7961 & 28.0613 & 5.28 & 1.4 & 0.102 & 0.074 & 0.499 & 0.206 & 84 & 120 \\
\hline 33 & 2011 & 6 & 10 & 17 & 43 & 13 & 40.8407 & 28.1496 & 11.99 & 1.4 & 0.204 & 0.15 & 0.19 & 0.034 & 91 & 167 \\
\hline 34 & 2011 & 6 & 12 & 6 & 9 & 29 & 40.8436 & 27.9604 & 20.02 & 0.9 & 0.138 & 0.128 & 0.536 & 0.062 & 165 & 137 \\
\hline 35 & 2011 & 6 & 14 & 5 & 37 & 33 & 40.8330 & 28.1436 & 4.18 & 1.5 & 0.078 & 0.12 & 0.258 & 0.042 & 110 & 143 \\
\hline 36 & 2011 & 6 & 23 & 20 & 25 & 11 & 40.8361 & 28.1303 & 0.7 & 0.9 & 0.082 & 0.056 & 0.282 & 0.019 & 63 & 131 \\
\hline 37 & 2011 & 6 & 24 & 12 & 37 & 45 & 40.8685 & 27.9132 & 15.47 & 1.2 & 0.027 & 0.034 & 0.091 & 0.033 & 25 & 167 \\
\hline 38 & 2011 & 6 & 24 & 12 & 58 & 49 & 40.8855 & 27.9133 & 18.97 & 1.7 & 0.193 & 0.284 & 0.798 & 0.016 & 13 & 179 \\
\hline 39 & 2011 & 6 & 24 & 13 & 20 & 26 & 40.8610 & 27.9173 & 14.68 & 1 & 0.373 & 0.553 & 1.12 & 0.02 & 39 & 160 \\
\hline 40 & 2011 & 7 & 2 & 3 & 30 & 53 & 40.8521 & 27.8458 & 17.53 & 1 & 0.124 & 0.181 & 0.338 & 0.072 & 15 & 172 \\
\hline 41 & 2011 & 7 & 6 & 12 & 45 & 53 & 40.8501 & 27.9888 & 19.94 & 0.7 & 0.494 & 0.537 & 0.521 & 0.044 & 127 & 145 \\
\hline 42 & 2011 & 7 & 7 & 9 & 42 & 35 & 40.8297 & 28.0240 & 25.81 & 0.7 & 0.555 & 0.789 & 1.221 & 0.046 & 108 & 128 \\
\hline 43 & 2011 & 7 & 10 & 10 & 11 & 40 & 40.7798 & 28.1440 & 5.57 & 0.6 & 0.202 & 0.103 & 0.46 & 0.088 & 79 & 127 \\
\hline 44 & 2011 & 7 & 14 & 9 & 15 & 41 & 40.8060 & 28.0134 & 20.56 & 1.6 & 0.192 & 0.288 & 0.633 & 0.069 & 116 & 102 \\
\hline 45 & 2011 & 7 & 22 & 15 & 16 & 13 & 40.8298 & 28.1305 & 15.2 & 1.1 & 0.206 & 0.182 & 0.831 & 0.053 & 111 & 135 \\
\hline 46 & 2011 & 7 & 23 & 5 & 14 & 59 & 40.8250 & 28.1243 & 11.96 & 1.5 & 0.127 & 0.102 & 0.393 & 0.038 & 89 & 112 \\
\hline
\end{tabular}


Where: yy, mo, dd, hh, mm,ss, lat, lon stand for year, month, day, hour, minute, second, latitude, longitude Exx, eyy, ezz, Nph for horizontal1, horizontal2, vertical location errors, respectively, and number of phases used 
Table S3. Catalogue of relocated events (Step 5: see main text) with statistics obtained with the NLDiffLoc, using the $1 \mathrm{D}$ velocity model of this study (2014 data set).

\begin{tabular}{|c|c|c|c|c|c|c|c|c|c|c|c|c|c|c|c|c|}
\hline No & yy & mo & dd & hh & $\mathrm{mm}$ & ss & Lat & Long & Depth & Ml & Exx & Eyy & Ezz & RMS & Nph & Gap \\
\hline & & & & & & & $\left({ }^{\circ}\right)$ & $\left(^{\circ}\right)$ & (km) & & (km) & (km) & (km) & (s) & & $\left(^{\circ}\right)$ \\
\hline 1 & 2014 & 9 & 21 & 4 & 35 & 29 & 40.8279 & 27.8751 & 3.7 & 1.7 & & & & 0.081 & 42 & 133 \\
\hline 2 & 2014 & 9 & 23 & 4 & 15 & 39 & 40.8054 & 27.7898 & 10.0 & 1.8 & 0.091 & 0.063 & 0.148 & 0.044 & 147 & 86 \\
\hline 3 & 2014 & 9 & 23 & 4 & 43 & 18 & 40.7996 & 27.7948 & 11.4 & 1.7 & 0.148 & 0.531 & 0.646 & 0.02 & 97 & 90 \\
\hline 4 & 2014 & 9 & 23 & 5 & 6 & 21 & 40.8067 & 27.7975 & 9.5 & 2 & 0.07 & 0.038 & 0.086 & 0.015 & 124 & 68 \\
\hline 5 & 2014 & 9 & 23 & 5 & 34 & 36 & 40.8055 & 27.7925 & 10.2 & 1.9 & 0.088 & 0.051 & 0.24 & 0.043 & 141 & 73 \\
\hline 6 & 2014 & 9 & 25 & 6 & 54 & 60 & 40.8000 & 27.7356 & 7.9 & 1.7 & 0.129 & 0.151 & 0.477 & 0.026 & 39 & 167 \\
\hline 7 & 2014 & 9 & 26 & 6 & 2 & 54 & 40.7888 & 27.7165 & 9.4 & 1.7 & 0.2 & 0.301 & 0.229 & 0.04 & 126 & 99 \\
\hline 8 & 2014 & 9 & 27 & 8 & 50 & 14 & 40.8107 & 27.9007 & 3.3 & 1 & 0.212 & 0.22 & 0.515 & 0.05 & 21 & 174 \\
\hline 9 & 2014 & 9 & 30 & 12 & 34 & 16 & 40.8169 & 27.7222 & 4.7 & 1.7 & 0.052 & 0.045 & 0.07 & 0.025 & 72 & 139 \\
\hline 10 & 2014 & 10 & 1 & 14 & 44 & 50 & 40.8325 & 27.8917 & 3.9 & 1.3 & 0.152 & 0.208 & 0.277 & 0.074 & 31 & 152 \\
\hline 11 & 2014 & 10 & 3 & 11 & 19 & 24 & 40.8628 & 27.8552 & 10.1 & 1.3 & 0.265 & 0.531 & 0.841 & 0.124 & 38 & 155 \\
\hline 12 & 2014 & 10 & 3 & 21 & 40 & 19 & 40.7219 & 27.7818 & 25.4 & 1.7 & 0.297 & 0.401 & 0.625 & 0.111 & 90 & 132 \\
\hline 13 & 2014 & 10 & 4 & 11 & 58 & 35 & 40.8360 & 27.7524 & 3.0 & 2.2 & 0.063 & 0.122 & 0.192 & 0.028 & 84 & 136 \\
\hline 14 & 2014 & 10 & 4 & 17 & 31 & 45 & 40.8395 & 27.7928 & 4.5 & 1.8 & 0.16 & 0.314 & 0.715 & 0.022 & 62 & 175 \\
\hline 15 & 2014 & 10 & 5 & 14 & 48 & 4 & 40.81 & 27.7243 & 3.6 & 1.6 & 0.167 & 0.225 & 0.042 & 0.009 & 68 & 114 \\
\hline 16 & 2014 & 10 & 6 & 11 & 4 & 57 & 40.8121 & 27.7676 & 6.5 & 1.7 & 0.672 & 0.408 & 0.391 & 0.002 & 63 & 125 \\
\hline 17 & 2014 & 10 & 8 & 3 & 11 & 44 & 40.7878 & 27.6762 & 10.4 & 1.5 & 0.423 & 0.182 & 0.464 & 0.032 & 46 & 119 \\
\hline 18 & 2014 & 10 & 11 & 6 & 42 & 58 & 40.7227 & 27.7705 & 10.7 & 2.3 & 0.183 & 0.429 & 0.766 & 0.059 & 49 & 178 \\
\hline 19 & 2014 & 10 & 11 & 12 & 7 & 0 & 40.7394 & 27.8128 & 0.0 & 1.6 & 0.328 & 0.104 & 0.116 & 0.185 & 47 & 146 \\
\hline 20 & 2014 & 10 & 12 & 4 & 58 & 26 & 40.8390 & 27.7662 & 3.5 & 1.7 & 0.07 & 0.054 & 0.125 & 0.047 & 125 & 140 \\
\hline 21 & 2014 & 10 & 12 & 22 & 8 & 19 & 40.8349 & 27.7715 & 13.9 & 1.5 & 0.7 & 0.151 & 0.553 & 0.009 & 43 & 138 \\
\hline 22 & 2014 & 10 & 17 & 8 & 44 & 29 & 40.7140 & 27.7370 & 5.1 & 1.5 & 0.185 & 0.332 & 0.349 & 0.054 & 40 & 174 \\
\hline 23 & 2014 & 10 & 18 & 5 & 25 & 50 & 40.8329 & 27.7483 & 17.2 & 1 & 0.715 & 0.594 & 0.395 & 0.009 & 24 & 116 \\
\hline 24 & 2014 & 10 & 18 & 10 & 17 & 42 & 40.8093 & 27.8204 & 13.1 & 1.9 & 0.137 & 0.08 & 0.322 & 0.034 & 70 & 151 \\
\hline 25 & 2014 & 10 & 19 & 23 & 49 & 33 & 40.8230 & 27.7435 & 11.5 & 1.7 & 0.569 & 0.465 & 0.6 & 0.003 & 35 & 169 \\
\hline 26 & 2014 & 10 & 20 & 3 & 48 & 37 & 40.8145 & 27.7890 & 6.9 & 1.5 & 0.054 & 0.08 & 0.116 & 0.038 & 132 & 81 \\
\hline 27 & 2014 & 10 & 22 & 6 & 7 & 16 & 40.8151 & 27.8222 & 12.4 & 1.4 & 0.319 & 0.739 & 0.555 & 0.028 & 15 & 180 \\
\hline 28 & 2014 & 10 & 22 & 17 & 11 & 35 & 40.7576 & 27.8581 & 5.1 & 2.4 & 1.083 & 0.199 & 0.629 & 0.053 & 54 & 154 \\
\hline 29 & 2014 & 10 & 23 & 0 & 9 & 42 & 40.7515 & 27.6776 & 12.4 & 2.2 & 0.352 & 0.635 & 0.603 & 0.044 & 39 & 134 \\
\hline 30 & 2014 & 10 & 23 & 16 & 29 & 40 & 40.7483 & 27.8410 & 4.2 & 1.8 & 0.807 & 0.536 & 0.735 & 0.105 & 36 & 176 \\
\hline 31 & 2014 & 10 & 25 & 1 & 46 & 52 & 40.8080 & 27.8032 & 10.8 & 1.5 & 0.094 & 0.128 & 0.246 & 0.032 & 83 & 92 \\
\hline 32 & 2014 & 10 & 25 & 3 & 5 & 1 & 40.8036 & 27.7999 & 9.6 & 1.9 & 0.096 & 0.07 & 0.147 & 0.038 & 136 & 112 \\
\hline 33 & 2014 & 10 & 25 & 4 & 21 & 39 & 40.8035 & 27.8039 & 10.5 & 1.5 & 0.08 & 0.061 & 0.165 & 0.015 & 92 & 126 \\
\hline 34 & 2014 & 10 & 25 & 15 & 9 & 6 & 40.8165 & 27.6666 & 19.4 & 1.7 & 0.398 & 1.081 & 0.403 & 0.017 & 12 & 128 \\
\hline 35 & 2014 & 10 & 26 & 3 & 21 & 34 & 40.8042 & 27.7308 & 7.3 & 1.6 & 0.07 & 0.059 & 0.192 & 0.051 & 93 & 120 \\
\hline 36 & 2014 & 10 & 26 & 7 & 41 & 51 & 40.8046 & 27.7344 & 15.5 & 2 & 0.175 & 0.148 & 0.657 & 0.006 & 56 & 134 \\
\hline 37 & 2014 & 10 & 26 & 19 & 24 & 37 & 40.8066 & 27.8076 & 10.5 & 1.9 & 0.131 & 0.054 & 0.137 & 0.01 & 83 & 152 \\
\hline 38 & 2014 & 10 & 27 & 21 & 22 & 10 & 40.7717 & 27.7855 & 0.0 & 1.6 & 0.024 & 0.026 & 0.237 & 0.027 & 90 & 93 \\
\hline 39 & 2014 & 11 & 2 & 22 & 1 & 31 & 40.8868 & 27.6170 & 5.2 & 1.7 & 0.693 & 0.19 & 0.559 & 0.001 & 17 & 168 \\
\hline 40 & 2014 & 11 & 5 & 5 & 56 & 5 & 40.7965 & 27.8383 & 5.1 & 1.4 & 0.221 & 0.138 & 0.641 & 0.025 & 77 & 140 \\
\hline 41 & 2014 & 11 & 5 & 23 & 31 & 48 & 40.7292 & 27.9154 & 6.5 & 1.4 & 0.833 & 0.594 & 0.714 & 0.001 & 20 & 119 \\
\hline 42 & 2014 & 11 & 7 & 0 & 38 & 38 & 40.8883 & 27.7666 & 14.3 & 1 & 0.294 & 0.257 & 0.684 & 0.024 & 45 & 130 \\
\hline 43 & 2014 & 11 & 10 & 6 & 17 & 38 & 40.7930 & 27.8438 & 0.2 & 1.8 & 0.118 & 0.079 & 0.113 & 0.089 & 47 & 135 \\
\hline 44 & 2014 & 11 & 13 & 4 & 26 & 15 & 40.8136 & 27.7386 & 4.9 & 1.5 & 0.081 & 0.053 & 0.129 & 0.037 & 93 & 71 \\
\hline 45 & 2014 & 11 & 13 & 15 & 51 & 32 & 40.7787 & 27.7423 & 19.7 & 1.7 & 0.564 & 0.233 & 0.609 & 0.014 & 70 & 115 \\
\hline
\end{tabular}

Where: yy, mo, dd, hh, mm,ss, lat, lon stand for year, month, day, hour, minute, second, latitude, longitude

Exx, eyy, ezz, Nph for horizontal1, horizontal2, vertical location errors, respectively, and number of phases used 
Table S4. Catalogue of relocated events (Step 5: see main text) with statistics obtained with the NLDiffLoc, using the $3 \mathrm{D}$ velocity model of this study after applying station corrections (2014 data set).

\begin{tabular}{|c|c|c|c|c|c|c|c|c|c|c|c|c|c|c|c|c|}
\hline No & yy & mo & dd & hh & mm & ss & Lat & Long & Depth & Ml & Exx & Eyy & Ezz & RMS & Nph & Gap \\
\hline & & & & & & & $\left({ }^{\circ}\right)$ & $\left(^{\circ}\right)$ & $(\mathbf{k m})$ & & (km) & (km) & (km) & (s) & & $\left(^{\circ}\right)$ \\
\hline 1 & 2014 & 9 & 21 & 4 & 35 & 28 & 40.8462 & 27.8754 & 4.16 & 1.7 & 0.046 & 0.064 & 0.067 & 0.05 & 57 & 156 \\
\hline 2 & 2014 & 9 & 23 & 4 & 15 & 40 & 40.8439 & 27.7854 & 6.33 & 1.8 & 0.218 & 0.085 & 0.113 & 0.059 & 116 & 101 \\
\hline 3 & 2014 & 9 & 23 & 4 & 43 & 18 & 40.8469 & 27.8022 & 5.22 & 1.7 & 1.178 & 0.842 & 0.584 & 0.094 & 68 & 153 \\
\hline 4 & 2014 & 9 & 23 & 5 & 34 & 36 & 40.8405 & 27.7905 & 4.89 & 2 & 0.055 & 0.032 & 0.138 & 0.035 & 113 & 87 \\
\hline 5 & 2014 & 9 & 25 & 6 & 54 & 60 & 40.8376 & 27.7507 & 8.01 & 1.9 & 0.074 & 0.061 & 0.133 & 0.02 & 104 & 154 \\
\hline 6 & 2014 & 9 & 26 & 6 & 2 & 55 & 40.8309 & 27.7308 & 5.25 & 1.7 & 0.076 & 0.041 & 0.132 & 0.04 & 159 & 76 \\
\hline 7 & 2014 & 9 & 27 & 8 & 50 & 14 & 40.8361 & 27.8948 & 4.71 & 1.7 & 0.052 & 0.062 & 0.134 & 0.048 & 56 & 149 \\
\hline 8 & 2014 & 9 & 30 & 12 & 34 & 16 & 40.8397 & 27.7345 & 5.42 & 1 & 0.226 & 0.076 & 0.319 & 0.021 & 143 & 84 \\
\hline 9 & 2014 & 10 & 1 & 14 & 44 & 49 & 40.8509 & 27.8905 & 3.55 & 1.7 & 0.043 & 0.141 & 0.136 & 0.057 & 53 & 154 \\
\hline 10 & 2014 & 10 & 3 & 11 & 19 & 25 & 40.8514 & 27.8779 & 3.88 & 1.3 & 0.046 & 0.077 & 0.086 & 0.024 & 48 & 163 \\
\hline 11 & 2014 & 10 & 3 & 21 & 40 & 22 & 40.8340 & 27.8769 & 5.59 & 1.3 & 0.054 & 0.057 & 0.116 & 0.016 & 50 & 140 \\
\hline 12 & 2014 & 10 & 4 & 11 & 58 & 35 & 40.8243 & 27.7265 & 7 & 1.7 & 0.39 & 0.42 & 0.446 & 0.006 & 111 & 130 \\
\hline 13 & 2014 & 10 & 4 & 17 & 31 & 44 & 40.8558 & 27.7948 & 4.83 & 2.2 & 0.187 & 0.139 & 0.686 & 0.004 & 71 & 151 \\
\hline 14 & 2014 & 10 & 5 & 14 & 48 & 4 & 40.8150 & 27.7076 & 5.21 & 1.8 & 0.057 & 0.026 & 0.081 & 0.002 & 77 & 173 \\
\hline 15 & 2014 & 10 & 6 & 11 & 4 & 58 & 40.8277 & 27.7455 & 3.83 & 1.6 & 0.68 & 0.683 & 0.582 & 0.011 & 53 & 174 \\
\hline 16 & 2014 & 10 & 8 & 3 & 11 & 44 & 40.8216 & 27.7532 & 0.92 & 1.7 & 0.05 & 0.02 & 0.104 & 0.021 & 83 & 102 \\
\hline 17 & 2014 & 10 & 11 & 6 & 42 & 59 & 40.7594 & 27.7838 & 11.43 & 1.5 & 0.445 & 0.316 & 0.809 & 0.083 & 28 & 161 \\
\hline 18 & 2014 & 10 & 11 & 12 & 7 & 1 & 40.7538 & 27.7917 & 2.44 & 2.3 & 0.578 & 0.535 & 0.691 & 0.088 & 21 & 123 \\
\hline 19 & 2014 & 10 & 12 & 4 & 45 & 29 & 40.8109 & 27.7050 & 13.52 & 1.6 & 0.241 & 0.075 & 0.439 & 0.046 & 93 & 169 \\
\hline 20 & 2014 & 10 & 12 & 22 & 8 & 19 & 40.8669 & 27.7496 & 3.47 & 1.7 & 0.167 & 0.063 & 0.48 & 0.002 & 72 & 132 \\
\hline 21 & 2014 & 10 & 17 & 8 & 44 & 30 & 40.7406 & 27.7486 & 7.91 & 1.5 & 0.222 & 0.236 & 0.464 & 0.028 & 25 & 143 \\
\hline 22 & 2014 & 10 & 17 & 19 & 52 & 53 & 40.8295 & 27.8642 & 4.9 & 1.5 & 0.052 & 0.057 & 0.125 & 0.056 & 72 & 121 \\
\hline 23 & 2014 & 10 & 18 & 5 & 25 & 52 & 40.8932 & 27.7166 & 2.87 & 1 & 0.626 & 0.4 & 0.548 & 0.005 & 57 & 146 \\
\hline 24 & 2014 & 10 & 18 & 10 & 17 & 43 & 40.8471 & 27.8087 & 6.61 & 1.9 & 0.102 & 0.094 & 0.247 & 0.042 & 72 & 101 \\
\hline 25 & 2014 & 10 & 19 & 23 & 49 & 32 & 40.8230 & 27.8027 & 2.27 & 1.7 & 0.176 & 0.435 & 0.564 & 0.005 & 63 & 163 \\
\hline 26 & 2014 & 10 & 20 & 3 & 48 & 37 & 40.8462 & 27.7916 & 4.91 & 1.5 & 0.063 & 0.051 & 0.062 & 0.064 & 108 & 103 \\
\hline 27 & 2014 & 10 & 22 & 6 & 7 & 16 & 40.8717 & 27.8299 & 3.61 & 1.4 & 0.432 & 0.124 & 1.165 & 0.047 & 31 & 168 \\
\hline 28 & 2014 & 10 & 22 & 17 & 11 & 36 & 40.8101 & 27.8667 & 5.14 & 2.4 & 0.79 & 0.817 & 0.31 & 0.024 & 17 & 98 \\
\hline 29 & 2014 & 10 & 23 & 0 & 9 & 43 & 40.8012 & 27.6865 & 15.73 & 2.2 & 0.565 & 0.928 & 1.305 & 0.048 & 9 & 180 \\
\hline 30 & 2014 & 10 & 23 & 16 & 29 & 41 & 40.8430 & 27.6378 & 10.08 & 1.8 & 0.678 & 0.095 & 0.175 & 0.004 & 106 & 114 \\
\hline 31 & 2014 & 10 & 25 & 1 & 46 & 53 & 40.8452 & 27.8120 & 6.21 & 1.5 & 0.154 & 0.044 & 0.131 & 0.02 & 73 & 166 \\
\hline 32 & 2014 & 10 & 25 & 3 & 5 & 1 & 40.8484 & 27.8104 & 6.29 & 1.9 & 0.132 & 0.094 & 0.107 & 0.027 & 88 & 168 \\
\hline 33 & 2014 & 10 & 25 & 4 & 21 & 39 & 40.8421 & 27.8096 & 6.59 & 1.5 & 0.136 & 0.045 & 0.095 & 0.02 & 75 & 175 \\
\hline 34 & 2014 & 10 & 25 & 15 & 9 & 8 & 40.7394 & 27.6703 & 5.68 & 1.7 & 0.46 & 1.457 & 1.625 & 0.12 & 10 & 125 \\
\hline 35 & 2014 & 10 & 26 & 3 & 21 & 34 & 40.8303 & 27.7331 & 5.19 & 1.6 & 0.034 & 0.021 & 0.034 & 0.02 & 125 & 113 \\
\hline 36 & 2014 & 10 & 26 & 7 & 41 & 52 & 40.8463 & 27.7379 & 6.68 & 2 & 0.229 & 0.656 & 0.248 & 0.034 & 91 & 108 \\
\hline 37 & 2014 & 10 & 26 & 19 & 24 & 37 & 40.8446 & 27.7972 & 6.7 & 1.9 & 0.069 & 0.054 & 0.173 & 0.013 & 105 & 149 \\
\hline 38 & 2014 & 10 & 27 & 21 & 20 & 29 & 40.8263 & 27.7068 & 18.68 & 1.6 & 0.537 & 0.362 & 1.326 & 0.002 & 92 & 162 \\
\hline 39 & 2014 & 11 & 2 & 22 & 1 & 31 & 40.8702 & 27.6634 & 14.65 & 1.7 & 1.539 & 0.716 & 0.702 & 0.001 & 53 & 156 \\
\hline 40 & 2014 & 11 & 5 & 5 & 56 & 4 & 40.8378 & 27.8186 & 0.53 & 1.4 & 0.076 & 0.065 & 0.176 & 0.027 & 84 & 163 \\
\hline 41 & 2014 & 11 & 5 & 23 & 31 & 50 & 40.7643 & 27.8128 & 11.69 & 1.4 & 0.885 & 0.578 & 0.981 & 0.004 & 9 & 112 \\
\hline 42 & 2014 & 11 & 7 & 0 & 38 & 39 & 40.8938 & 27.7604 & 6.31 & 1 & 0.312 & 0.212 & 0.514 & 0.003 & 15 & 123 \\
\hline 43 & 2014 & 11 & 10 & 6 & 17 & 38 & 40.7877 & 27.8170 & 1.31 & 1.8 & 0.632 & 0.623 & 0.31 & 0.014 & 14 & 130 \\
\hline 44 & 2014 & 11 & 13 & 4 & 26 & 15 & 40.8366 & 27.7449 & 4.68 & 1.5 & 0.079 & 0.026 & 0.086 & 0.027 & 109 & 98 \\
\hline 45 & 2014 & 11 & 13 & 15 & 51 & 33 & 40.8343 & 27.7871 & 5.23 & 1.7 & 0.188 & 0.101 & 0.89 & 0.015 & 78 & 134 \\
\hline
\end{tabular}

Where: yy, mo, dd, hh, mm,ss, lat, lon stand for year, month, day, hour, minute, second, latitude, longitude

Exx, eyy, ezz, Nph for horizontal1, horizontal2, vertical location errors, respectively, and number of phases used 
Table S5: Station correction values for $\mathrm{P}$ and $\mathrm{S}$ phases for the 1D-velocity model of this study for the 2011 data-set 1 .

\begin{tabular}{|c|c|c|c|c|c|c|}
\hline ID & Phase & Nres & AveRes & StdDev & ResMin & ResMax \\
\hline OBS1 & P & 40 & 0.02 & 0.16 & -0.21 & 0.60 \\
\hline OBS1 & S & 10 & 4.59 & 8.95 & -0.09 & 22.89 \\
\hline OBS2 & $\mathrm{P}$ & 37 & -0.03 & 0.17 & -0.31 & 0.54 \\
\hline OBS2 & $\mathrm{S}$ & 6 & 0.28 & 0.31 & -0.19 & 0.68 \\
\hline OBS3 & $\mathrm{P}$ & 36 & 0.10 & 0.09 & -0.07 & 0.29 \\
\hline OBS3 & $\mathrm{S}$ & 17 & 1.04 & 4.63 & -0.40 & 19.57 \\
\hline OBS4 & $\mathrm{P}$ & 29 & 0.54 & 3.38 & -6.08 & 3.67 \\
\hline OBS4 & $\mathrm{S}$ & 9 & -2.29 & 1.88 & -5.55 & -0.68 \\
\hline OBS5 & $\mathrm{P}$ & 59 & 0.05 & 0.11 & -0.16 & 0.45 \\
\hline OBS5 & $\mathrm{S}$ & 31 & 0.16 & 0.27 & -0.38 & 0.95 \\
\hline OBS6 & $\mathrm{P}$ & 53 & -0.16 & 0.61 & -1.11 & 1.54 \\
\hline OBS6 & $\mathrm{S}$ & 14 & 1.66 & 5.56 & -1.59 & 21.57 \\
\hline OBS7 & $\mathrm{P}$ & 60 & -0.08 & 0.15 & -0.39 & 0.56 \\
\hline OBS7 & $\mathrm{S}$ & 33 & 0.40 & 0.32 & -0.21 & 1.37 \\
\hline OBS8 & $\mathrm{P}$ & 59 & -0.09 & 0.15 & -0.42 & 0.58 \\
\hline OBS8 & $\mathrm{S}$ & 21 & -0.01 & 0.20 & -0.40 & 0.42 \\
\hline OBS9 & $\mathrm{P}$ & 58 & -0.22 & 2.03 & -15.51 & 0.59 \\
\hline OBS9 & $\mathrm{S}$ & 38 & -0.19 & 0.21 & -0.85 & 0.30 \\
\hline OBS10 & $\mathrm{P}$ & 48 & 0.32 & 0.27 & -0.02 & 0.81 \\
\hline OBS10 & $\mathrm{S}$ & $/$ & $/$ & $/$ & $/$ & $/$ \\
\hline
\end{tabular}

Where: Nres, AveRes, StdDev, ResMin, ResMax stand for: Number of Residuals, Average Residual, Standard Deviation, Minimum Residual and Maximum Residual respectively. 
Table S6: Station correction values for $\mathrm{P}$ and $\mathrm{S}$ phases for the 3D-velocity model of this study for the 2011 data-set 1 .

\begin{tabular}{|c|c|c|c|c|c|c|}
\hline ID & Phase & Nres & AveRes & StdDev & ResMin & ResMax \\
\hline OBS1 & $\mathrm{P}$ & 31 & -0.06 & 0.18 & -0.38 & 0.57 \\
\hline OBS1 & $\mathrm{S}$ & 6 & 0.90 & 0.49 & 0.42 & 1.95 \\
\hline OBS2 & $\mathrm{P}$ & 27 & -0.04 & 0.23 & -0.36 & 0.73 \\
\hline OBS2 & $\mathrm{S}$ & 4 & -0.27 & 0.23 & -0.46 & 0.12 \\
\hline OBS3 & $\mathrm{P}$ & 27 & 0.09 & 0.10 & -0.25 & 0.33 \\
\hline OBS3 & $\mathrm{S}$ & 14 & 0.18 & 0.13 & -0.05 & 0.46 \\
\hline OBS5 & $\mathrm{P}$ & 41 & 0.01 & 0.26 & -0.50 & 1.23 \\
\hline OBS5 & $\mathrm{S}$ & 24 & 0.20 & 0.24 & -0.32 & 0.64 \\
\hline OBS6 & $\mathrm{P}$ & 40 & -0.05 & 0.69 & -1.24 & 1.76 \\
\hline OBS6 & $\mathrm{S}$ & 10 & 0.30 & 1.04 & -0.49 & 3.35 \\
\hline OBS7 & $\mathrm{P}$ & 42 & -0.02 & 0.18 & -0.62 & 0.71 \\
\hline OBS7 & $\mathrm{S}$ & 21 & 0.04 & 0.25 & -0.72 & 0.38 \\
\hline OBS8 & $\mathrm{P}$ & 41 & 0.00 & 0.23 & -0.60 & 1.00 \\
\hline OBS8 & $\mathrm{S}$ & 13 & 0.88 & 2.14 & 0.00 & 8.28 \\
\hline OBS9 & $\mathrm{P}$ & 40 & -0.34 & 2.32 & -14.78 & 0.49 \\
\hline OBS9 & $\mathrm{S}$ & 27 & 0.30 & 0.33 & -0.47 & 1.32 \\
\hline OBS10 & $\mathrm{P}$ & 31 & 0.03 & 0.05 & -0.14 & 0.16 \\
\hline OBS10 & $\mathrm{S}$ & $/$ & $/$ & $/$ & $/$ & $/$ \\
\hline
\end{tabular}

Where: Nres, AveRes, StdDev, ResMin, ResMax stand for: Number of Residuals, Average Residual, Standard Deviation, Minimum Residual and Maximum Residual respectively. 
Table S7: Station correction values for $\mathrm{P}$ and $\mathrm{S}$ phases for the 1D-velocity model of this study for the 2014 data-set 2 .

\begin{tabular}{|c|c|c|c|c|c|c|}
\hline ID & Phase & Nres & AveRes & StdDev & ResMin & ResMax \\
\hline OBS1 & $\mathrm{P}$ & 39 & -0.44 & 2.45 & -14.03 & 1.86 \\
\hline OBS1 & $\mathrm{S}$ & 26 & -1.66 & 1.30 & -5.63 & 0.03 \\
\hline OBS3 & $\mathrm{P}$ & 34 & -0.51 & 3.53 & -20.47 & 2.57 \\
\hline OBS3 & $\mathrm{S}$ & 29 & 1.81 & 6.66 & -4.53 & 26.96 \\
\hline OBS4 & $\mathrm{P}$ & 41 & -0.24 & 0.59 & -2.90 & 0.24 \\
\hline OBS4 & $\mathrm{S}$ & 37 & 0.90 & 1.12 & -2.53 & 3.06 \\
\hline OBS5 & $\mathrm{P}$ & 39 & -0.03 & 0.66 & -1.26 & 3.55 \\
\hline OBS5 & $\mathrm{S}$ & 33 & 4.23 & 13.14 & -1.30 & 64.11 \\
\hline OBS6 & $\mathrm{P}$ & 18 & -0.36 & 0.87 & -2.46 & 1.16 \\
\hline OBS6 & $\mathrm{S}$ & 14 & 4.61 & 7.39 & 0.06 & 22.20 \\
\hline OBS7 & $\mathrm{P}$ & 37 & -0.69 & 2.81 & -17.15 & 0.17 \\
\hline OBS7 & $\mathrm{S}$ & 33 & 1.60 & 4.60 & -1.21 & 25.20 \\
\hline OBS8 & $\mathrm{P}$ & 46 & 0.06 & 0.58 & -2.52 & 2.09 \\
\hline OBS8 & $\mathrm{S}$ & 40 & 0.88 & 3.89 & -0.22 & 24.91 \\
\hline OBS9 & $\mathrm{P}$ & 4 & 1.69 & 1.20 & 0.24 & 3.32 \\
\hline OBS9 & $\mathrm{S}$ & 2 & 0.86 & 0.94 & -0.07 & 1.80 \\
\hline OBS10 & $\mathrm{P}$ & 29 & -0.27 & 0.77 & -4.11 & 0.16 \\
\hline OBS10 & $\mathrm{S}$ & 19 & 1.87 & 3.55 & -0.14 & 12.47 \\
\hline
\end{tabular}

Where: Nres, AveRes, StdDev, ResMin, ResMax stand for: Number of Residuals, Average Residual, Standard Deviation, Minimum Residual and Maximum Residual respectively. 
Table S8: Station correction values for $\mathrm{P}$ and $\mathrm{S}$ phases for the 3D-velocity model of this study for the 2014 data-set 2 .

\begin{tabular}{|c|c|c|c|c|c|c|}
\hline ID & Phase & Nres & AveRes & StdDev & ResMin & ResMax \\
\hline OBS1 & $\mathrm{P}$ & 41 & -1.29 & 5.35 & -30.96 & 0.65 \\
\hline OBS1 & $\mathrm{S}$ & 29 & 0.11 & 0.61 & -1.09 & 2.77 \\
\hline OBS3 & $\mathrm{P}$ & 36 & -0.73 & 4.49 & -19.79 & 5.05 \\
\hline OBS3 & $\mathrm{S}$ & 31 & 2.77 & 9.78 & -9.96 & 43.92 \\
\hline OBS4 & $\mathrm{P}$ & 46 & -0.61 & 2.12 & -14.33 & 0.07 \\
\hline OBS4 & $\mathrm{S}$ & 40 & 0.80 & 1.04 & -0.16 & 5.08 \\
\hline OBS5 & $\mathrm{P}$ & 34 & -2.66 & 15.16 & -89.64 & 2.84 \\
\hline OBS5 & $\mathrm{S}$ & 31 & 4.09 & 13.50 & -2.30 & 63.67 \\
\hline OBS6 & $\mathrm{P}$ & 24 & -1.71 & 5.92 & -29.61 & 0.36 \\
\hline OBS6 & $\mathrm{S}$ & 19 & 3.10 & 6.13 & -1.36 & 22.09 \\
\hline OBS7 & $\mathrm{P}$ & 43 & -0.27 & 2.60 & -16.68 & 1.85 \\
\hline OBS7 & $\mathrm{S}$ & 39 & 0.90 & 4.38 & -6.60 & 25.08 \\
\hline OBS8 & $\mathrm{P}$ & 48 & -0.23 & 0.60 & -3.61 & 0.35 \\
\hline OBS8 & $\mathrm{S}$ & 38 & 1.34 & 4.59 & -4.80 & 27.87 \\
\hline OBS9 & $\mathrm{P}$ & 4 & 0.65 & 0.72 & -0.07 & 1.56 \\
\hline OBS9 & $\mathrm{S}$ & 3 & 2.51 & 1.99 & -0.09 & 4.75 \\
\hline OBS10 & $\mathrm{P}$ & 29 & -0.40 & 1.02 & -5.20 & 0.20 \\
\hline OBS10 & $\mathrm{S}$ & 21 & 2.68 & 3.95 & -0.36 & 14.55 \\
\hline
\end{tabular}


Table S9: List of selected events detected by all 10 OBSs (2011 dataset), displayed in FigureS1.

\begin{tabular}{|c|c|c|c|c|c|c|c|c|c|c|c|}
\hline $\mathbf{N}^{\circ}$ & year & month & day & $\mathbf{h h}$ & $\mathbf{m m}$ & $\mathbf{S s}$ & $\begin{array}{c}\text { Lat }\left(^{\circ}\right) \\
\mathbf{3 D} \\
\text { absolute } \\
\text { location) }\end{array}$ & $\begin{array}{c}\text { Long }\left(^{\circ}\right) \\
\mathbf{( 3 D} \\
\text { absolute } \\
\text { location) }\end{array}$ & $\begin{array}{c}\text { Depth (km) } \\
\text { (3D } \\
\text { absolute } \\
\text { location) }\end{array}$ & $\begin{array}{c}\text { Average } \\
\text { RMS-1D } \\
(\mathbf{s})\end{array}$ & $\begin{array}{c}\text { Average } \\
\text { RMS-3D } \\
(\mathbf{s})\end{array}$ \\
\hline 1 & 2011 & 5 & 7 & 4 & 14 & 26 & 40.8291 & 27.9908 & 12.9 & 0.18 & 0.08 \\
\hline 2 & 2011 & 5 & 7 & 17 & 27 & 50 & 40.8332 & 27.9835 & 12.3 & 0.22 & 0.10 \\
\hline 3 & 2011 & 5 & 9 & 23 & 8 & 8 & 40.8187 & 27.9872 & 11.2 & 0.26 & 0.08 \\
\hline 4 & 2011 & 5 & 12 & 14 & 32 & 44 & 40.8263 & 27.9889 & 12.3 & 0.23 & 0.11 \\
\hline 5 & 2011 & 5 & 13 & 10 & 40 & 3 & 40.8256 & 27.992 & 10.9 & 0.19 & 0.09 \\
\hline 6 & 2011 & 5 & 18 & 3 & 17 & 1 & 40.8338 & 27.9905 & 12.3 & 0.22 & 0.10 \\
\hline 7 & 2011 & 5 & 19 & 4 & 38 & 36 & 40.834 & 28.136 & 2.2 & 0.24 & 0.18 \\
\hline 8 & 2011 & 5 & 19 & 20 & 0 & 34 & 40.8198 & 28.1902 & 13.5 & 0.27 & 0.14 \\
\hline 9 & 2011 & 6 & 9 & 20 & 43 & 27 & 40.8296 & 28.1321 & 2.4 & 0.20 & 0.20 \\
\hline 10 & 2011 & 6 & 12 & 6 & 9 & 29 & 40.8371 & 27.9656 & 20.7 & 0.20 & 0.21 \\
\hline
\end{tabular}

Where hh, mm,ss stand for hour, minute, second 
Table S10: Table of the 10 events triggered by the M 5.1 earthquake of the $25^{\text {th }}$ of July, 2011 used for calculating the composite focal mechanism of Figure S5.

\begin{tabular}{|c|c|c|c|c|c|c|c|c|}
\hline No & yy & mo & dd & mm & ss & Lat & Long & Depth \\
\hline & & & & & & $\left(^{\circ}\right)$ & $\left(^{\circ}\right)$ & $(\mathbf{k m})$ \\
\hline 1 & 2011 & 7 & 25 & 18 & 37 & 40.818558 & 27.768202 & 2.13 \\
\hline 2 & 2011 & 7 & 25 & 20 & 27 & 40.816772 & 27.763325 & 0.98 \\
\hline 3 & 2011 & 7 & 26 & 5 & 36 & 40.818748 & 27.738325 & 5.77 \\
\hline 4 & 2011 & 7 & 26 & 10 & 47 & 40.817307 & 27.752171 & 0.4 \\
\hline 5 & 2011 & 7 & 26 & 16 & 18 & 40.815395 & 27.746065 & 0.93 \\
\hline 6 & 2011 & 7 & 27 & 8 & 20 & 40.819805 & 27.774345 & 0.2 \\
\hline 7 & 2011 & 7 & 27 & 10 & 21 & 40.819927 & 27.747383 & 5 \\
\hline 8 & 2011 & 7 & 28 & 11 & 34 & 40.819996 & 27.764313 & 1 \\
\hline 9 & 2011 & 7 & 30 & 3 & 41 & 40.822121 & 27.758406 & 1.46 \\
\hline 10 & 2011 & 7 & 30 & 10 & 31 & 40.815159 & 27.748770 & 2.25 \\
\hline
\end{tabular}

Where: yy, mo, dd, hh, mm,ss, lat, lon stand for year, month, day, hour, minute, second, latitude, longitude 

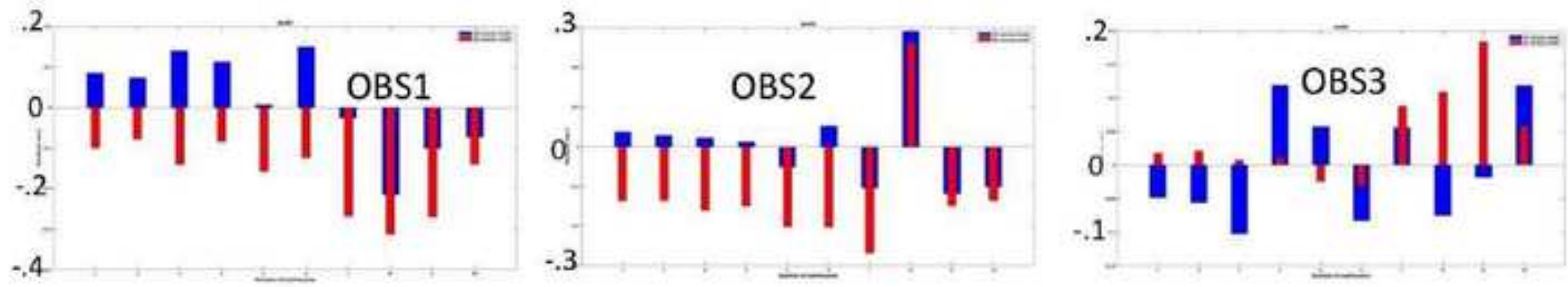

Residual (s)=observed-predicted
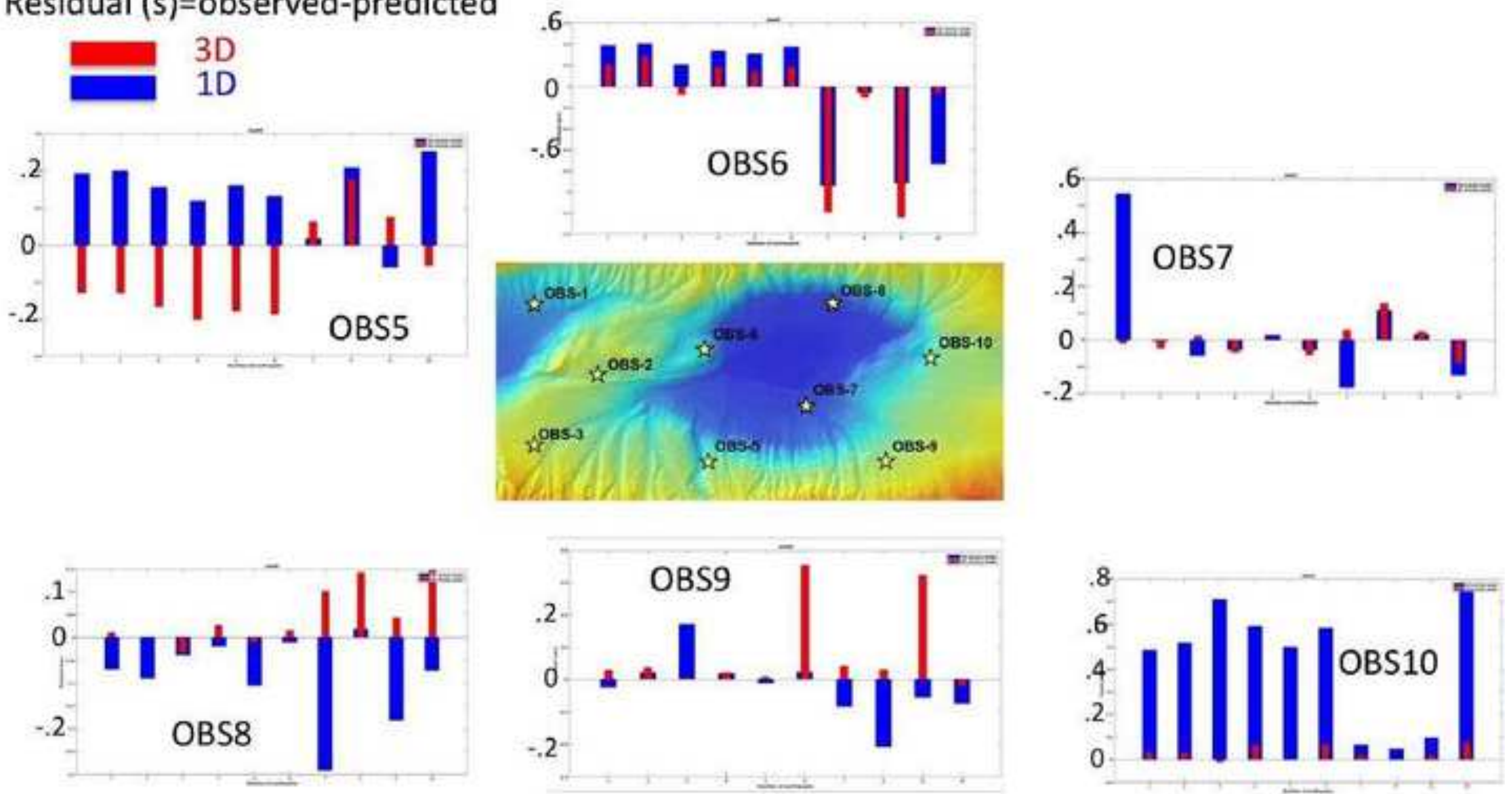


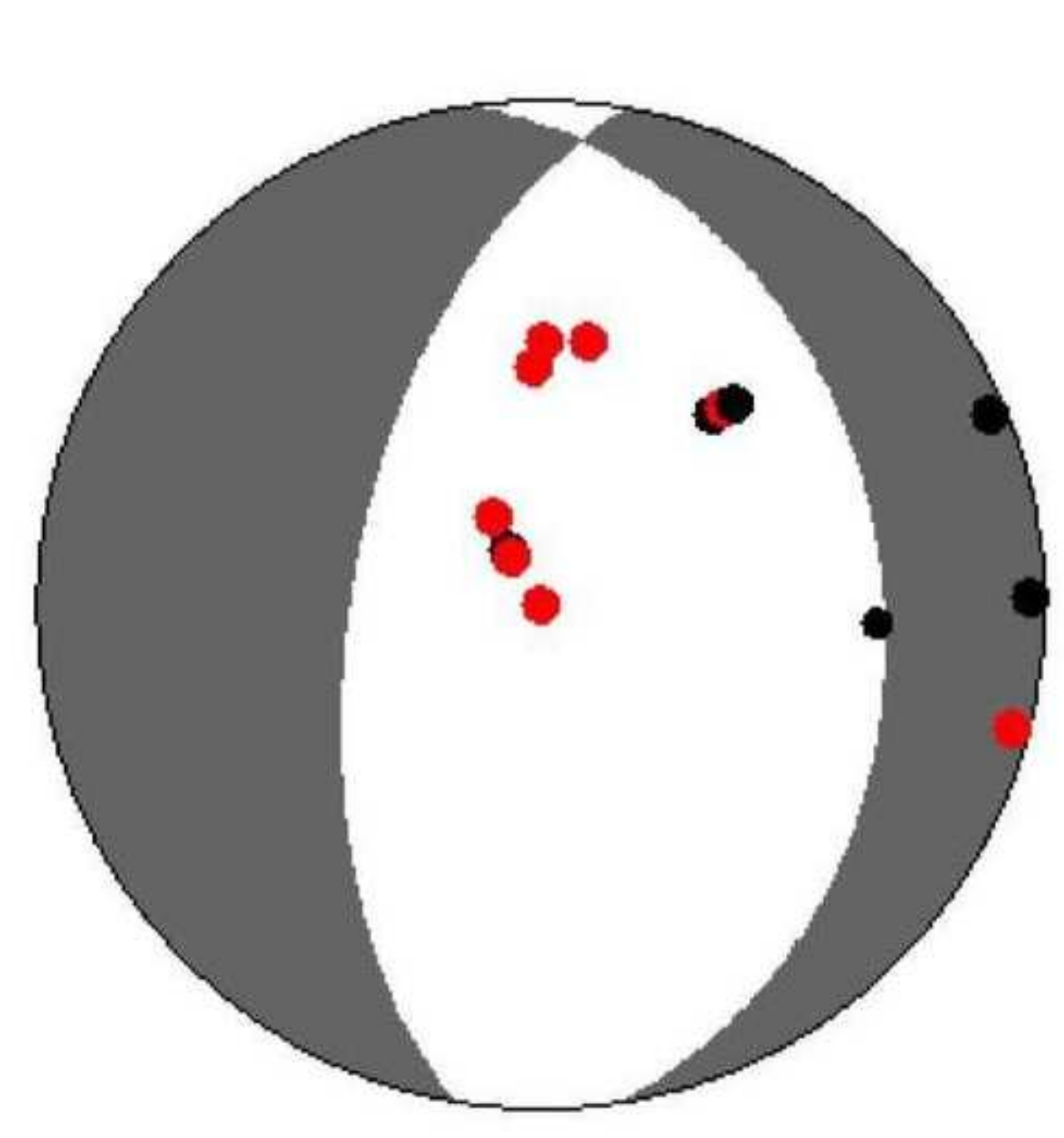

$\pm$ Tables, Figures) FigureS2.jpeg

(2)

.

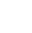




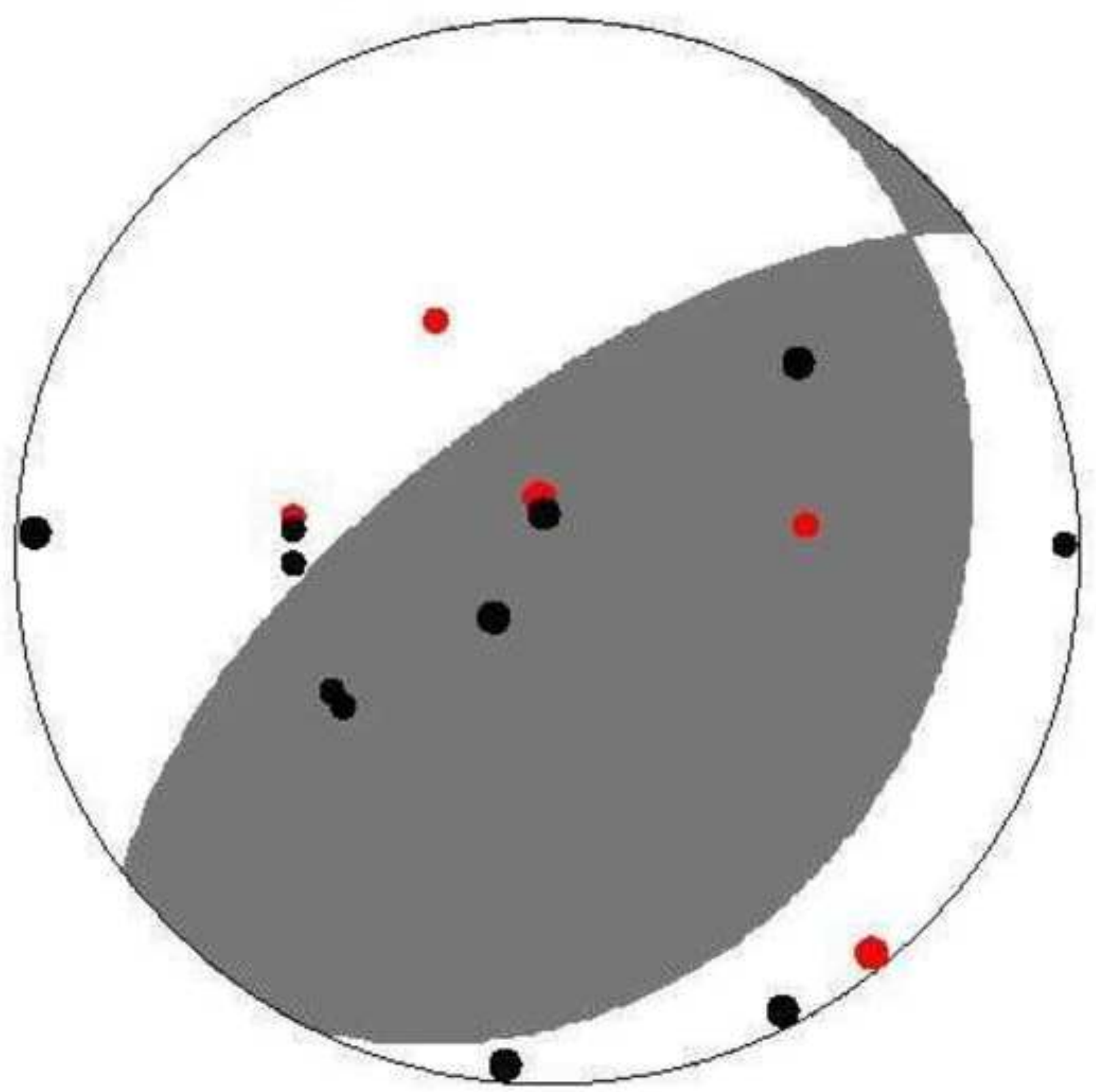


Figure S4

Click here to download Supplemental Material (Main Page, Tables, Figures)

FigureS4.jpeg

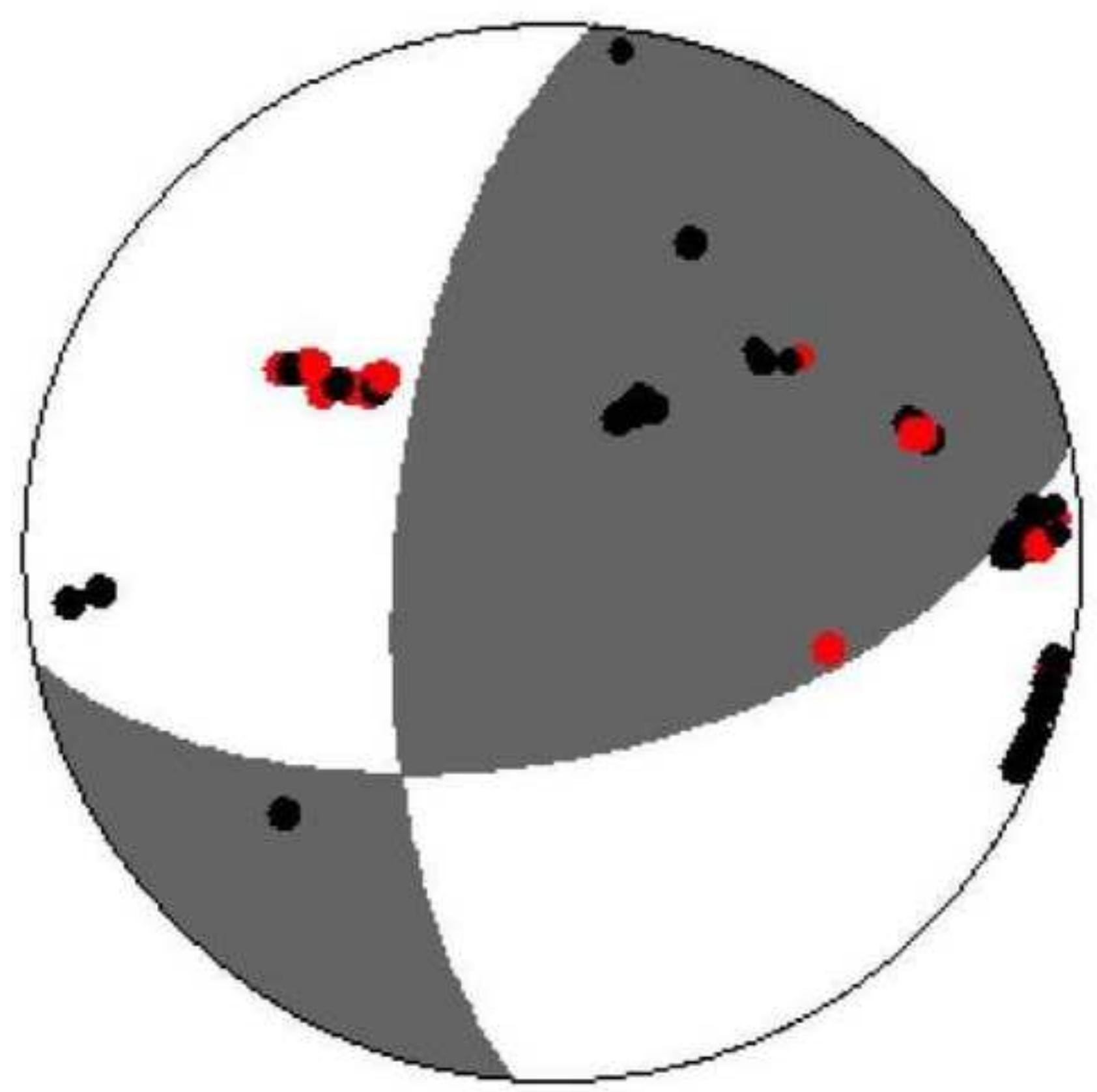




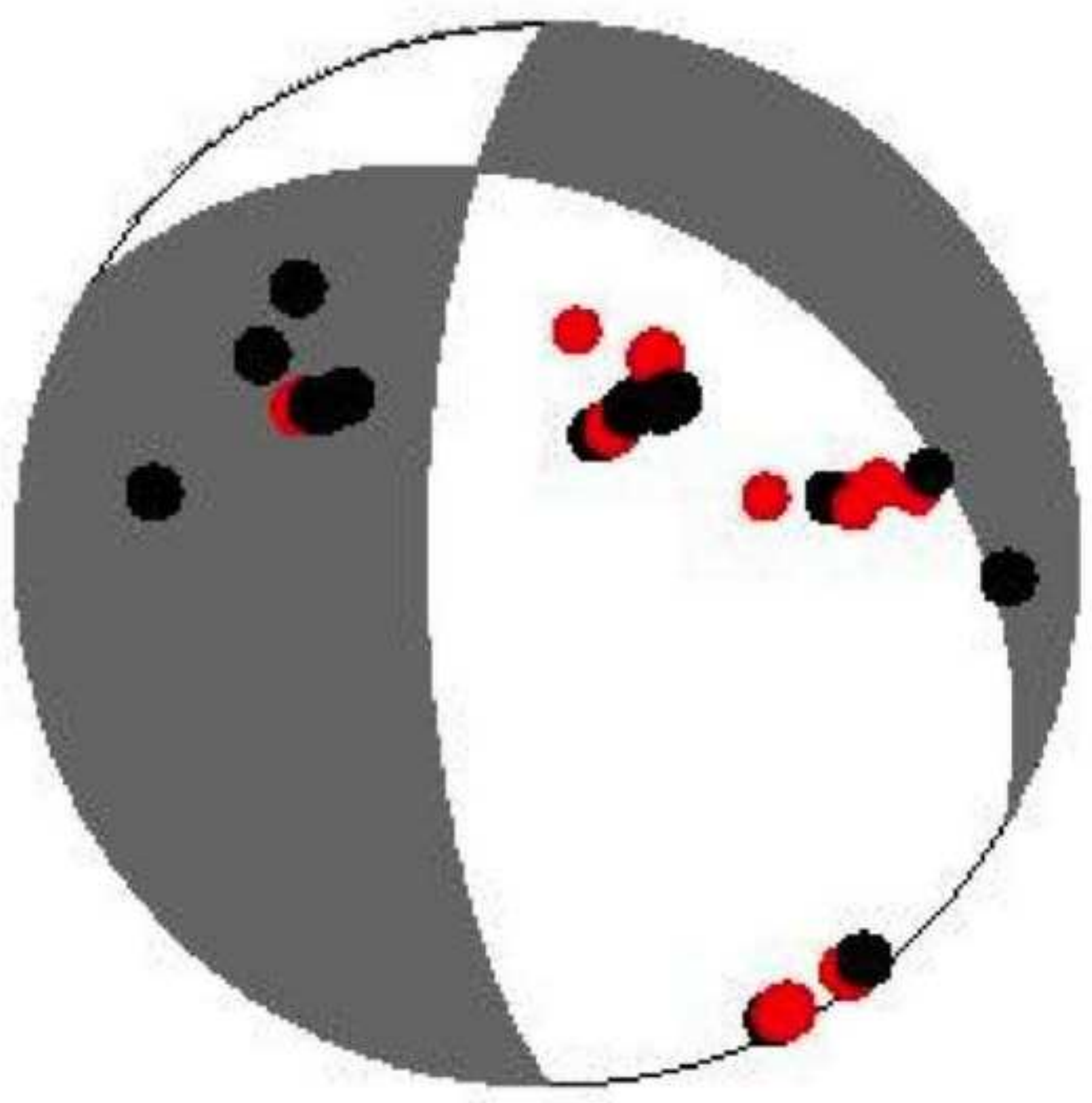



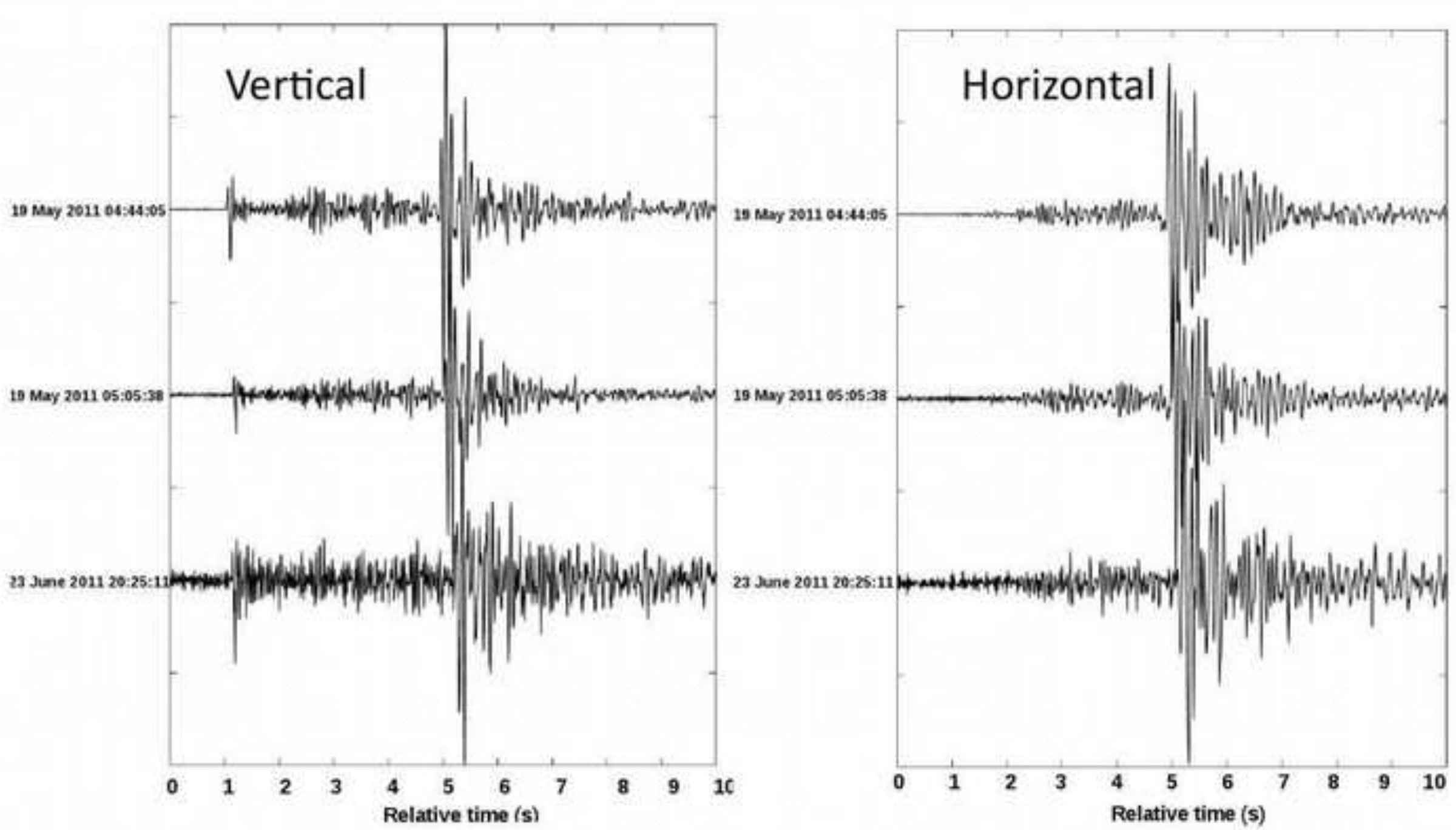

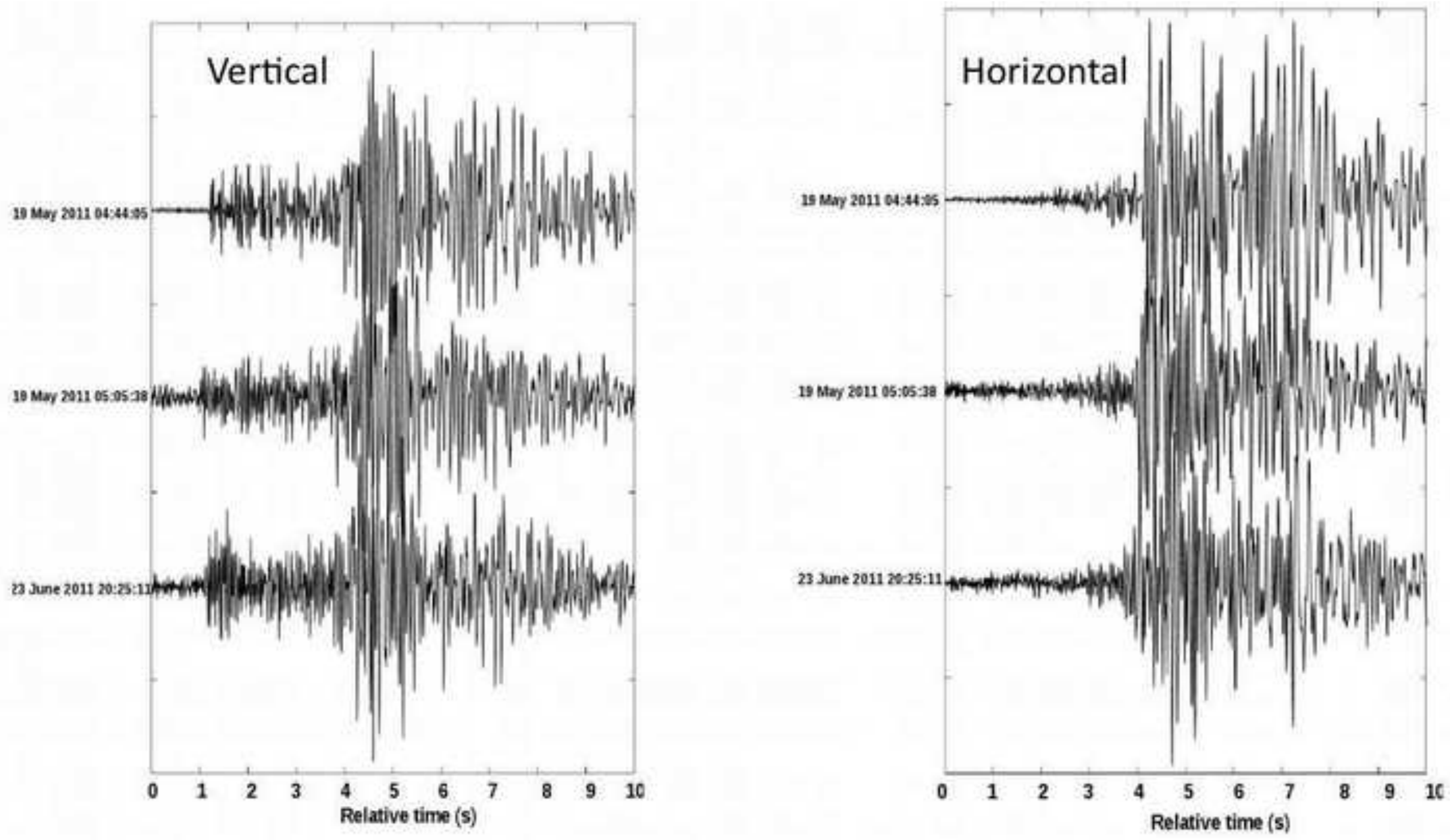


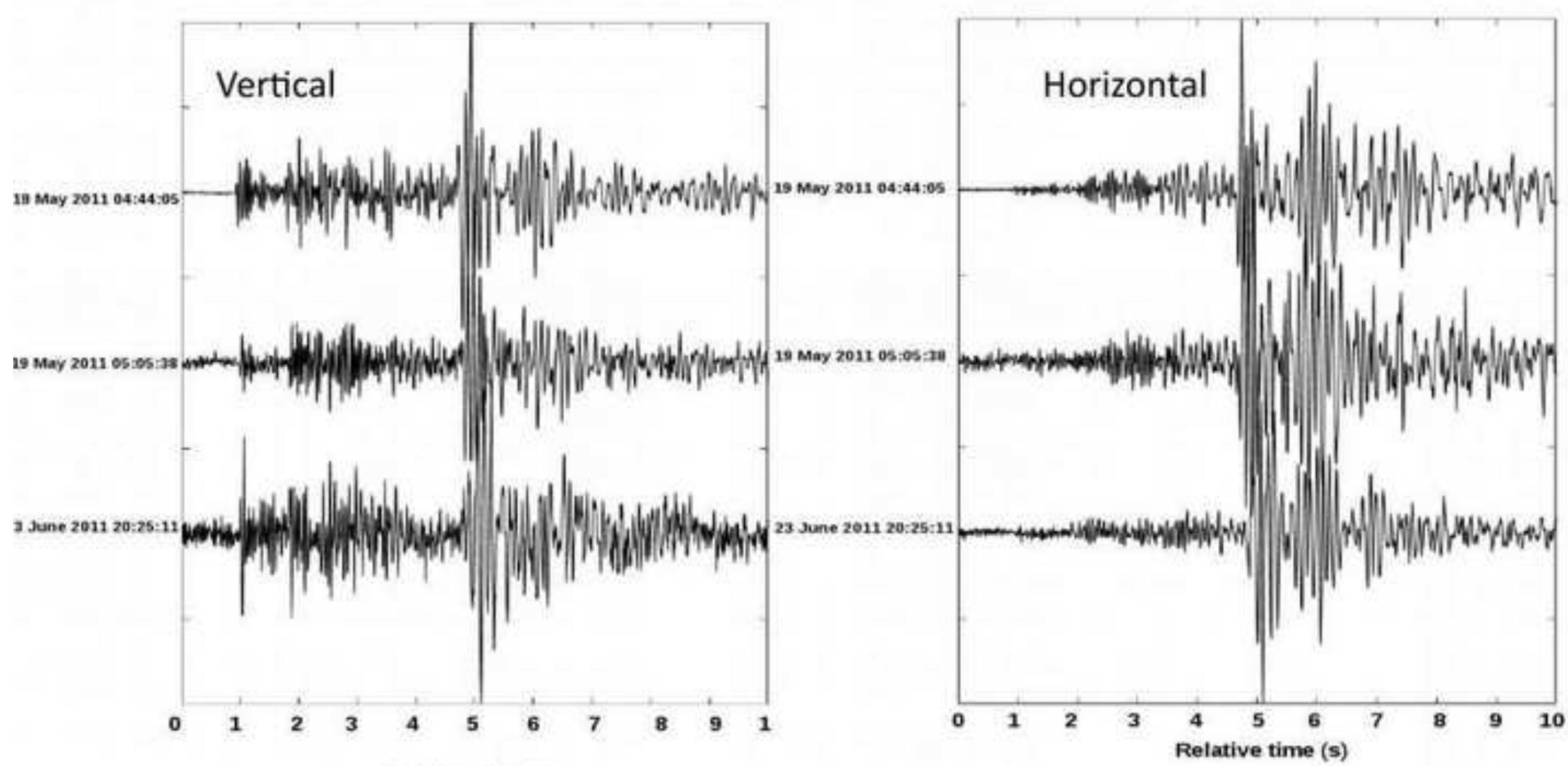

Relative time (s) 

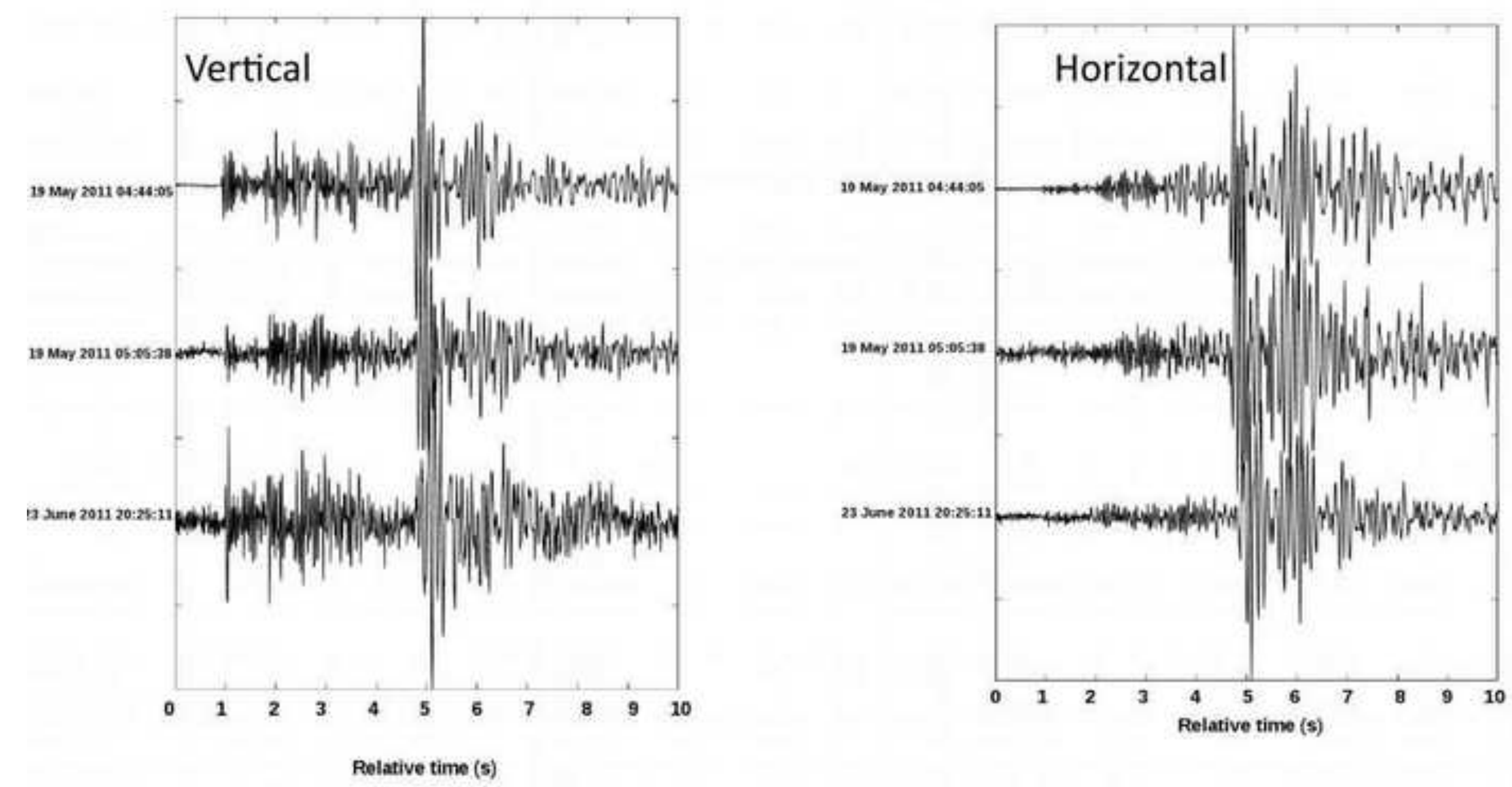